\author{
Universidade de São Paulo \\ Faculdade de Medicina de Ribeirão Preto \\ Departamento de Neurociências e Ciências do Comportamento \\ Programa de Pós-Graduação em Saúde Mental
}

NATÁLIA MOTA DE SOUZA CHAGAS

Transtornos neurocognitivos em idosos na atenção básica: o uso de instrumentos de avaliação da cognição social como método de rastreio e diagnóstico

Ribeirão Preto - SP 


\section{Transtornos neurocognitivos em idosos na atenção básica: o uso de instrumentos de avaliação da cognição social como método de rastreio e diagnóstico}

"Versão Versão corrigida. A versão original encontra-se disponível tanto na Biblioteca da Unidade que aloja o Programa, quanto na Biblioteca Digital de Teses e Dissertações da USP (BDTD)"

Dissertação de Mestrado apresentada ao Programa de Pós-Graduação em Saúde Mental da Faculdade de Medicina de Ribeirão Preto da Universidade de São Paulo para obtenção de título de mestre.

Área de Concentração: Saúde Mental

Orientadora: Profa. Dra. Flávia de Lima Osório

Ribeirão Preto - SP

2020 
Autorizo a reprodução e divulgação total ou parcial deste trabalho, por qualquer meio convencional ou eletrônico, para fins de estudo e pesquisa, desde que citada a fonte.

FICHA CATALOGRÁFICA

Serviço de documentação da Faculdade de Medicina de Ribeirão Preto - SP

Chagas, Natália Mota de Souza

Transtornos neurocognitivos em idosos na atenção básica: o uso de instrumentos de avaliação da cognição social como método de rastreio e diagnóstico / Natália Mota de Souza Chagas. - Ribeirão Preto, 2020.

$118 \mathrm{f}$ : il.

Dissertação (Mestrado) - Faculdade de Medicina de Ribeirão Preto da Universidade de São Paulo. Programa de Pós Graduação em Saúde Mental. Área de concentração: Saúde Mental.

Orientadora: Osório, Flávia de Lima

1. Transtorno neurocognitivo. 2. Cognição social. 3. Reconhecimento de expressões faciais da emoção 4. Teoria da Mente 


\section{FOLHA DE APROVAÇÃO}

Nome: Natália Mota de Souza Chagas

Título: Transtornos neurocognitivos em idosos na atenção básica: o uso de instrumentos de avaliação da cognição social como método de rastreio e diagnóstico.

Dissertação apresentada à Faculdade de Medicina de Ribeirão Preto da Universidade de São Paulo para obtenção do título de Mestre em Saúde Mental.

Aprovada em: 17/04/2020

Banca Examinadora

Profa. Dra. Flávia de Lima Osório

Instituição: Faculdade de Medicina de Ribeirão Preto - USP

Julgamento: Aprovada

Prof. Dr. Octávio Marques Pontes Neto

Instituição: Faculdade de Medicina de Ribeirão Preto - USP

Julgamento: Aprovada

Profa. Dra. Sofia Cristina Iost Pavarini

Instituição: Universidade de São Carlos - UFSCar

Julgamento: Aprovada 
DEDICATÓRIA

À minha avó Alice (in memorian),

que sempre esteve ao meu lado e que eu sinto saudades diariamente. 


\section{AGRADECIMENTOS}

À toda minha família, em especial aos meus pais, Milton e Cidinha, e meu irmão, Pedro, que mesmo distantes fisicamente, sempre se fizeram presentes através do amor e encorajamento nas minhas decisões.

Ao meu esposo, Marcos Hortes, pelos ensinamentos na vida acadêmica, por me ensinar diariamente sobre companheirismo e que me inspira a ser uma pessoa melhor.

À minha querida orientadora, Profa. Dra. Flávia de Lima Osório, por toda paciência e acolhimento, sempre me auxiliando com calma e dedicação, além de suas orientações valiosas e enriquecedoras durante todo o trajeto.

Aos idosos participantes, que disponibilizaram tempo e atenção se voluntariando tão generosamente a essa pesquisa.

Ao grupo ProVive, pela oportunidade de ingressar na pesquisa e pela ajuda na coleta dos dados, sobretudo os pesquisadores Daiene de Morais, Ana Julia Bomfim e Bianca Leticia.

Aos colegas de trabalho, Rebeca Mendes e Livio Leal, pela parceria na coleta e pelo compartilhamento de experiências diárias, o que deixou tudo mais leve e alegre.

Aos meus amigos queridos, em especial, André Boin, Saara Barros, Diogo Cunha, Maria Clara Faleiros e Rosane Castaldelli, que sempre acreditaram em mim e sempre se fizeram presentes nos bons e maus momentos, dando o verdadeiro sentido da palavra amizade. 


\section{Autoria: Natália Mota de Souza Chagas}

Título: Transtornos neurocognitivos em idosos na atenção básica: o uso de instrumentos de avaliação da cognição social como método de rastreio e diagnóstico

O presente trabalho foi realizado com apoio da Coordenação de Aperfeiçoamento de Pessoal de Nível Superior - Brasil (CAPES) - Código de Financiamento 001

"This study was financed in part by the Coordenação de Aperfeiçoamento de Pessoal de Nível Superior - Brasil (CAPES) - Finance Code 001"

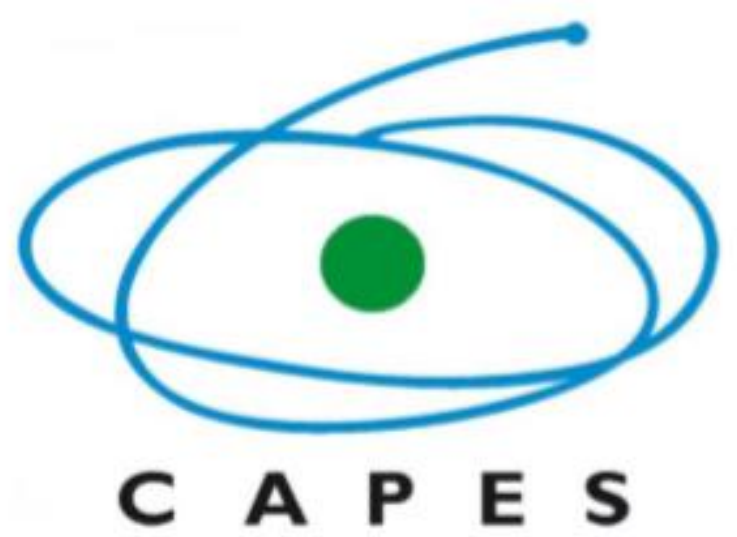

Ribeirão Preto 2020 


\section{RESUMO}

CHAGAS, N. M. S. Transtornos neurocognitivos em idosos na atenção básica: o uso de instrumentos de avaliação da cognição social como método de rastreio e diagnóstico. 2020. 118 f. Dissertação (Mestrado em Saúde Mental) - Faculdade de Medicina de Ribeirão Preto, Universidade de São Paulo, Ribeirão Preto, 2020.

Introdução: Os transtornos neurocognitivos compreendem um grupo de distúrbios onde o prejuízo principal está na função cognitiva. Estes transtornos são diagnosticados a partir de um declínio cognitivo em relação a um nível de desempenho anterior, tendo sido relatado ou observado pelo próprio indivíduo ou por um informante com conhecimento. Até o DSM-IV, estes transtornos eram denominados como demência, sendo sua nomenclatura modificada a partir da publicação do DSM-5, sendo então chamados de transtornos neurocognitivos. A partir da publicação deste manual em 2013, o domínio cognição social foi incluso para a realização do diagnóstico desta patologia. Entre os subtipos desse domínio, encontra-se a Teoria da Mente (ToM), que está relacionada com a habilidade de inferir estados mentais a si mesmo e aos outros, e as expressões faciais de emoções que são fundamentais para a interação social e desenvolvem um importante papel no funcionamento do indivíduo. Estudos realizados previamente demonstram um declínio na capacidade de reconhecer as expressões faciais das emoções com o avançar da idade, apontando para pior desempenho nos testes de avaliação da cognição social em idosos. Portanto, a inclusão do domínio de cognição social para diagnóstico de transtorno neurocognitivo, de acordo com o DSM-5, demonstra a necessidade de inclusão de novos testes para auxiliar no rastreio desse transtorno. Objetivo: O objetivo principal deste estudo foi verificar se instrumentos de avaliação da cognição social podem funcionar como variáveis de rastreio de transtornos neurocognitivos em uma população de idosos no nível de atenção primária da saúde. Método: O estudo foi realizado com sujeitos acima de 60 anos residentes em uma área de abrangência na cidade de São Carlos, no estado de São Paulo. Foram realizadas três visitas domiciliares ao idoso no intervalo de 30 dias, sendo as mesmas divididas em: aplicação dos testes neuropsicológicos, aplicação dos testes de cognição social compostos pela Bateria de tarefas de ToM e a tarefa de Reconhecimento de Expressões Faciais de Emoções (REFE), além de uma avaliação psiquiátrica para determinar o possível diagnóstico de transtorno neurocognitivo leve (TNL) e maior (TNM). A amostra total avaliada foi composta por 317 elegíveis, sendo que 222 foram 
incluídos no estudo e completaram pelo menos uma tarefa de cognição social e a entrevista diagnóstica. Resultados: Foi observada uma diferença estatisticamente significativa no desempenho entre o grupo controle e o grupo com TNM e com o TNL tanto na Bateria de tarefas de ToM ( $<<0,001$ e p $<0,001)$, quanto no Penn Emotion Recognition Test $(\mathrm{p}<0,001$ e $\mathrm{p}<0,001)$. Ainda na tarefa de REFE, diferenças significativas foram encontradas entre os grupos controle, com TNL e TNM em todas as emoções, exceto tristeza $(p=0,800)$. Além disso, através dos itens mais discriminativos de ambas ferramentas utilizadas, foi proposto um instrumento único denominado Bateria Breve de Cognição Social, que se demonstrou com boa validade discriminativa entre os grupos e boa validade convergente em relação à Bateria de tarefas de ToM $(r=0,617 ; p<0,001)$ e a tarefa de REFE $(r=0,811 ; p<0,001)$. Conclusão: Existem diferenças significativas entre os grupos nos instrumentos de cognição social utilizados e estes podem ser úteis na identificação de Transtornos neurocognitivos.

Palavras-chave: transtorno neurocognitivo, cognição social, reconhecimento de expressões faciais da emoção, teoria da mente, propriedades psicométricas. 


\begin{abstract}
CHAGAS, N. M. S. Neurocognitive disorders in the elderly in primary care: the use of social cognitive assessment instruments as a method of screening and diagnosis. 2020. 118 f. Dissertation (Master's Degree in Mental Health) - Ribeirão Preto Medical School, University of São Paulo. Ribeirão Preto, 2020.
\end{abstract}

Introduction: Neurocognitive disorders comprise a group of disorders where the main impairment is in cognitive function. These disorders are diagnosed from a cognitive decline from a previous level of performance, having been reported or observed by the individual himself or by a knowledgeable informant. Until the DSM-IV, these disorders were called dementia, and their nomenclature was changed from the publication of the DSM-5, so they were called neurocognitive disorders. From the publication of this manual in 2013, the social cognition domain was included for the diagnosis of this pathology. Among the subtypes of this domain is the Theory of Mind (ToM), which is related to the ability to infer mental states to oneself and others, and the facial expressions of emotions that are fundamental to social interaction and develop a important role in the functioning of the individual. Previous studies have shown a decline in the ability to recognize facial expressions of emotions with advancing age, pointing to poorer performance on social cognition assessment tests in the elderly. Therefore, the inclusion of the social cognition domain for diagnosis of neurocognitive disorder, according to DSM-5, demonstrates the need to include new tests to assist in the screening of this disorder. Objective: The main objective of this study was to verify whether social cognition assessment tools can function as screening variables for neurocognitive disorders in an elderly population at the primary health care level. Method: The study was conducted with subjects over 60 years old living in a coverage area in the city of São Carlos, in the state of São Paulo. Three home visits to the elderly were made within 30 days, divided into: application of neuropsychological tests, application of social cognition tests composed by the ToM Task Battery and the task of Recognition of Facial Expressions of Emotions (REFE) in addition to a psychiatric evaluation to determine the possible diagnosis of mild neurocognitive disorder (Mild NCD) and major neurocognitive disorder (Major NCD). The total sample evaluated consisted of 317 eligible, 222 were included in the study and completed at least one social cognition task and the diagnostic interview. Results: A 
statistically significant difference in performance was observed between the control group and the mild and major neurocognitive disroders groups in the ToM Task Battery and the Penn Emotion Recognition Test. Still in the REFE task, significant differences were found between the control groups, with Mild NCD and Major NCD in all emotions except sadness. In addition, through the most discriminative items of both tools used, a unique instrument called Brief Social Cognition Battery was proposed, which demonstrated good discriminative validity between the groups and good convergent validity in relation to the ToM Task Battery $(\mathrm{r}=0.617 ; \mathrm{p}<0.001)$ and the REFE task $(\mathrm{r}=0.811 ; \mathrm{p}<0.001)$. Conclusion: There are significant differences between the groups in the social cognition instruments used and these may be useful in identifying neurocognitive disorders.

Keywords: neurocognitive disorder, social cognition, recognition of facial emotions, theory of mind, psychometric properties. 


\section{LISTA DE QUADROS}

Quadro 1 - Instrumentos neuropsicológicos separados por domínio neurocognitivo segundo o

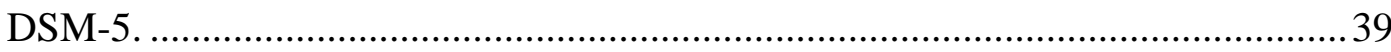




\section{LISTA DE FIGURAS}

Figura 1 - Fluxograma referente à inclusão/exclusão dos sujeitos da amostra.

Figura 2 - Curva ROC da Bateria de tarefas de Teoria da Mente tendo-se como referência os grupos controle e TNM

Figura 3 - Curva ROC da tarefa de REFE (Penn Recognition Test) tendo-se como referência os grupos controle e com TNM.

Figura 4 - Curva ROC da Bateria Breve de Cognição Social entre os grupos controle e com TNL 63

Figura 5 - Curva ROC da Bateria Breve de Cognição Social tendo-se como referência os grupos controle e com TNM

Figura 6 - Curva ROC da Bateria Breve de Cognição Social tendo-se como referência os grupos com TNL e com TNM

Figura 7 - Curva ROC da Bateria Breve de Cognição Social tendo-se como referência os grupos controle e TNL em relação ao grupo com TNM 


\section{LISTA DE TABELAS}

Tabela 1 - Dados sociodemográficos dos grupos avaliados e desempenho nas baterias cognitivas

Tabela 2 - Correlação entre os instrumentos de cognição social e variáveis cognitivas, idade e escolaridade

Tabela 3 - Desempenho dos grupos na Bateria de tarefas de Teoria da Mente 46

Tabela 4 - Valores de sensibilidade e especificidade por escore na Bateria de tarefas de Teoria da Mente

Tabela 5 - Média de acertos na tarefa de REFE (Penn Emotion Recognition Test)

Tabela 6 - Desempenho dos grupos em cada estímulo das expressões de alegria da tarefa de REFE

Tabela 7 - Desempenho dos grupos em cada estímulo das expressões de raiva da tarefa de REFE

Tabela 8 - Desempenho dos grupos em cada estímulo das expressões de nojo da tarefa de REFE 53

Tabela 9 - Desempenho dos grupos em cada estímulo das expressões de medo da tarefa de REFE

Tabela 10 - Desempenho dos grupos em cada estímulo das expressões de tristeza da tarefa de REFE 56

Tabela 11 - Desempenho dos grupos em cada estímulo da expressão neutro da tarefa de REFE

Tabela 12 -Valores de sensibilidade e especificidade por escore na tarefa de REFE (Penn Emotion Recognition Test) 
Tabela 13 - Desempenho dos grupos na Bateria Breve de Cognição Social

Tabela 14 - Média de acertos dos grupos na Bateria Breve de Cognição Social 62

Tabela 15 -Valores de sensibilidade e especificidade por escore na Bateria Breve de Cognição Social entre os grupos controle e TNL .63

Tabela 16 -Valores de sensibilidade e especificidade por escore na Bateria Breve de Cognição Social entre os grupos controle e TNM 65

Tabela 17 -Valores de sensibilidade e especificidade por escore na Bateria Breve de Cognição Social entre os grupos TNL e TNM 66

Tabela 18 -Valores de sensibilidade e especificidade por escore na Bateria Breve de Cognição Social entre os grupos controle e TNL em relação ao grupo com TNM 67 


\section{LISTA DE ABREVIAÇÕES E SIGLAS UTILIZADAS}

APA

BBRC

CCL

DSM

IBGE

MEEM

NIA-AA

REFE

RMET

SIAB

TASIT

TCLE

ToM

TDR

TNL

TNM
Associação de Psiquiatria Americana

Bateria Breve de Rastreio Cognitivo

Comprometimento Cognitivo Leve

Manual de Diagnóstico e Classificação dos Transtornos Mentais

Instituto Brasileiro de Geografia e Estatística

Mini-exame do Estado Mental

National Institute on Aging and Alzheimer's Association

Reconhecimento de Expressões Faciais de Emoções

Reading the Mind in the Eyes Test

Sistema de Informaçãoda Atenção Básica

The Awareness of Social Inference Test

Termo de Consentimento Livre e Esclarecido

Theory of Mind

Teste do Desenho do Rrelógio

Transtorno Neurocognitivo Leve

Transtorno Neurocognitivo Maior 


\section{SUMÁRIO}

1. INTRODUÇÃ

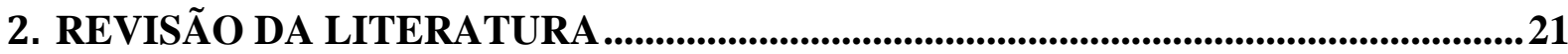

2.1)Mudanças nos critérios de demência no DSM-5..................................................................21

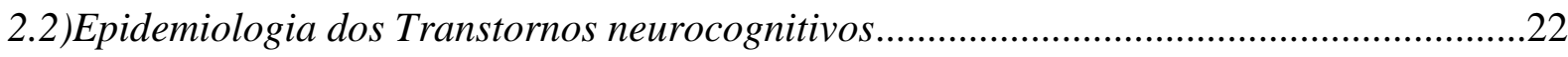

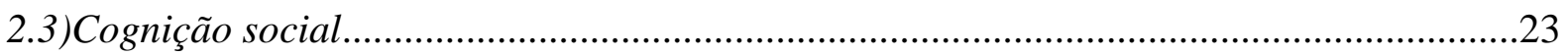

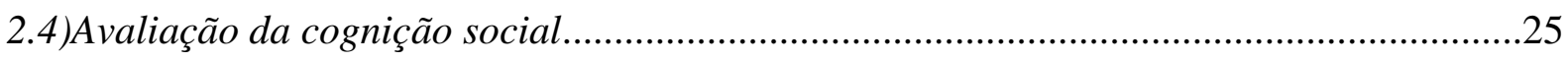

2.5)Cognição social e Transtornos neurocognitivos.........................................................28

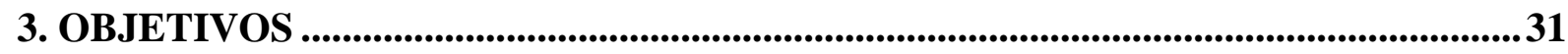

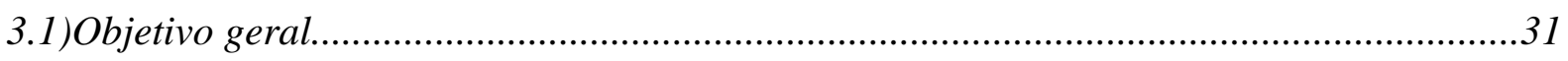

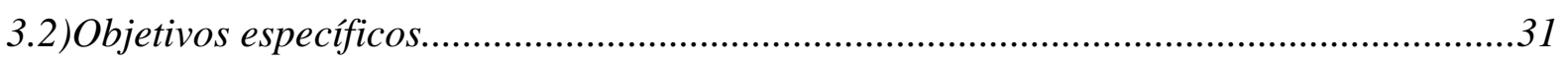

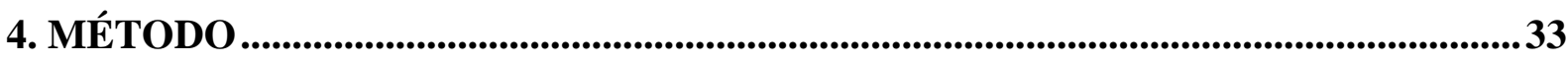

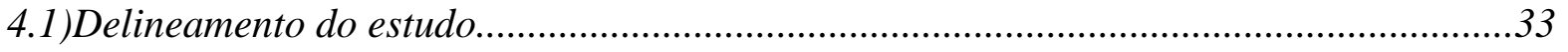

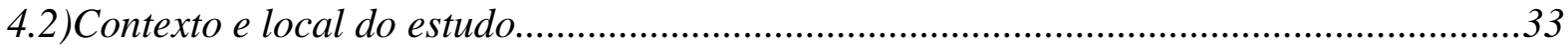

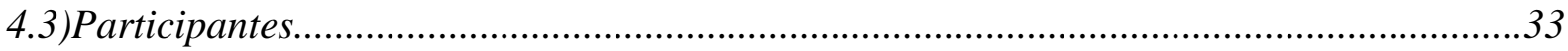

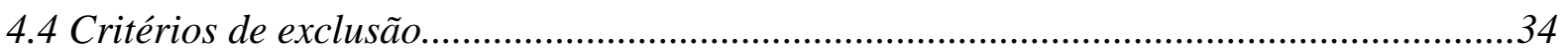

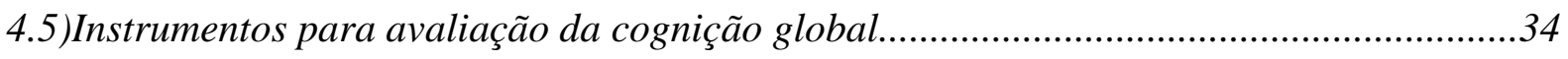

4.6)Instrumentos para avaliação da cognição social..........................................................36

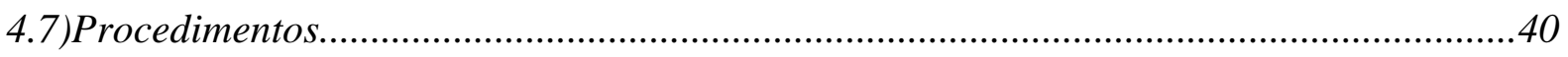

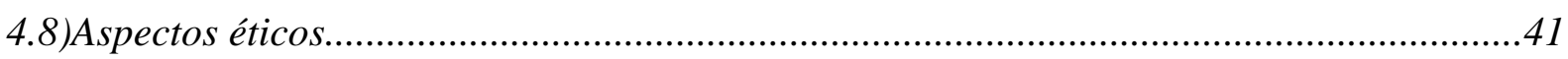

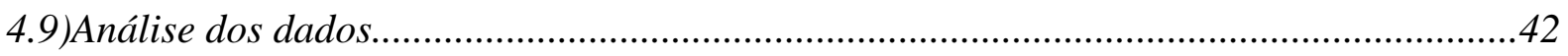

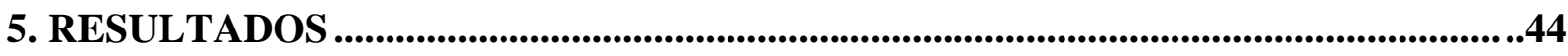

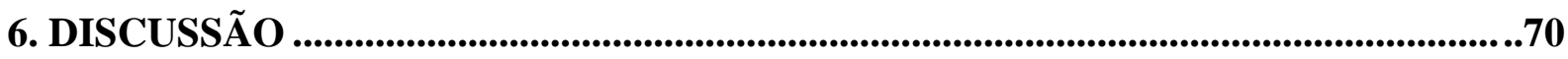

7. CONCLUSÃO

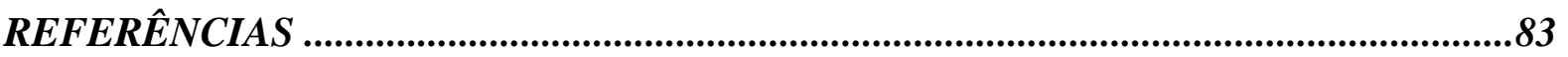


APÊENICES.

APÊNDICE A - Termo de Consentimento Livre e Esclarecido ...........................................93

APÊNDICE B - Aprovação pelo Comitê de Ética..............................................................95

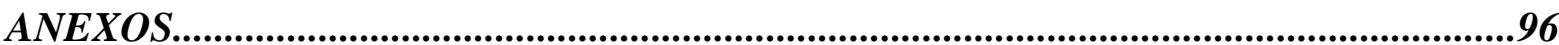

ANEXO A - Bateria Breve de Cognição Social ..................................................................97 
INTRODUÇÃO 


\section{INTRODUÇÃO}

Os transtornos neurocognitivos compreendem um grupo de distúrbios onde o prejuízo principal está na função cognitiva. A principal característica desses transtornos é o fato de não estarem presentes no início da vida do indivíduo e se desenvolverem com o decorrer dos anos, sendo marcado por declínio do funcionamento socio-ocupacional quando comparado ao seu desempenho anterior. Ainda que déficits cognitivos possam estar presentes em diversos transtornos mentais, apenas aqueles que englobam os sintomas cognitivos como sintomas principais fazem parte dessa categoria (APA, 2013).

De maneira geral, estes transtornos são diagnosticados a partir de um declínio cognitivo em relação a um nível de desempenho anterior, tendo sido relatado pelo próprio indivíduo, por um informante com conhecimento, ou observado por um clínico.

Os critérios diagnósticos para demência não tiveram modificações significativas desde a terceira edição do Manual Diagnóstico e Estatístico de Transtornos Mentais (APA, 1987) e só após quase 30 anos foram propostos novos critérios para a identificação dessa patologia pela National Institute on Aging and Alzheimer's Association (NIA-AA) e pela Associação de Psiquiatria Americana (APA), incluindo entre esses alterações comportamentais e de personalidade, além da cognição social. Desta forma, a inclusão de novos critérios possibilitará o diagnóstico de maior número de casos, além de que a proposta de mudança de nomenclatura realizada pela APA de demência para Transtorno Neurocognitivo Maior (TNM) abrangerá quadros anteriormente excluídos e pouco descritos.

Além disso, a inserção do domínio cognição social nos critérios diagnósticos em conjunto com as alterações dos demais domínios possivelmente exigirão adaptação nos meios de investigação do quadro, tanto nos instrumentos de rastreamento, quanto na investigação do TNM.

A falta de instrumentos para rastreio cognitivo adequados à população brasileira pode ser considerada um dos motivos de uma grande parcela de sujeitos com Transtorno neurocognitivo permanecerem sem o diagnóstico correto, acarretando em uma falta de intervenção precoce. Este fato traz a necessidade de um instrumento de rastreio cognitivo com acurácia adequada, que seja de fácil interpretação e que não interfira no tempo disponível para os atendimentos de rotina, principalmente na atenção primária. 
Este estudo trouxe uma forma de avaliação inédita no que diz respeito ao rastreio do Transtorno neurocognitivo, uma vez que sugere o uso de um instrumento reduzido para análise da cognição social para aventar a hipótese desse transtorno, domínio que foi incorporado recentemente no DSM-5 (APA, 2013).

\section{REVISÃO DA LITERATURA}

\section{1) Mudanças nos critérios de demência no DSM-5}

Em 2013, a Associação de Psiquiatria Americana publicou um novo Manual de Diagnóstico e Classificação dos Transtornos Mentais com mudanças significativas no tópico sobre demência e transtornos cognitivos (APA, 2013). A primeira grande mudança refere-se à nomenclatura, sendo dois novos termos introduzidos no atual manual. A denominação demência foi substituída por TNM e os casos mais leves de prejuízo cognitivo sem interferência funcional, que antes eram diagnosticados como comprometimento cognitivo leve (CCL), atualmente receberam a denominação de TNL.

Outra mudança foi que o comprometimento de memória não é mais apreciado como critério essencial. Além disso, houve um rearranjo geral nos domínios cognitivos do DSM-5 com destaque para atenção que aparece como critério independente. É importante notar mais duas mudanças significativas: é possível fazer o diagnóstico com o prejuízo de apenas um domínio cognitivo e a inclusão do domínio cognição social.

O diagnóstico do TNL pelo DSM-5 se assemelha aos manuais antigos, a única diferença é pela necessidade de exclusão de estado confusional agudo e de outras condições médicas. Esse transtorno pode ser caracterizado como estágio intermediário entre o envelhecimento cognitivo normal e a demência (Varjassyová et al., 2013) e tem como critérios: (i) prejuízo em um ou mais domínios cognitivos, como: atenção complexa, linguagem, memória e aprendizagem, função executiva, percepção motora ou cognição social; (ii) os déficits cognitivos não interferem na independência das atividades cotidianas, (iii) não ocorrem exclusivamente no contexto de delirium e (iv) não são explicados por outro transtorno mental. Seu impacto sobre as atividades rotineiras é leve, sendo o indivíduo capaz 
de compensar estes através de um esforço adicional (Hugo e Ganguli, 2014). Já para o diagnóstico de TNM, que corresponde à demência no DSM-IV, requer a identificação de um prejuízo importante em um ou mais domínios cognitivos já citados anteriormente, associado à interferência substancial na realização das atividades de vida diária (Hugo e Ganguli, 2014). Além da avaliação clínica, o prejuízo cognitivo encontrado deve ser documentado por testes neuropsicológicos padronizados ou, na falta destes, por uma avaliação clínica quantificada. (APA, 2013).

As funções cognitivas como atenção complexa, memória e aprendizagem, função executiva, linguagem já são habitualmente investigadas e existem testes bem conhecidos e com boas qualidades psicométricas para esta avaliação. Entretanto, para o domínio de cognição social, recentemente incluído como possível domínio a ser avaliado para considerar a presença de um Transtorno neurocognitivo, ainda é necessário o desenvolvimento e o estudo de instrumentos sobre a perspectiva psicométrica para uma melhor avaliação e levantamento do diagnóstico de déficit cognitivo.

\section{2) Epidemiologia dos Transtornos neurocognitivos}

Existe aumento rápido e significativo da população brasileira acima de 60 anos. Dados do último Censo do Instituto Brasileiro de Geografia e Estatística de 2010 mostraram que existe mais de 20 milhões de brasileiros com idade superior a 60 anos, o que corresponde a 10,8\% da população (IBGE, 2010). Este percentual é mais que o dobro considerando os últimos 40 anos e, em número absoluto, esta população aumentou mais que quatro vezes. É esperado que esta faixa da população continue crescendo com o aumento progressivo da expectativa de vida. Concomitantemente, mesmo sobre uma perspectiva otimista, incluindo a melhora do controle dos fatores de risco cardiovasculares, a mudança do estilo de vida e a diminuição da prevalência de TNM, o número absoluto de casos deve crescer com o rápido envelhecimento da população brasileira.

Devido às diversidades dos critérios diagnósticos para a classificação do TNM, são encontradas diferenças nas estimativas de prevalência para tal transtorno. A inclusão do comprometimento de memória a longo prazo como quesito necessário para o diagnóstico do TNM contribuiu significativamente para diferenças na prevalência entre os critérios do DSMIII e os sistemas posteriores baseados no DSM, com maior frequência do TNM observado no 
DSM-III do que no DSM III-R e DSM-IV (Erkinjuntti et al., 1997).

Como já citado anteriormente, devido à mudança recente na nomenclatura utilizada, existe uma escassez de dados específicos sobre a epidemiologia dos Transtornos neurocognitivos sendo, portanto, consideradas as referências para o termo demência e CCL.

Diante disso, as estimativas de prevalência do CCL são variáveis, oscilando entre 2 a 10\% nos indivíduos com 65 anos e 5 a 25\% nos de 85 anos de idade (APA, 2013). Já a prevalência de demência na população acima de 65 anos varia entre 5 e 7\%, com maiores valores encontrados na América Latina (Prince et al., 2013). Atualmente, existem mais de 30 milhões de pessoas com demência no mundo, 58\% destas vivendo em países de baixa ou média renda como o Brasil, e estimativas apontam que este número pode duplicar em 20 anos (Prince et al., 2013; Sosa, Acosta e Prince, 2012).

No Brasil, os estudos de prevalência encontraram taxas que variaram de $5,1 \%$ (Scazufca et al., 2008) a 12,9\% (Bottino et al., 2008). As diferenças encontradas entre as taxas, possivelmente, estão relacionadas aos diferentes métodos e instrumentos utilizados, além de características próprias de cada região. Em número absoluto, estima-se que o Brasil seja o nono país com maior número de casos com demência, cerca de um milhão (Prince et al., 2013).

\section{3) Cognição social}

O domínio cognição social passou a ser estudado em meados da década de 70 com o objetivo de entender a capacidade das pessoas de perceber as crenças e intenções de outro indivíduo e de compreender normas, procedimentos e regras sociais, as quais permitem as pessoas conviverem em sociedade (Garrido, Azevedo e Palma, 2011). Além disso, os autores Fiske e Taylor (1991) referem que além desta habilidade de inferir sobre outras pessoas, a cognição social também inclui a inferência sobre si mesmo, ou seja, a maneira que o indivíduo acha que pensa sobre outras pessoas.

Até o momento, não há uma definição exata de quantos seriam os componentes que melhor descrevem a cognição social, no entanto, um estudo realizado por Pinkman et al. (2014) descreveu quatro domínios principais que englobariam todos os aspectos a serem 
considerados na avaliação da cognição social, a saber: processamento de emoções, percepção social, atribuição do estado mental (Teoria da Mente) e o viés de atribuição.

O processamento de emoções é caracterizado pela capacidade de perceber e usar emoções de forma adequada. Este domínio se subdivide e, em um desses subdomínios, encontra-se o reconhecimento de expressões faciais. Já a percepção social compreende a capacidade de decodificar e interpretar dicas sociais de acordo com o ambiente (Sergi e Green, 2003). Para isto, é necessário que o indivíduo tenha plena capacidade de perceber e compreender o contexto social, como regras sociais, por exemplo. O viés de atribuição referese a como o indivíduo infere as causas dos acontecimentos, fazendo atribuições tanto positivas como negativas, em relação a si mesmo ou a outras pessoas (Green et al., 2008).

Outro domínio da cognição social é a Teoria da Mente (ToM) ou também chamada de atribuição de estado mental. Premack e Woodruff (1976) foram os primeiros pesquisadores a investigarem a existência de uma ToM, a qual está relacionada com a habilidade de inferir estados mentais a si mesmo e aos outros. Esses autores tentaram demonstrar que chimpanzés poderiam interpretar a intenção do comportamento de um humano.

As ferramentas para avaliação da ToM foram desenvolvidas inicialmente na década de 80 com foco na avaliação do público infantil e tinham a finalidade de investigar o desenvolvimento da compreensão de crenças pelas crianças. A avaliação da ToM nesta faixa etária se faz, geralmente, através de instrumentos que avaliam a falsa crença e espera-se que a criança consiga distinguir entre seus próprios desejos e as perspectivas de uma terceira pessoa (Wimmer e Perner, 1983).

O conhecimento acumulado ao longo das últimas três décadas acerca da aquisição e desenvolvimento de habilidades de ToM nas crianças contrasta com a reduzida compreensão desta competência em populações normativas de idade adulta. Este fato ocorre devido uma mudança nos parâmetros utilizados para sua investigação nesta faixa etária, uma vez que não se trata apenas da avaliação se um indivíduo possui ou não uma ToM, mas quais seriam os processos cognitivos que estão envolvidos na utilização desta competência (Apperly, 2012).

Um modelo recentemente proposto por Shamay-Tsoory et al. (2010) separa a ToM em processos cognitivos e afetivos. O processo cognitivo trata da capacidade do indivíduo em fazer inferências sobre os estados cognitivos, crenças e pensamentos de outras pessoas. Este subdomínio normalmente é avaliado através de tarefas de crença falsa de primeira e segunda ordem. Resumidamente, a tarefa de crença falsa podem ser de primeira ordem, ou seja, crenças sobre um estado mental (“A pensa que B fez algo") ou de segunda ordem, isto é, uma 
crença sobre as crenças de outra pessoa (“A pensa que B pensa que A fez algo”).

É interessante observar que diversas variáveis relacionadas à ToM afetiva, como habilidades sociais e comportamento afetivo, podem estar associadas, na verdade, a uma terceira variável, a empatia (Pavarini e Souza, 2010). A empatia possui múltiplas definições na literatura, no entanto, enquanto componente emocional, ela é definida como uma resposta emocional e a capacidade de se colocar no lugar do outro, ou seja, ter habilidade de sentir o que o outro está sentindo (Hoffman, 2002). Alguns autores defendem que a ToM e a empatia compartilham do uso dos mesmos mecanismos cognitivos (Preston e De Wall, 2002), enquanto outros defendem que a ToM seria um pré-requisito para o desenvolvimento da empatia (Feshbach, 1987).

Além da ToM, o processamento de faces e emoções é essencial para a cognição social. O reconhecimento de expressão facial das emoções (REFE) é definido como a capacidade de identificar emoções faciais de outras pessoas, facilitando a inferência e a interpretação de suas ações, compartilhando sentimentos e amparando nos relacionamentos interpessoais (SZE et al., 2012).

Um dos primeiros pesquisadores a descrever sobre a expressão facial das emoções foi Charles Darwin em 1965, quando fez publicações que enalteceram que as expressões faciais são fundamentais para as relações, presentes não só nos humanos, mas também nos animais. Subsequentemente, influenciado por tal pesquisador, é ressaltado as pesquisas realizadas por Paul Ekman e Wallace Friesen (1971), os quais propuseram a universalidade das emoções consideradas básicas, a saber: alegria, tristeza, medo, nojo, raiva e surpresa.

As expressões faciais das emoções envolvem mudanças na musculatura do rosto específicas para cada tipo emoção básica (Ekman \& Friesen, 1976). Estas reações juntas constituem um importante meio de comunicação não verbal, além de possuírem papel significativo na adaptação, sobrevivência e desenvolvimento de interações sociais (Souza et al., 2008).

\section{4) Avaliação da cognição social}

A avaliação estruturada da cognição social é bastante útil em condições neurológicas e psiquiátricas. As perdas mais comuns na cognição social são prejuízo na ToM, redução da 
empatia, percepção social prejudicada e comportamento social alterado. Os danos normalmente se manifestam clinicamente como dificuldade em reconhecer e responder a situações sociais simples, assim como interpretar expressões faciais, compreender a linguagem corporal ou responder a sinais sociais, como por exemplo, olhar nos olhos (Henry et al., 2016).

A ToM é um campo importante dentro do estudo do domínio cognição social. A partir do estudo de Premack e Woodruff (1976), a ToM foi estudada em diversos transtornos neuropsiquiátricos (Tonelli, 2009). Sua avaliação tem sido feita em diferentes populações e condições clínicas distintas através de diversos instrumentos.

A tarefa de crença falsa foi tida como um marco da ToM. Desenvolvida por Wimmer e Perner (1983). Se a tarefa de Premack e Woodruff exigia que o chimpanzé se colocasse no lugar do ator humano para resolver o problema, a tarefa de Wimmer e Perner é baseada na leitura de uma história a uma criança e que existem elementos que possibilitam a inferência que o indivíduo tem uma crença que difere da realidade.

Alguns exemplos de tarefa de falsa crença são o Sally-Anne Task (Baron-Cohen, Leslie e Frith, 1985) e a Ice Cream Story (Perner e Wimmer, 1985). No contexto das histórias apresentadas, os sujeitos assistem a uma situação em que o figurante coloca um objeto em um local e, logo depois, os mesmos assistem a transferência do objeto para outro local feito por outra pessoa na ausência do protagonista. Por fim, os indivíduos deveriam inferir onde o protagonista iria procurar o objeto, uma vez que este não estava presente quando foi transferido para outro local. Dessa forma, argumenta-se que existe um desenvolvimento paulatino da compreensão de diferentes estados mentais por parte das crianças, que se tornam cada vez mais complexos ao longo do seu desenvolvimento, concluindo-se que uma criança de quarto anos já possui a capacidade de compreender uma crença falsa (Martins, Barreto e Castiajo, 2013).

Apesar da tarefa de crença falsa ser tida como o principal marco de uma ToM, estudos têm encontrado evidências de que há estados mentais considerados mais simples, cuja compreensão antecede a crença falsa (Peterson e Slaughter, 2006). Da mesma forma, existem estados mentais mais complexos, com utilização de recursos cognitivos mais elaborados e vivências de situações sociais mais complexas, observados no indivíduo a partir da adolescência e idade adulta (Brune e Brune-Cohrs, 2008).

O teste de Faux Pas apresenta aos indivíduos algumas situações de inadequação social 
e visa avaliar, de forma geral, a capacidade de perceber e julgar a situação inadequada apresentada (Baron-Cohen et al., 1999). Já no Reading the Mind in the Eyes Test (RMET), são apresentadas expressões faciais, especificamente da região dos olhos, para que os sujeitos identifiquem os sentimentos ou pensamentos da pessoa da foto (Baron-Cohen et al., 2001).

Os testes de avaliação de ToM são importantes para prever possíveis deficiências cognitivas. Muitas pesquisas têm sido realizadas em indivíduos mais velhos, principalmente naqueles que são acometidos por algum quadro neurodegenerativo (Kemp, Després \& Dufour, 2012). Já foi observado em estudos prévios que pacientes com TNM apresentam pior desempenho nos testes de teoria ToM, como por exemplo, demonstrado por Gregory et al. (2002) que diferentes testes podem indicar o comprometimento de regiões cerebrais distintas. Outras tarefas também são utilizadas na avaliação da ToM, como testes de compreensão de metáfora, sarcasmo, ironia e decepção.

Outra possível forma de avaliação do domínio cognição social é através da tarefa de REFE. O reconhecimento de emoções está associado ao comportamento, humor e qualidade de vida do indivíduo. Caso ocorra algum dano neste processo, isto pode favorecer o surgimento de alterações comportamentais e comprometimento nas interações sociais (Torres et al., 2015).

Dentre as maneiras clássicas de sistematizar as expressões emocionais, as faces da série de Ekman e Friesen são as mais utilizadas para avaliar a capacidade de REFE pelos indivíduos (Varjassiová et al., 2013). Segundo Ekman e Friesen (1976), haveria a existência de seis emoções básicas (alegria, tristeza, nojo, raiva, surpresa e medo) independentemente da cultura e tais emoções não seriam aprendidas, pois seriam expressas através de movimentos musculares da face de acordo com a emoção experimentada. O fácil reconhecimento das expressões faciais poderia então ser explicado por serem emoções experimentadas por qualquer ser humano, inerente de sua nacionalidade.

Tal como acontece em outras áreas clínicas, a avaliação da ToM na idade adulta e do REFE em uma amostra clínica composta por indivíduos com TNM envolve instrumentos de origens distintas, incluindo a utilização de ferramentas adaptadas que foram inicialmente desenvolvidas para uma amostra infantil ou outras amostras clínicas. Diante disso, neste estudo foram utilizados dois instrumentos distintos para avaliação dos domínios escolhidos que pertencem à cognição social (ToM e REFE).

A Bateria de Tarefas de ToM, que será abordada mais a frente, foi inicialmente 
desenvolvida para avaliação de ToM em um público infantil por Hutchins, Prelock e Chace (2008). Foi optado pela tradução e adaptação transcultural desse instrumento com a finalidade de aplicar no contexto desse estudo, uma vez que as demais tarefas de ToM já existentes para avaliação do público adulto e idoso possuem informações com textos rebuscados, o que tornaria um viés devido à amostra ser predominantemente composto por um público analfabeto, com possível dificuldade no entendimento da tarefa proposta (Apperly et al., 2009).

Já o Penn Emotion Recognition Task, instrumento utilizado neste estudo para avaliar o domínio de reconhecimento de emoções e que também será abordado mais a frente, tem sido amplamente utilizado para avaliação da tarefa de REFE em diversos contextos, como por exemplo, na avaliação de cognição social em idosos com depressão (Bonfim, Ribeiro e Chagas, 2019), como fator preditor em indivíduos com risco de desenvolver esquizofrenia (Corcoran et al., 2015), entre outros.

Desta forma, considerando que a cognição social foi incluída como domínio cognitivo para o diagnóstico dos Transtornos neurocognitivos no DSM-5 e que nenhum dos instrumentos para rastreamento destes considera esse domínio até o momento, estudos que avaliem de forma mais aprofundada o uso de instrumentos para avaliação da ToM e de REFE no rastreio destes transtornos são importantes.

\section{5) Cognição social e Transtornos neurocognitivos}

Segundo o DSM-5, é sugerido que a investigação da cognição social nos Transtornos neurocognitivos seja feita a partir de testes que identifiquem emoções em imagens de rostos

que apresentam variedade de emoções positivas ou negativas e testes que avaliam a capacidade de considerar o estado mental de outra pessoa (pensamentos, desejos, intenções), ou seja, instrumentos que avaliam o reconhecimento de expressões de emoções faciais e/ou teoria da mente (APA, 2013).

Um estudo realizado por Takenoshita et al. (2017) identificou que pacientes diagnosticados com TNM apresentavam dificuldade em completar corretamente uma tarefa de ToM de primeira ordem. Neste estudo, foi aplicado o teste de Sally-Anne em 116 sujeitos com o diagnóstico referido e apenas cerca de $37 \%$ dos sujeitos responderam adequadamente ao teste comparado a $80 \%$ de indivíduos com a mesma faixa etária e sem o déficit cognitivo. 
Este resultado sugere que pacientes com Transtorno neurocognitivo apresentam alteração na ToM mesmo em tarefas básicas de avaliação deste domínio.

Também é demonstrado em estudos prévios que indivíduos com idade mais avançada possuem maior dificuldade em reconhecer as expressões faciais das emoções. Em estudo prévio, adultos mais velhos obtiveram desempenho inferior em testes com a finalidade de reconhecer expressões faciais quando comparados a adultos jovens em mesmas circunstâncias (Grainger et al., 2015). Estudos apontaram a possibilidade de que pessoas idosas com idade média de 74 anos possuem uma taxa de acertos menor em tarefas de reconhecimento de emoções em faces em comparação a pessoas mais jovens por causa da deterioração cognitiva geral que a idade avançada pode causar (Leime et al., 2013).

O teste de REFE também tem sido bastante explorado em pacientes com prejuízos cognitivos e parece deteriorar com a progressão dos anos (Varjassyová et al., 2013; Spoletini et al., 2008). O prejuízo na tarefa de REFE foi observado em pacientes com diagnóstico de TNM e também em pacientes com TNL (McCade, Savage \& Naismith, 2011). Em dois estudos prévios, pacientes com comprometimento cognitivo leve apresentaram dificuldades em reconhecer principalmente as emoções negativas (medo e tristeza), enquanto pacientes com TNM tiveram dificuldades em reconhecer todas as emoções (Scazufca et al., 2008; Weiss et al., 2008). Além disso, o comprometimento no processamento das emoções não é igualmente encontrado entre as diferentes causas de síndrome demencial, podendo estar relacionado com padrão de neurodegeneração presente (Kumfor et al., 2014).

A inclusão do domínio cognição social para possível diagnóstico de Transtorno neurocognitivo, juntamente com as demais alterações nos critérios diagnósticos, possivelmente exigirão adaptação nos meios de investigação do quadro tanto no que diz respeito aos instrumentos de rastreio, quanto na investigação do TNM. 
OBJETIVOS 


\section{OBJETIVOS}

\section{1) Objetivo geral}

Verificar o potencial de instrumentos de avaliação de diferentes domínios de cognição social para o rastreio de Transtornos neurocognitivos em idosos no nível de atenção primária da saúde.

\section{2) Objetivos específicos}

a. Verificar as correlações entre o desempenho na tarefa de REFE e na Bateria de tarefas de ToM com os demais domínios cognitivos avaliados a saber: validade convergente e divergente.

b. Comparar o desempenho dos idosos com e sem Transtorno neurocognitivo na tarefa de REFE e na de ToM.

c. Avaliar o potencial da Bateria de tarefas de ToM para rastreamento do Transtorno neurocognitivo, assim como determinar os pontos de corte que favoreçam a sensibilidade e especificidade (validade discriminativa).

d. Avaliar o potencial de uma tarefa de REFE para rastreamento do Transtorno neurocognitivo, determinando sua sensibilidade e especificidade (validade discriminativa).

e. Propor um instrumento breve para rastreio de Transtorno neurocognitivo com base nos itens mais discriminativos dos instrumentos utilizados para avaliação da ToM e REFE. 
MÉTODO 


\section{MÉTODO}

\section{1) Delineamento do estudo}

Constituiu-se em um estudo observacional, transversal, com comparação de grupos e características psicométricas.

\section{2) Contexto e local do estudo}

O município de São Carlos, localizado no interior do estado de São Paulo, na região Centro-Leste, possui 28.696 habitantes com mais de 60 anos segundo censo de 2010 (IBGE), correspondendo a $12,92 \%$ da população total. Esse estudo foi realizado na área de abrangência do núcleo de saúde da família Jardim Joquei-Guanabara, localizado na Rua Rio Araguaia, 750, no bairro Jardim Guanabara, região sudeste de São Carlos. Este bairro é caracterizado por possuir uma população de baixa renda financeira e alto índice de analfabetismo.

Esta pesquisa faz parte de um estudo maior conduzido pelo Prof. Dr. Marcos Hortes Nisihara Chagas, professor do curso de Gerontologia da Universidade Federal de São Carlos, em que o objetivo principal é a caracterização e avaliação cognitiva da população residente neste bairro, assim como a avaliação do impacto das mudanças nos critérios diagnósticos de demência pelo DSM-IV e DSM-5.

\section{3) Participantes}

A área de abrangência do Núcleo de Saúde da Família Jardim Joquei - Guanabara tem, segundo dados do Sistema de Informaçãoda Atenção Básica (SIAB) de 2014, 317 moradores com 60 anos ou mais. Foram elegíveis no estudo todos os indivíduos idosos com mais de 60 anos de idade, de ambos os sexos, residentes na área de abrangência citada. Todos os indivíduos cadastrados que manifestaram interesse em participar do estudo passaram por avaliação clínica através de entrevista psiquiátrica visando o diagnóstico de transtorno neurocognitivo, segundo os critérios do DSM-5. A partir disso, os participantes foram divididos em três grupos distintos: (i) um grupo controle composto de idosos sem declínio cognitivo; (ii) um grupo caracterizado por idosos com diagnóstico de TNL; (iii) um grupo de idosos com diagnóstico de TNM. 
4.4) Critérios de exclusão para os três grupos:

a) Presença de alguma comorbidade clínica grave que incapacitasse a comunicação verbal na avaliação pelo pesquisador;

b) Restrição ao leito;

c) Presença de déficits visuais ou auditivos graves que atrapalhassem a compreensão da entrevista e dos testes, em avaliação feita pelo pesquisador;

d) Sujeitos que encontravam-se internados no momento da avaliação.

e) Recusa em participar da pesquisa.

\section{5) Instrumentos para avaliação da cognição global}

\subsection{1) Entrevista clínica diagnóstica}

Os diagnósticos de TNL e TNM foram feitos utilizando-se os critérios do DSM-5 (APA, 2013) através de entrevista clínica minuciosa realizada por médico psiquiatra. Devido ao fato de ainda não existir um manual traduzido e validado para realização de entrevista estruturada para o português do Brasil do DSM-5, a coleta da história foi baseada no "Guia para o exame diagnóstico segundo o DSM-5”, publicado pela APA em 2014, o qual apresenta uma estrutura para investigação diagnóstica e traz questões de triagem para os transtornos psiquiátricos presentes no DSM-5 (Nussbaum, 2014).

\subsection{2) Bateria cognitiva global}

Os testes descritos adiante são instrumentos padronizados e amplamente utilizados para avaliação de prejuízo cognitivo, principalmente no diagnóstico de Transtorno neurocognitivo. Neste estudo, os testes abaixo foram utilizados para reforçar o diagnóstico e para avaliação da validade de construto dos demais instrumentos de avaliação de cognição social. 


\subsection{3) Lista de Figuras da Bateria Breve de Rastreio Cognitivo (BBRC)}

Esse teste utiliza figuras na avaliação de memória e consiste nas seguintes etapas: nomeação, memória incidental, memória imediata, aprendizagem, memória tardia e reconhecimento. Os testes de fluência verbal e desenho do relógio são utilizados como distratores nesta bateria.

\subsection{4) Teste de nomeação de Boston}

Este é o teste mais utilizado para avaliar a capacidade de nomeação no Brasil. O teste é composto 15 figuras com três graus de dificuldades (Kaplan, Goodglass e Weintraub, 1983). A aplicação é simples e consiste em solicitar ao participante para nomear os desenhos (Miotto et al., 2010). O teste apresenta valores normativos para o Brasil e sua nota de corte para Transtorno neurocognitivo é de 12 pontos (Bertolucci et al., 2001).

\subsection{5) Teste do Desenho do Relógio - TDR}

O TDR é comumente empregado na investigação da presença de comprometimento de algumas habilidades cognitivas como funções visuoconstrutiva e visuoespacial, representação simbólica e grafomotora, memória semântica e funções executivas. Para sua realização é entregue ao participante uma folha em branco e um lápis e dada a seguinte instrução: "Eu gostaria que você fizesse um desenho de um relógio com todos os números dentro"; após: "Agora, desenhe os ponteiros marcando $2 \mathrm{~h} 45 \mathrm{~min}$ ". A pontuação consiste numa escala de pontuação que varia de zero (relógio totalmente incorreto ou inexistente) a 10 pontos (relógio totalmente correto) (Brucki e Rocha, 2004; Fuzikawa et al., 2003). Em um estudo realizado previamente por Nitrini et al., (2005), a versão do TDR com pontuação máxima de 10 pontos foi aplicada a uma população de idosos, sendo 30 deles com diagnóstico de demência leve a moderada e 30 pacientes controles; uma pontuação abaixo de cinco pontos foi encontrada nos pacientes com demência, com sensibilidade de $90 \%$ e especificidade de $83,3 \%$. 


\subsection{6) Teste de Fluência Verbal Semântica}

O Teste de Fluência Verbal Semântica avalia diferentes domínios cognitivos como linguagem, memória semântica e função executiva. No teste de fluência semântica, o examinador pede ao sujeito que fale o maior número possível de animais, no período de um minuto. Segundo estudo brasileiro, a avaliação do desempenho do sujeito dependerá do seu grau de escolaridade: a nota de corte para Transtorno neurocognitivo para indivíduos com até oito anos de escolaridade é nove, e para indivíduos com mais de oito anos de escolaridade, a nota de corte é 13 (Brucki e Rocha, 2004).

\subsection{7) Mini Exame do Estado Mental (MEEM)}

O Mini-Mental é um instrumento de rastreamento amplamente utilizado que apresenta escore que varia de zero a 30 e avalia orientação temporal e espacial, memória (fixação e evocação), linguagem, atenção e cálculo (Folstein, Folstein e McHugh, 1975). Diversos estudos de validação para determinar suas qualidades psicométricos foram realizados no Brasil em diferentes populações (Brucki et al., 2003; Castro et al., 2008). Estudos publicados previamente por Nitrini et al., (2005) sugerem uma pontuação média levando em consideração a escolaridade da população, sendo considerado sem déficit cognitivo uma pontuação entre 13 e 19 para os analfabetos, assim como um escore acima de 26 pontos para a população com escolaridade acima de oito anos.

\section{6) Instrumentos para avaliação da cognição social}

\subsection{1) Bateria de tarefas de Teoria da Mente}

A Bateria de tarefas de Teoria da Mente foi inicialmente projetada para avaliar a compreensão da ToM por crianças de diferentes faixas etárias (Hutchins, Prelock e Chace, 2008). Esta bateria foi traduzida e adaptada transculturalmente para o português do Brasil como parte deste estudo, com o objetivo de avaliar a ToM em sujeitos com idade acima de 60 
anos de idade considerando que a ToM é uma das formas de avaliação da cognição social (Chagas, Chagas e Osório, 2017). Esta bateria consiste em um caderno de aplicação com diferentes histórias ilustradas que contém situações com a finalidade de avaliar a ToM. Abaixo dessas ilustrações, encontram-se questões que avaliam a cognição social através da ToM.

As histórias ilustradas são divididas em nove partes, listadas de A à I, compostas por situações que apresentam complexidades variadas na interpretação da ToM, desde reconhecimento de expressões faciais até a capacidade de inferir uma crença falsa.

A tarefa A compreende a Tarefa de Reconhecimento de Emoção, a qual é utilizada para avaliar o reconhecimento dos estados emocionais pelos sujeitos. Nessa tarefa, estão inseridas as questões 1 a 4 e são apresentadas faces em que os indivíduos são convidados a identificar a emoção que melhor corresponde à ilustração. A tarefa B denomina-se Tarefa da Emoção Baseada no Desejo, caracterizada por avaliar a compreensão do desejo do indivíduo como causa da emoção sentida pelo mesmo. Tal tarefa compreende uma questão teste e a pergunta 5, questionando como a paciente se sentiria caso conseguisse alcançar o objeto de seu desejo.

A tarefa C, nomeada Tarefa "Ver leva a Crer", compreende a questão 6, tendo como finalidade a avaliação da capacidade do indivíduo em perceber que a observação de uma situação leva a criação de uma crença (Ex: "Esta manhã Patrícia viu seus óculos em cima da mesa. Agora ela quer seus óculos. Onde Patrícia pensa que seus óculos estão?”). As questões 7 e 8 destinam-se avaliar a compreensão de que os sujeitos podem não ver a mesma situação dependendo do seu posicionamento, chamada Tarefa de Ponto de Vista, que consiste a tarefa D (Questão 7: “Quando Sandra olha para a estátua, o que ela vê?”).

Já a tarefa E, denominada Tarefa de Inferência da Ação Baseada na Percepção, foi proposta para avaliar o entendimento do indivíduo de que as percepções influenciam no comportamento, ou seja, o conhecimento pode ser adquirido através da percepção visual e que o conhecimento pode levar a um comportamento determinado, avaliada nesta bateria através da questão 9 (“Onde Francisco vai procurar as chave?”). Na tarefa F, é avaliada a habilidade do indivíduo em inferir a crença de outra pessoa através de mudanças inesperadas na situação apresentada, então chamada de Tarefa Padrão de Crença Falsa, representada pela questão 10 (“'Onde Antonio irá procurar o livro primeiro?”).

A sétima tarefa (tarefa G) compreende a Tarefa de Emoção Baseada na Crença e na 
Realidade e a Tarefa de Emoção de Segunda Ordem, compreendendo as questões 11 a 13. Estas tarefas foram desenvolvidas para avaliar o entendimento que o indivíduo possui de que as crenças, bem como os eventos relacionados à elas, podem desencadear reações emocionais, ou seja, requer um pensamento elaborado sobre o que alguém acha das emoções e desejos de outra pessoa (Questão 11, 12 e 13, respectivamente: "Se Luís achar que seu pai comprou um avião para ele, como Luís irá se sentir?"; "Como Luis se sentiu quando o pai deu um trem para ele?”; “Quando o pai deu o trem para Luís, como o pai achou que Luís se sentiu?”)

A tarefa H, denominada Tarefa de Discrepância entre a Mensagem e o Desejo, é composta por quatro questões de controle e pela questão 14 e tem como objetivo avaliar a capacidade do sujeito em inferir a crença de outra pessoa ao interpretar um desejo apresentado por este (“Qual tigela José realmente quer?”). Por fim, a questão 15 está compreendida da tarefa I chamada Tarefa de Crença Falsa de Segunda Ordem, e traz uma avaliação de tarefa de crença falsa de segunda ordem ("O que a mãe responde para o avô? Ela diz para ele que Henrique acha que vai ganhar um patins, uma bicicleta, uma bola de basquete ou uma luva de beisebol?").

Para todas as tarefas na Bateria de Tarefas de ToM, é apresentado aos sujeitos uma opção de resposta correta e três plausíveis distrações. A bateria completa é composta por 26 questões que variam entre Questões teste e Questões de controle. As perguntas chamadas de Questões teste são consideradas de principal relevância e que, quando respondidas corretamente, recebem pontuação no valor de um para cada item. São estas perguntas que avaliam a tarefa proposta, o conhecimento e habilidade do sujeito em relação a ToM. As Questões de controle somam um total de 11 questões e são utilizadas para introduzir a tarefa que será avaliada. Estas questões não possuem pontuação e estão dispostas de forma aleatória ao longo do teste. No final da aplicação da Bateria de tarefas de ToM, são somados os pontos obtidos nas questões teste, podendo-se atingir um total de 15 pontos (Chagas, Chagas e Osório, 2017).

\subsection{2) Penn Emotion Recognition Test.}

Trata-se de uma tarefa para avaliação do REFE. Este teste é composto por 96 fotografias coloridas de expressões faciais com as seguintes emoções básicas: alegria, tristeza, raiva, medo, nojo, além de faces/rostos sem emoção (neutro). Devido as emoções de medo e surpresa compartilharem alterações faciais que acabam por produzir uma 
confusão na sua identificação, a diferenciação entre essas duas expressões apresentam alto nível de dificuldade. Por este motivo, em alguns estudos e instrumentos de avaliação, como neste caso, estas duas emoções têm sido agrupadas em uma única categoria (Morgan et al., 2009).

Por meio de uma tela de computador, são apresentadas 16 fotografias de cada emoção, sendo que as emoções básicas são apresentadas em baixa intensidade (oito fotografias) e em alta intensidade (oito fotografias). Os participantes tiveram de escolher a valência emocional de cada expressão entre seis opções de respostas sem tempo limite, de forma que o participante passasse para a próxima imagem automaticamente ao responder a anterior.

Para análise, foram utilizados o escore total de acertos, os subescores de acerto de cada emoção e os acertos por intensidade de cada emoção (Gur et al., 2002).

Esta tarefa foi feita e apresentada com a utilização do software Superlab 4.0 (Cedruscorporation ${ }^{\circledR}$ ) em um computador com tela de 13 polegadas da marca Dell® (modelo 7348).

No quadro 1, apresenta-se um breve resumo dos diferentes instrumentos utilizados.

Quadro $1-$ Instrumentos neuropsicológicos separados por domínio
neurocognitivo segundo o DSM-5.

Aprendizado e memória

- Lista de Figuras da Bateria Breve de Rastreio Cognitivo

- Itens de memória do Mini Exame do Estado Mental

Linguagem

- Teste de nomeação de Boston

- Teste de Fluência Verbal

- Itens de linguagem do Mini Exame do Estado Mental

Funcionamento executivo

- Teste de Fluência Verbal

- Teste do Desenho do Relógio

- Itens de funcionamento executivo do Mini Exame do Estado Mental 
Percepção motora (visuoespacial)

- Teste do Desenho do Relógio

- Itens de percepção motora do Mini Exame do Estado Mental

Cognição social

- Penn Emotion Recognition Test

- Bateria de tarefas de Teoria da Mente

\section{7) Procedimentos}

Inicialmente, os idosos foram convidados a participar do estudo durante uma visita domiciliar realizada pelos pesquisadores envolvidos. $\mathrm{O}$ grupo de pesquisadores foi composto por cinco gerontólogos formados pela Universidade Federal de São Carlos, treinados por um professor graduado em Medicina e com especialização em Psiquiatria Geriátrica e por três médicos com residência médica em Psiquiatria pela Faculdade de Medicina de Ribeirão Preto. Os pesquisadores forneceram todas as explicações e dúvidas sobre a pesquisa e que a não participação não iria afetar em nada seu atendimento na unidade de saúde. Todos os idosos que aceitaram participar do estudo assinaram o Termo de Consentimento Livre e Esclarecido (Apêndice A). Foi solicitado ao responsável da casa para que a avaliação fosse realizada no local da casa mais apropriado em relação à iluminação e acústica.

A avaliação dos idosos que aceitaram participar da pesquisa foi dividida em três momentos diferentes. Em um primeiro momento, os participantes foram submetidos à bateria geral de testes cognitivos, descritos no Quadro 1 (exceto as tarefas de cognição social), a qual fora realizada pelos cinco gerontólogos. O tempo aproximado de duração desta primeira avaliação foi de 60 minutos. Em um segundo momento, a entrevista clínica diagnóstica foi realizada por um dos três psiquiatras com experiência profissional de cinco anos na área, sendo direcionada principalmente para o diagnóstico de TNL e TNM, segundo os critérios do DSM-5. O tempo aproximado para execução desta segunda etapa foi de 30 a 50 minutos. Por último, em um terceiro momento, foram aplicados o teste Penn Emotion Recognition Test e a Bateria de tarefas de Teoria da Mente por cinco gerontólogos da Universidade Federal de São Carlos. Para esta etapa, o tempo gasto foi de aproximadamente 30 minutos.

A coleta dos dados teve início em março de 2016 e seu término em fevereiro de 2017. $\mathrm{O}$ intervalo entre as três avaliações foi menor que 30 dias, evitando-se com isso uma perda expressiva de sujeitos e mudança no quadro psiquiátrico diagnosticado. 
No total dos 317 idosos elegíveis, foram avaliados 282 idosos, sendo que 267 participantes realizaram a avaliação psiquiátrica e 222 realizaram a avaliação através dos instrumentos de cognição social.

O fluxograma abaixo apresenta um resumo dos dados obtidos:

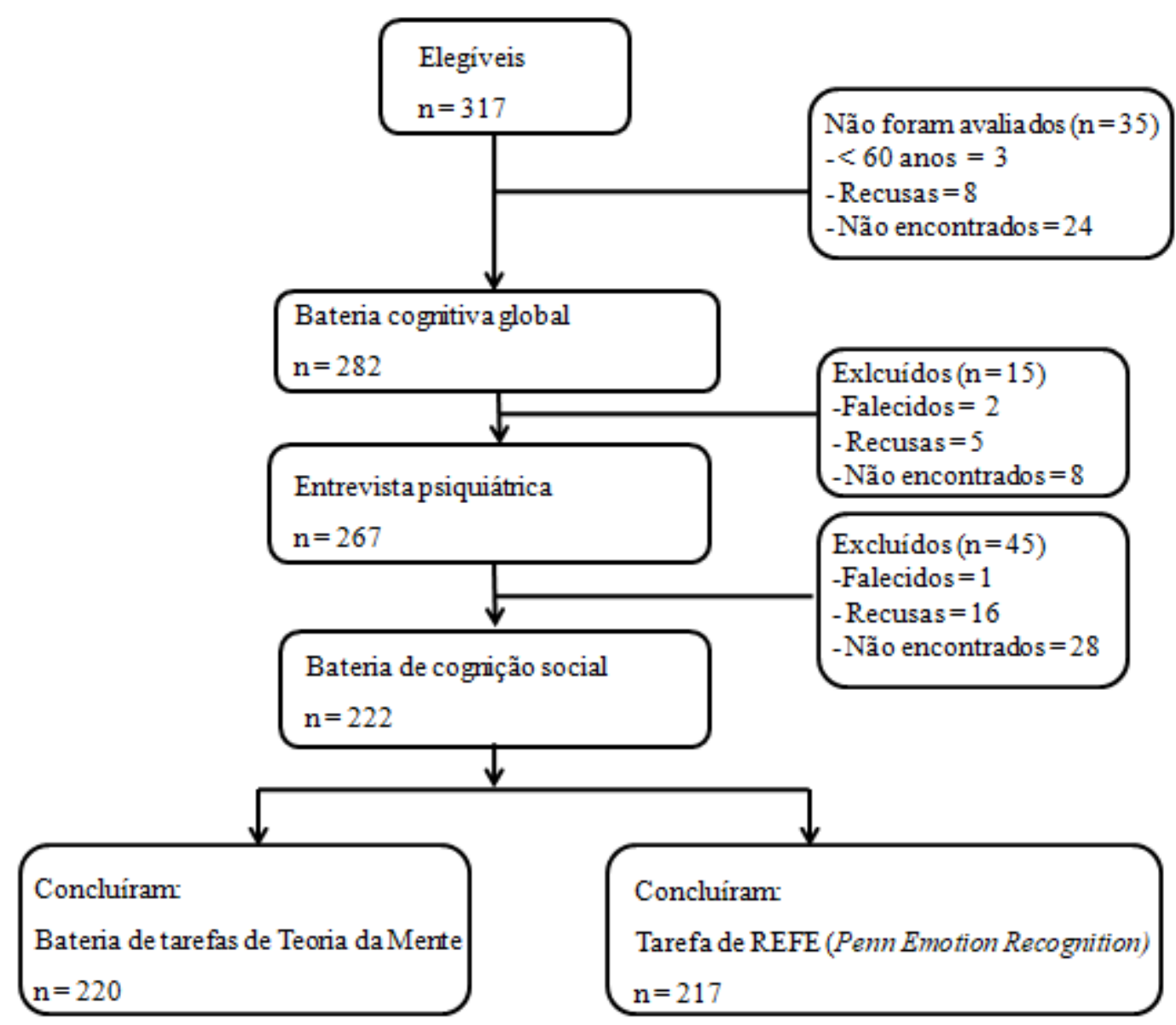

Figura 1- Fluxograma referente à inclusão/exclusão dos sujeitos da amostra

\section{8) Aspectos éticos}

Este estudo foi aprovado no Comitê de Ética em Pesquisa da Universidade Federal de São Carlos-CAAE: 48602515.5.0000.5504 (Apêndice B).

A todos os participantes foi entregue o Termo de Consentimento Livre e Esclarecido (TCLE), fornecendo-lhes informações sobre as justificativas, objetivos, procedimentos, riscos e benefícios do estudo ao qual foram convidados a participar. Somente foram aceitos no estudo aqueles participantes que devidamente assinarem o TCLE. 
Foi assegurado ao sujeito a total liberdade de retirar seu consentimento em qualquer momento no transcorrer da pesquisa e deixar de participar do estudo, sem que isso lhe trouxesse qualquer prejuízo. Do mesmo modo, a não participação no estudo não acarretou em qualquer prejuízo no atendimento ou seguimento no serviço de referência.

Foram garantidos esclarecimentos quanto a qualquer dúvida que surgisse no transcorrer do procedimento e informação atualizada sobre o estudo, ainda que isso pudesse afetar sua vontade de continuar participando. Da mesma forma, foi garantida a segurança de não serem identificados, bem como de que todas as informações fornecidas por eles foram mantidas sob caráter confidencial.

\section{9) Análise dos dados}

1) A caracterização dos dados clínicos e demográficos da amostra foi feita através de estatística descritiva e de testes de comparação de grupos: Qui-quadrado $\left(\mathrm{X}^{2}\right)$ para dados nominais e ANOVA para dados contínuos com correção de Bonferroni.

2) A comparação do desempenho dos diferentes grupos no Penn Emotion Recognition Test e na Bateria de tarefas de Teoria da Mente foi feito por Quiquadrado $\left(\mathrm{X}^{2}\right)$ para dados nominais e ANOVA para dados contínuos com correção de Bonferroni.

3) A análise da capacidade discriminativa do Penn Emotion Recognition Test e da Bateria de tarefas de Teoria da Mente foi feita por meio da curva ROC (área sob a curva, indicadores de sensibilidade e especificidade e diferentes pontos de corte).

4) As correlações entre os escores totais do Penn Emotion Recognition Test e da Bateria de tarefas de Teoria da Mente foram realizadas por meio do coeficiente de correlação de Pearson (validade convergente). Os valores de 0 a 0,3 foram considerados desprezíveis, de 0,3 a 0,5 fracos, de 0,5 a 0,7 moderados, de 0,7 a 0,9 fortes e acima de 0,9 muito fortes (Mukaka, 2012). Estas tarefas também foram correlacionas com as demais tarefas de cognição global para avaliação da validade convergente entre elas.

As análises estatísticas foram realizadas utilizando o pacote estatístico SPSS, versão 21.0. O nível de significância considerado é de $\mathrm{p} \leq 0,05$. 
RESULTADOS 


\section{RESULTADOS}

A amostra final foi composta por 222 sujeitos, com média de idade de 70,43 anos (DP: $\pm 7,76$; idade mínima de 60 anos e máxima de 93 anos). A média de escolaridade foi de 3,06 anos de estudo (DP: $\pm 3,02$, mínimo: 0, máximo: 15 anos), com 58,10\% da amostra composta por sujeitos do sexo feminino.

De acordo com a avaliação clínica, a prevalência de TNM e do TNL dos sujeitos que realizaram a avaliação de cognição social foi de $10,36 \%$ e $23,42 \%$, respectivamente. Os dados relativos à idade, à escolaridade e ao desempenho na bateria cognitiva divididos por grupos estão apresentados na Tabela 1.

Tabela 1 - Dados sócio demográficos dos grupos avaliados e desempenho nas baterias cognitivas

\begin{tabular}{|c|c|c|c|c|}
\hline Variáveis & $\begin{array}{l}\text { Controle } \\
\mathrm{N}=147\end{array}$ & $\begin{array}{l}\text { TNL } \\
\mathrm{N}=52\end{array}$ & $\begin{array}{l}\text { TNM } \\
\mathbf{N}=\mathbf{2 3}\end{array}$ & Estatística \\
\hline Idade & $68,94( \pm 6,87)^{\mathrm{a}, \mathrm{b}}$ & $73,11( \pm 8,32)^{\mathrm{a}}$ & $73,87( \pm 9,28)^{b}$ & $\mathrm{~F}_{2,219}=8,63 ; \mathrm{p}<0,001$ \\
\hline Sexo $(F / M)$ & $81 / 66$ & $34 / 18$ & $14 / 9$ & $X^{2}=1,75 ; p=0,417$ \\
\hline $\begin{array}{l}\text { Escolaridade } \\
\text { (anos) }\end{array}$ & $3,56( \pm 3,15)^{\mathrm{a}, \mathrm{b}}$ & $2,34( \pm 2,76)^{\mathrm{a}}$ & $1,56( \pm 1,59)^{\mathrm{b}}$ & $\mathrm{F}_{2,217}=6,57 ; \mathrm{p}<0,002$ \\
\hline $\begin{array}{l}\text { BBRC - Memória } \\
\text { aprendizado }\end{array}$ & $21,54( \pm 5,34)^{\mathrm{a}, \mathrm{b}}$ & $18,41( \pm 5,21)^{\mathrm{a}, \mathrm{c}}$ & $14,04( \pm 7,06)^{b, c}$ & $F_{2,215}=20,66 ; p<0,001$ \\
\hline $\begin{array}{l}\text { BBRC - Memória } \\
\text { tardia }\end{array}$ & $7,23( \pm 2,34)^{\mathrm{a}, \mathrm{b}}$ & $5,76( \pm 2,55)^{\mathrm{a}}$ & $4,45( \pm 3,24)^{\mathrm{b}}$ & $\mathrm{F}_{2,213}=15,63 ; \mathrm{p}<0,001$ \\
\hline $\begin{array}{l}\text { BBRC - } \\
\text { Reconhecimento }\end{array}$ & $8,93( \pm 2,05)^{\mathrm{b}}$ & $8,15( \pm 2,42)^{\mathrm{c}}$ & $5,22( \pm 3,86)^{\mathrm{b}, \mathrm{c}}$ & $\mathrm{F}_{2,213}=23,43 ; \mathrm{p}<0,001$ \\
\hline $\begin{array}{l}\text { Teste de fluência } \\
\text { verbal }\end{array}$ & $11,08( \pm 4,01)^{\mathrm{b}}$ & $9,67( \pm 2,81)$ & $8,00( \pm 3,87)^{\mathrm{b}}$ & $\mathrm{F}_{2,217}=8,09 ; \mathrm{p}<0,001$ \\
\hline $\begin{array}{l}\text { Teste do Desenho } \\
\text { do Relógio }\end{array}$ & $5,41( \pm 3,64)^{a, b}$ & $3,68( \pm 3,26)^{a}$ & $2,30( \pm 1,91)^{\mathrm{b}}$ & $\mathrm{F}_{2,215}=11,05 ; \mathrm{p}<0,001$ \\
\hline $\begin{array}{l}\text { Teste de } \\
\text { nomeação de } \\
\text { Boston }\end{array}$ & $11,64( \pm 2,63)^{b}$ & $10,98( \pm 2,60)^{\mathrm{c}}$ & $8,59( \pm 3,30)^{\mathrm{b}, \mathrm{c}}$ & $\mathrm{F}_{2,214}=12,37 ; \mathrm{p}<0,001$ \\
\hline MEEM & $23,82( \pm 3,92)^{\mathrm{a}, \mathrm{b}}$ & $21,23( \pm 3,67)^{\mathrm{a}, \mathrm{c}}$ & $16,26( \pm 4,64)^{\mathrm{b}, \mathrm{c}}$ & $F_{2,217}=39,46 ; p<0,001$ \\
\hline
\end{tabular}

F: Feminino; M: Masculino; TNL: Transtorno neurocognitivo leve; TNM: Transtorno neurocognitivo maior; BBRC: bateria breve de rastreio cognitivo; MEEM: mini-exame do estado mental; ${ }^{\mathrm{a}} \mathrm{p}<0,05$ (controle e TNL); ${ }^{\mathrm{b}} \mathrm{p}<0,05$ (controle e TNM); ${ }^{\mathrm{c} p}<0,05$ (TNL e TNM). 
A média de anos de escolaridade encontrada nos grupos controle e com TNL foi maior que a encontrada no grupo com TNM. Além disso, foi encontrada diferença estatística entre os grupos em todos os testes de avaliação global da cognição. Os testes de Memória de aprendizado (compreendida na BBRC) e o MEEM apresentaram diferenças nos três grupos estudados, sendo o desempenho do grupo controle melhor que o dos grupos com TNL e TNM e, o desempenho do grupo com TNL melhor que o grupo com TNM. Já nos testes de Reconhecimento (também compreendido na BBRC) e no Teste de nomeação de Boston, foi encontrada diferença apenas entre os grupos controle e com TNM e entre os grupos com TNL e com TNM, não sendo encontrada diferença entre os grupos controle e com TNL.

A Tabela 2 traz a validade convergente entre os instrumentos de cognição social e variáveis cognitivas, apontando uma correlação moderada entre os escores das tarefas de cognição social e os diferentes instrumentos de avaliação da cognição. A correlação entre o escore total da Bateria de tarefas de ToM e a tarefa de REFE foi moderada, demonstrando que ambas possivelmente fazem parte de um mesmo construto.

Tabela 2 - Correlação entre os instrumentos de cognição social e variáveis cognitivas, idade e escolaridade.

\begin{tabular}{llllllllll}
\hline & Idade & Escolaridade & $\begin{array}{l}\text { BBRC } \\
\text { Mem. }\end{array}$ & $\begin{array}{l}\text { BBRC } \\
\text { M. } \\
\text { tardia }\end{array}$ & $\begin{array}{l}\text { Fluência } \\
\text { verbal }\end{array}$ & TDR & MEEM & $\begin{array}{l}\text { Teste de } \\
\text { nomeação } \\
\text { de Boston }\end{array}$ & $\begin{array}{l}\text { ToM } \\
\text { total }\end{array}$ \\
\hline ToM & $-0,281^{* *}$ & $0,261^{* *}$ & $0,335^{* *}$ & $0,398^{* *}$ & $0,276^{* *}$ & $0,460^{* *}$ & $0,336^{* *}$ & $0,318^{* *}$ & - \\
total & & & & & & & & & \\
REFE & $-0,423^{* *}$ & $0,305^{* *}$ & $0,303^{* *}$ & $0,329^{* *}$ & $0,291^{* *}$ & $0,447^{* *}$ & $0,381^{* *}$ & $0,493^{* *}$ & $0,547^{* *}$ \\
total & & & & & & & & & \\
Raiva & $-0,180^{* *}$ & 0,123 & $0,191^{* *}$ & $0,168^{*}$ & 0,072 & $0,198^{* *}$ & $0,194^{* *}$ & $0,255^{* *}$ & $0,371^{* *}$ \\
Alegria & $-0,175^{* *}$ & 0,082 & $0,160^{*}$ & 0,100 & $0,157^{*}$ & $0,181^{* *}$ & $0,187^{* *}$ & $0,208^{* *}$ & $0,178^{* *}$ \\
Nojo & $-0,328^{* *}$ & $0,178^{* *}$ & $0,196^{* *}$ & $0,228^{* *}$ & $0,217^{* *}$ & $0,268^{* *}$ & $0,256^{* *}$ & $0,362^{* *}$ & $0,351^{* *}$ \\
Medo & $-0,267^{* *}$ & 0,093 & $0,335^{* *}$ & $0,291^{* *}$ & $0,170^{*}$ & $0,226^{* *}$ & $0,206^{* *}$ & $0,238^{* *}$ & $0,358^{* *}$ \\
Triste & $-0,078$ & 0,045 & 0,034 & $-0,050$ & 0,047 & 0,090 & $-0,004$ & 0,066 & 0,133 \\
Neutro & $-0,280^{* *}$ & $0,335^{* *}$ & 0,091 & $0,273^{* *}$ & $0,209^{* *}$ & $0,375^{* *}$ & $0,306^{* *}$ & $0,364^{* *}$ & $0,381^{* *}$ \\
\hline
\end{tabular}

ToM: Teoria da Mente; REFE: Reconhecimento de expressões faciais das emoções; BBRC: Bateria Breve de Rastreio Cognitivo; TDR: Teste de Desenho do Relógio; MEEM: Mini Exame do Estado Mental; *p<0,05; $* * \mathrm{p}<0,01$. 
A Tabela 3 apresenta o desempenho dos diferentes grupos na Bateria de tarefas de ToM, considerando a resposta dada em cada questão e o escore total.

Tabela 3 - Desempenho dos grupos na Bateria de tarefas de ToM

\begin{tabular}{|c|c|c|c|c|}
\hline Variáveis & Controle & TNL & TNM & Estatística \\
\hline $\begin{array}{l}\text { Questão 1 } \\
\text { Acerto (\%) } \\
\text { Erro }(\%)\end{array}$ & $\begin{array}{l}69,4^{\mathrm{b}} \\
30,6\end{array}$ & $\begin{array}{l}57,7 \\
21,4\end{array}$ & $\begin{array}{l}38,1^{\mathrm{b}} \\
61,9\end{array}$ & $\mathrm{X}^{2}=8,81 ; \mathrm{p}=0,012$ \\
\hline $\begin{array}{l}\text { Questão } 2 \\
\text { Acerto (\%) } \\
\text { Erro (\%) }\end{array}$ & $\begin{array}{l}54,4 \\
45,6\end{array}$ & $\begin{array}{l}50,0 \\
50,0\end{array}$ & $\begin{array}{l}38,1 \\
61,9\end{array}$ & $\mathrm{X}^{2}=2,05 ; \mathrm{p}=0,358$ \\
\hline $\begin{array}{l}\text { Questão 3 } \\
\text { Acerto (\%) } \\
\text { Erro (\%) }\end{array}$ & $\begin{array}{l}55,1 \\
44,9\end{array}$ & $\begin{array}{l}53,8 \\
46,2\end{array}$ & $\begin{array}{l}57,1 \\
42,9\end{array}$ & $X^{2}=0,06 ; p=0,967$ \\
\hline $\begin{array}{l}\text { Questão } 4 \\
\text { Acerto (\%) } \\
\text { Erro (\%) }\end{array}$ & $\begin{array}{l}42,2 \\
57,8\end{array}$ & $\begin{array}{l}26,9 \\
73,1\end{array}$ & $\begin{array}{l}19,0 \\
81,0\end{array}$ & $X^{2}=6,87 ; p=0,032$ \\
\hline $\begin{array}{l}\text { Questão 5 } \\
\text { Acerto (\%) } \\
\text { Erro (\%) }\end{array}$ & $\begin{array}{l}87,1^{\mathrm{a}} \\
12,9\end{array}$ & $\begin{array}{l}71,2^{\mathrm{a}} \\
28,8\end{array}$ & $\begin{array}{l}71,4 \\
28,6\end{array}$ & $\mathrm{X}^{2}=8,23 ; \mathrm{p}=0,016$ \\
\hline $\begin{array}{l}\text { Questão 6 } \\
\text { Acerto (\%) } \\
\text { Erro (\%) }\end{array}$ & $\begin{array}{l}72,1 \\
27,9\end{array}$ & $\begin{array}{l}71,2 \\
28,8\end{array}$ & $\begin{array}{l}57,1 \\
42,9\end{array}$ & $X^{2}=1,99 ; p=0,369$ \\
\hline $\begin{array}{l}\text { Questão } 7 \\
\text { Acerto (\%) } \\
\text { Erro (\%) }\end{array}$ & $\begin{array}{l}45,6 \\
54,4\end{array}$ & $\begin{array}{l}53,8 \\
46,2\end{array}$ & $\begin{array}{l}47,6 \\
52,4\end{array}$ & $X^{2}=1,05 ; p=0,591$ \\
\hline $\begin{array}{l}\text { Questão } 8 \\
\text { Acerto (\%) } \\
\text { Erro (\%) }\end{array}$ & $\begin{array}{l}39,7 \\
60,3\end{array}$ & $\begin{array}{l}32,7 \\
67,3\end{array}$ & $\begin{array}{l}42,9 \\
57,1\end{array}$ & $X^{2}=1,00 ; p=0,606$ \\
\hline $\begin{array}{l}\text { Questão } 9 \\
\text { Acerto (\%) } \\
\text { Erro (\%) }\end{array}$ & $\begin{array}{l}59,9 \\
40,1\end{array}$ & $\begin{array}{l}61,5 \\
38,5\end{array}$ & $\begin{array}{l}61,9 \\
38,1\end{array}$ & $X^{2}=0,06 ; p=0,968$ \\
\hline $\begin{array}{l}\text { Questão 10 } \\
\text { Acerto (\%) } \\
\text { Erro }(\%)\end{array}$ & $\begin{array}{l}75,5^{\mathrm{a}, \mathrm{b}} \\
24,5\end{array}$ & $\begin{array}{l}53,8^{\mathrm{a}} \\
46,2\end{array}$ & $\begin{array}{l}28,6^{\mathrm{b}} \\
71,4\end{array}$ & $\mathrm{X}^{2}=22,42 ; \mathrm{p}<0,001$ \\
\hline $\begin{array}{l}\text { Questão 11 } \\
\text { Acerto (\%) } \\
\text { Erro (\%) }\end{array}$ & $\begin{array}{l}59,2 \\
40,8\end{array}$ & $\begin{array}{l}55,8 \\
44,2\end{array}$ & $\begin{array}{l}38,1 \\
61,9\end{array}$ & $X^{2}=3,33 ; p=0,190$ \\
\hline $\begin{array}{l}\text { Questão } 12 \\
\text { Acerto (\%) } \\
\text { Erro }(\%)\end{array}$ & $\begin{array}{l}31,3 \\
68,7\end{array}$ & $\begin{array}{l}15,4 \\
84,6\end{array}$ & $\begin{array}{l}14,3 \\
85,7\end{array}$ & $X^{2}=6,70 ; p=0,035$ \\
\hline $\begin{array}{l}\text { Questão 13 } \\
\text { Acerto (\%) }\end{array}$ & 43,8 & 30,8 & 23,8 & $X^{2}=4,96 ; p=0,084$ \\
\hline
\end{tabular}


Tabela 3 - Desempenho dos grupos na Bateria de tarefas de ToM

(continuação)

\begin{tabular}{|c|c|c|c|c|}
\hline Variáveis & Controle & TNL & TNM & Estatística \\
\hline Erro (\%) & 56,2 & 69,2 & 76,2 & \\
\hline \multicolumn{5}{|l|}{ Questão 14} \\
\hline Acerto (\%) & 39,5 & 26,9 & 33,3 & $X^{2}=2,69 ; p=0,261$ \\
\hline Erro $(\%)$ & 60,5 & 73,1 & 66,7 & \\
\hline \multicolumn{5}{|l|}{ Questão 15} \\
\hline Acerto (\%) & 47,6 & 30,8 & 33,3 & $X^{2}=5,23 ; p=0,073$ \\
\hline Erro $(\%)$ & 52,4 & 69,2 & 66,7 & \\
\hline $\begin{array}{l}\text { ToM Total } \\
\overline{\mathrm{X}}(\mathrm{DP}: \pm)\end{array}$ & $8,22( \pm 3,12)^{\mathrm{a}, \mathrm{b}}$ & $6,92( \pm 2,86)^{\mathrm{a}}$ & $6,04( \pm 2,83)^{b}$ & $\mathrm{~F}_{2,215}=6,98 ; \mathrm{p}<0,001$ \\
\hline
\end{tabular}

Foram observadas diferenças estatisticamente significativas para as questões 1, 4, 5, 10 e 12 . No entanto, após análise pelo teste post hoc para verificar a diferença dos grupos dois a dois, esta se manteve apenas entre os grupos controle e TNM na Questão 1, controle e TNL na Questão 5 e entre os grupos controle e TNL, e controle e TNM na Questão 10.

Em relação ao desempenho total na bateria, houve diferença significativa entre os grupos. O teste post hoc de Bonferroni apontou para diferenças entre os grupos controle e com TNL e entre o grupo controle e com TNM, não se encontrando diferenças no desempenho entre os grupos clínicos.

A Figura 2 apresenta a curva ROC relativa à Bateria de tarefas de ToM tendo-se como referência os grupos controle e com TNM. A área sob a curva foi de 0,70 (IC95\%: 0,58-0,80), sendo considerada regular (Metz, 1978). 


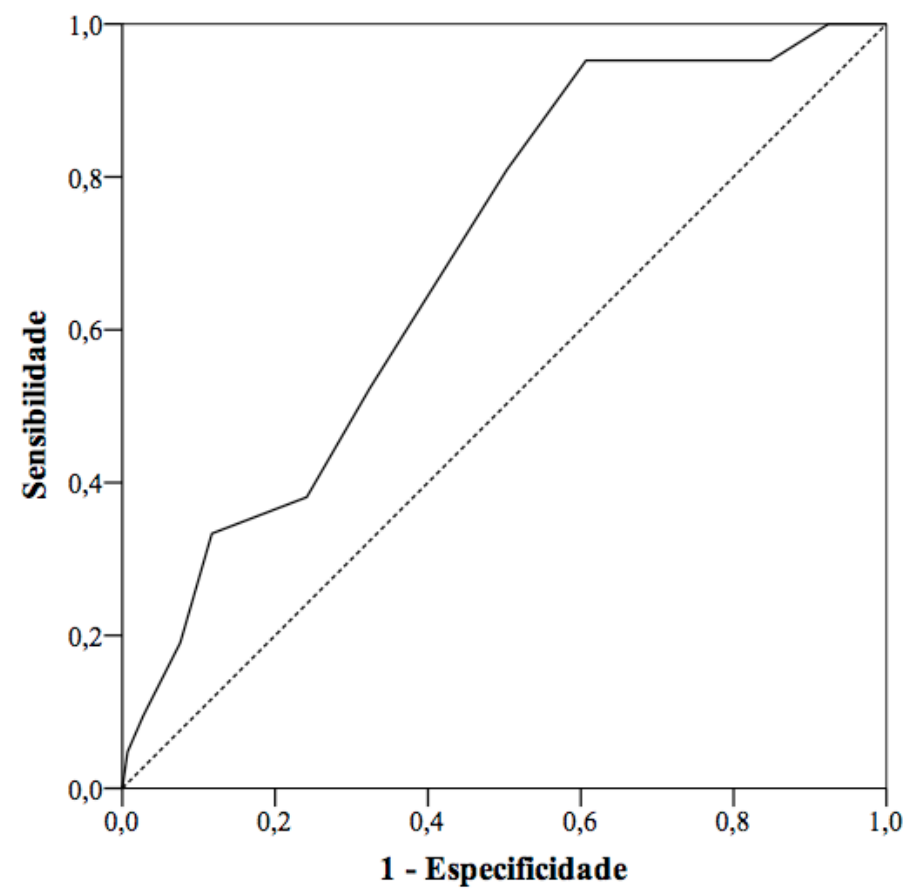

Figura 2 - Curva ROC da Bateria de tarefas de ToM tendo-se como referência os grupos controle e TNM.

A Tabela 4 apresenta os valores de sensibilidade e especificidade referente a diferentes pontos de corte da Bateria de tarefas de ToM para discriminar sujeitos com e sem TNM. O ponto de corte que apresenta melhor equilíbrio entre a sensibilidade e especificidade foi oito, sendo que a nota maior ou igual a nove aumenta em $14 \%$ a sensibilidade, ou seja, quanto maior a pontuação, menor a probabilidade do indivíduo ser diagnosticado com TNM, assim como nota menor ou igual a seis, aumenta em $12 \%$ a especificidade, aumentando as chances do sujeito possuir um TNM.

Tabela 4 - Valores de sensibilidade e especificidade por ponto de corte na Bateria de tarefas de ToM

\begin{tabular}{lll}
\hline Pontos de corte & Sensibilidade & Especificidade \\
\hline$<\mathbf{4}$ & $19,0 \%$ & $92,4 \%$ \\
$<\mathbf{5}$ & $33,3 \%$ & $88,3 \%$ \\
$\mathbf{< 6}$ & $38,1 \%$ & $75,9 \%$ \\
$<\mathbf{7}$ & $52,4 \%$ & $67,6 \%$ \\
$\mathbf{<}$ & $66,7 \%$ & $58,6 \%$ \\
$\mathbf{< 9}$ & $81,0 \%$ & $49,7 \%$ \\
$\mathbf{< 1 0}$ & $95,2 \%$ & $39,3 \%$ \\
$\mathbf{< 1 1}$ & $95,2 \%$ & $30,3 \%$ \\
$<\mathbf{1 2}$ & $95,2 \%$ & $15,2 \%$ \\
$<\mathbf{1 3}$ & $100,0 \%$ & $7,6 \%$ \\
\hline
\end{tabular}


A Tabela 5 apresenta as médias de acertos na tarefa de REFE (Penn Emotion Recognition Test). Houve diferenças significativas entre os três grupos no reconhecimento global das emoções, exceto no reconhecimento da tristeza. Também pode se observar que houve diferença estatisticamente significativa no reconhecimento das emoções de baixa intensidade nas emoções alegria e medo entre os grupos controle e TNM. Em relação às emoções de intensidade alta, houve diferença significativa no reconhecimento das emoções raiva entre os grupos controle e TNM, e medo entre os grupos controle e TNM e entre os grupos clínicos.

Tabela 5 - Média de acertos dos grupos na tarefa de REFE (Penn Emotion Recognition Test).

\begin{tabular}{|c|c|c|c|c|}
\hline Emoções/ & Controle & TNL & TNM & Estatística \\
\hline Intensidade & $\bar{X}(D P: \pm)$ & $\bar{X}(D P: \pm)$ & $\bar{X}(D P: \pm)$ & \\
\hline Alegria & $14,44( \pm 2,00)^{b}$ & $13,94( \pm 2,71)$ & $13,13( \pm 2,77)^{b}$ & $\mathrm{~F}_{2,214}=3,66 ; \mathrm{p}=0,027$ \\
\hline $\begin{array}{l}\text { Alta } \\
\text { Baixa }\end{array}$ & $\begin{array}{l}7,51( \pm 0,98) \\
6,93( \pm 1,33)^{b}\end{array}$ & $\begin{array}{l}7,31( \pm 1,79) \\
6,62( \pm 1,67)\end{array}$ & $\begin{array}{l}7,08( \pm 1,20) \\
6,04( \pm 1,82)^{b}\end{array}$ & $\begin{array}{l}\mathrm{F}_{2,214}=1,91 ; \mathrm{p}=0,150 \\
\mathrm{~F}_{2,214}=3,86 ; \mathrm{p}=0,022\end{array}$ \\
\hline Tristeza & $7,68( \pm 3,28)$ & $7,62( \pm 3,40)$ & $7,17( \pm 3,71)$ & $\mathrm{F}_{2,214}=0,22 ; \mathrm{p}=0,800$ \\
\hline Alta & $4,57( \pm 1,99)$ & $4,47( \pm 1,89)$ & $4,00( \pm 1,75)$ & $\mathrm{F}_{2,214}=0,86 ; \mathrm{p}=0,423$ \\
\hline Baixa & $3,10( \pm 1,75)$ & $3,15( \pm 1,95)$ & $3,17( \pm 2,40)$ & $\mathrm{F}_{2,214}=0,02 ; \mathrm{p}=0,977$ \\
\hline Medo & $9,86( \pm 3,17)^{b}$ & $9,54( \pm 3,39)^{\mathrm{c}}$ & $7,17( \pm 3,63)^{\mathrm{b}, \mathrm{c}}$ & $\mathrm{F}_{2,214}=6,66 ; \mathrm{p}=0,002$ \\
\hline Alta & $5,65( \pm 1,78)^{b}$ & $5,53( \pm 1,95)^{\mathrm{c}}$ & $4,13( \pm 2,32)^{b, c}$ & $\mathrm{~F}_{2,214}=6,52 ; \mathrm{p}=0,002$ \\
\hline Baixa & $4,20( \pm 1,70)^{b}$ & $4,01( \pm 1,78)$ & $3,04( \pm 1,73)^{b}$ & $\mathrm{~F}_{2,214}=4,57 ; \mathrm{p}=0,011$ \\
\hline Nojo & $5,21( \pm 3,44)$ & $4,05( \pm 3,20)$ & $3,87( \pm 3,36)$ & $\mathrm{F}_{2,214}=3,18 ; \mathrm{p}=0,043$ \\
\hline Alta & $2,39( \pm 1,80)$ & $1,74( \pm 1,62)$ & $1,78( \pm 1,53)$ & $F_{2,214}=3,26 ; p=0,040$ \\
\hline Baixa & $2,82( \pm 1,96)$ & $2,31( \pm 2,00)$ & $2,08( \pm 1,95)$ & $\mathrm{F}_{2,214}=2,22 ; \mathrm{p}=0,111$ \\
\hline Raiva & $5,98( \pm 2,80)^{b}$ & $5,25( \pm 2,86)$ & $4,43( \pm 2,19)^{b}$ & $\mathrm{~F}_{2,214}=3,80 ; \mathrm{p}=0,024$ \\
\hline Alta & $4,24( \pm 2,11)^{b}$ & $3,58( \pm 2,11)$ & $2,56( \pm 1,72)^{b}$ & $\mathrm{~F}_{2,214}=7,36 ; \mathrm{p}<0,001$ \\
\hline Baixa & $1,74( \pm 1,40)$ & $1,66( \pm 1,39)$ & $1,87( \pm 1,21)$ & $\mathrm{F}_{2,214}=0,17 ; \mathrm{p}=0,842$ \\
\hline Neutro & $10,21( \pm 4,15)^{\mathrm{a}, \mathrm{b}}$ & $7,86( \pm 5,00)^{\mathrm{a}}$ & $6,00( \pm 5,09)^{b}$ & $\mathrm{~F}_{2,214}=11,84 ; \mathrm{p}<0,001$ \\
\hline
\end{tabular}


Tabela 5 - Média de acertos dos grupos na tarefa de REFE (Penn Emotion Recognition Test).

(continuação)

\begin{tabular}{lllll}
\hline Emoções/ & Controle & TNL & TNM & Estatística \\
Intensidade & $\overline{\mathbf{X}}(\mathbf{D P}: \pm)$ & $\overline{\mathbf{X}}(\mathbf{D P}: \pm)$ & $\overline{\mathbf{X}}(\mathbf{D P}: \pm)$ & \\
\hline Total & $53,39( \pm 10,01)^{\mathrm{a}, \mathrm{b}}$ & $48,29( \pm 11,21)^{\mathrm{a}, \mathrm{c}}$ & $41,78( \pm 11,63)^{\mathrm{b}, \mathrm{c}}$ & $\mathrm{F}_{2,214}=14,31 ; \mathrm{p}<0,001$ \\
Alta & $24,38( \pm 4,55)^{\mathrm{b}}$ & $22,65( \pm 4,80)^{\mathrm{c}}$ & $19,57( \pm 5,32)^{\mathrm{b}, \mathrm{c}}$ & $\mathrm{F}_{2,214}=11,41 ; \mathrm{p}<0,001$ \\
Baixa & $18,80( \pm 4,13)^{\mathrm{b}}$ & $17,78( \pm 5,01)$ & $16,22( \pm 4,75)^{\mathrm{b}}$ & $\mathrm{F}_{2,214}=3,84 ; \mathrm{p}<0,023$ \\
\hline
\end{tabular}

TNL: Transtorno neurocognitivo leve; TNM: Transtorno neurocognitivo maior; ${ }^{a} \mathrm{p}<0,05$ (controle e TNL); ${ }^{\mathrm{b}} \mathrm{p}<0,05$ (controle e TNM); ${ }^{\mathrm{p}} \mathrm{p}<0,05$ (TNL e TNM).

(conclusão)

De forma a se avaliar o poder discriminativo dos componentes da tarefa de REFE, foi realizada uma análise de cada item. As Tabelas 6 a 11 apresentam o desempenho dos grupos em cada item das expressões de alegria, raiva, nojo, medo, tristeza e neutro em alta e baixa intensidade da tarefa de REFE, respectivamente.

Tabela 6 - Desempenho dos grupos em cada estímulo das expressões de alegria da tarefa de REFE.

\begin{tabular}{|c|c|c|c|c|}
\hline Variáveis & Controle & TNL & TNM & Estatística \\
\hline \multicolumn{5}{|c|}{ Baixa intensidade } \\
\hline \multicolumn{5}{|l|}{ Face 25} \\
\hline Acerto $(\%)$ & 97,9 & 7,8 & 4,3 & $X^{2}=3,52 ; p=0,172$ \\
\hline Erro $(\%)$ & 2,1 & 92,2 & 95,7 & \\
\hline \multicolumn{5}{|l|}{ Face 26} \\
\hline Acerto $(\%)$ & 93,0 & 17,6 & 13,0 & $X^{2}=4,92 ; p=0,085$ \\
\hline Erro $(\%)$ & 7,0 & 82,4 & 87,0 & \\
\hline \multicolumn{5}{|l|}{ Face 27} \\
\hline Acerto $(\%)$ & 91,6 & 86,3 & 82,6 & $X^{2}=2,38 ; p=0,304$ \\
\hline Erro $(\%)$ & 8,4 & 13,7 & 17,4 & \\
\hline \multicolumn{5}{|l|}{ Face 28} \\
\hline Acerto $(\%)$ & $71,3^{b}$ & 37,3 & $53,5^{\mathrm{b}}$ & $X^{2}=7,27 ; p=0,026$ \\
\hline Erro $(\%)$ & 28,7 & 62,7 & 43,5 & \\
\hline \multicolumn{5}{|l|}{ Face 73} \\
\hline Acerto $(\%)$ & 93,7 & 96,1 & 82,6 & $X^{2}=4,71 ; p=0,094$ \\
\hline Erro $(\%)$ & 6,3 & 3,9 & 17,4 & \\
\hline \multicolumn{5}{|l|}{ Face 74} \\
\hline Acerto $(\%)$ & 74,8 & 72,5 & 56,5 & $X^{2}=3,31 ; p=0,190$ \\
\hline Erro $(\%)$ & 25,2 & 27,2 & 43,5 & \\
\hline \multicolumn{5}{|l|}{ Face 75} \\
\hline Acerto $(\%)$ & 94,4 & 94,1 & 91,3 & $X^{2}=0,34 ; p=0,844$ \\
\hline
\end{tabular}


Tabela 6 - Desempenho dos grupos em cada estímulo das expressões de alegria da tarefa de REFE.

(continuação)

\begin{tabular}{|c|c|c|c|c|}
\hline Variáveis & Controle & TNL & TNM & Estatística \\
\hline Erro (\%) & 5,6 & 5,9 & 8,7 & \multirow[b]{3}{*}{$X^{2}=1,35 ; p=0,509$} \\
\hline \multicolumn{5}{|l|}{ Face 76} \\
\hline Acerto (\%) & 76,2 & 76,5 & 65,2 & \\
\hline Erro $(\%)$ & 23,8 & 23,5 & 34,8 & \\
\hline \multicolumn{5}{|c|}{ Alta intensidade } \\
\hline Face 29 & & & & \multirow{3}{*}{$X^{2}=0,17 ; p=0,916$} \\
\hline Acerto (\%) & 88,8 & 90,2 & 13,0 & \\
\hline Erro $(\%)$ & 11,2 & 9,8 & 87,0 & \\
\hline \multicolumn{5}{|l|}{ Face 30} \\
\hline Acerto $(\%)$ & 95,8 & 94,1 & 91,3 & \multirow[t]{2}{*}{$X^{2}=0,92 ; p=0,630$} \\
\hline Erro $(\%)$ & 4,2 & 5,9 & 8,7 & \\
\hline \multicolumn{5}{|l|}{ Face 31} \\
\hline Acerto (\%) & 97,9 & 96,1 & 95,7 & \multirow[t]{2}{*}{$X^{2}=0,70 ; p=0,703$} \\
\hline Erro $(\%)$ & 2,1 & 3,9 & 4,3 & \\
\hline \multicolumn{5}{|l|}{ Face 32} \\
\hline Acerto $(\%)$ & 95,8 & 98,0 & 95,7 & \multirow[t]{2}{*}{$X^{2}=0,56 ; p=0,756$} \\
\hline Erro $(\%)$ & 4,2 & 2,0 & 4,3 & \\
\hline \multicolumn{5}{|l|}{ Face 77} \\
\hline Acerto (\%) & 95,1 & 90,2 & 95,7 & \multirow[t]{2}{*}{$X^{2}=1,73 ; p=0,421$} \\
\hline Erro $(\%)$ & 4,9 & 9,8 & 4,3 & \\
\hline \multicolumn{5}{|l|}{ Face 78} \\
\hline Acerto $(\%)$ & 94,4 & 90,2 & 82,6 & \multirow[t]{2}{*}{$X^{2}=4,12 ; p=0,124$} \\
\hline Erro $(\%)$ & 5,6 & 9,8 & 17,4 & \\
\hline \multicolumn{5}{|l|}{ Face 79} \\
\hline Acerto (\%) & $96,5^{b}$ & 90,2 & $78,3^{\mathrm{b}}$ & \multirow[t]{2}{*}{$X^{2}=11,11 ; p=0,004$} \\
\hline Erro $(\%)$ & 3,5 & 9,8 & 21,7 & \\
\hline \multicolumn{5}{|l|}{ Face 80} \\
\hline Acerto $(\%)$ & 86,7 & 82,4 & 82,6 & \multirow[t]{2}{*}{$\mathrm{X}^{2}=0,71 ; \mathrm{p}=0,701$} \\
\hline Erro $(\%)$ & 13,3 & 17,6 & 17,4 & \\
\hline
\end{tabular}

TNL: Transtorno neurocognitivo leve; TNM: Transtorno neurocognitivo maior; ${ }^{\mathrm{a}} \mathrm{p}<0,05$ (controle e TNL); ${ }^{\mathrm{b}} \mathrm{p}<0,05$ (controle e TNM); ${ }^{\mathrm{c}}<0,05$ (TNL e TNM).

(conclusão)

Tabela 7 - Desempenho dos grupos em cada estímulo das expressões de raiva da tarefa de REFE.

\begin{tabular}{lllll}
\hline Variáveis & Controle & TNL & TNM & Estatística \\
\hline Baixa intensidade & & & & \\
Face 01 & & & & \\
Acerto $(\%)$ & 72,0 & 60,8 & 65,2 & $\mathrm{X}^{2}=2,35 ; \mathrm{p}=0,309$ \\
Erro $(\%)$ & 28,0 & 39,2 & 34,8 &
\end{tabular}


Tabela 7 - Desempenho dos grupos em cada estímulo das expressões de raiva da tarefa de REFE.

(continuação)

\begin{tabular}{|c|c|c|c|c|}
\hline Variáveis & Controle & TNL & TNM & Estatística \\
\hline $\begin{array}{l}\text { Face } 02 \\
\text { Acerto }(\%) \\
\text { Erro }(\%)\end{array}$ & $\begin{array}{l}86,0 \\
14,0\end{array}$ & $\begin{array}{l}92,2 \\
7,8\end{array}$ & $\begin{array}{l}95,7 \\
4,3\end{array}$ & $X^{2}=2,69 ; p=0,261$ \\
\hline $\begin{array}{l}\text { Face } \mathbf{0 3} \\
\text { Acerto }(\%) \\
\text { Erro }(\%)\end{array}$ & $\begin{array}{l}53,8 \\
46,2\end{array}$ & $\begin{array}{l}58,8 \\
41,2\end{array}$ & $\begin{array}{l}56,5 \\
43,5\end{array}$ & $\mathrm{X}^{2}=0,39 ; \mathrm{p}=0,822$ \\
\hline $\begin{array}{l}\text { Face } 04 \\
\text { Acerto }(\%) \\
\text { Erro }(\%)\end{array}$ & $\begin{array}{l}81,8 \\
18,2\end{array}$ & $\begin{array}{l}92,2 \\
7,8\end{array}$ & $\begin{array}{l}87,0 \\
13,0\end{array}$ & $X^{2}=3,21 ; p=0,201$ \\
\hline $\begin{array}{l}\text { Face } 49 \\
\text { Acerto }(\%) \\
\text { Erro }(\%)\end{array}$ & $\begin{array}{l}96,5 \\
3,5\end{array}$ & $\begin{array}{l}98,0 \\
2,0\end{array}$ & $\begin{array}{l}87,0 \\
13,0\end{array}$ & $X^{2}=5,34 ; p=0,069$ \\
\hline $\begin{array}{l}\text { Face } 50 \\
\text { Acerto }(\%) \\
\text { Erro }(\%)\end{array}$ & $\begin{array}{l}84,6 \\
15,4\end{array}$ & $\begin{array}{l}80,4 \\
19,6\end{array}$ & $\begin{array}{l}91,3 \\
8,7\end{array}$ & $\mathrm{X}^{2}=1,45 ; \mathrm{p}=0,483$ \\
\hline $\begin{array}{l}\text { Face } 51 \\
\text { Acerto }(\%) \\
\text { Erro }(\%)\end{array}$ & $\begin{array}{l}71,3 \\
28,7\end{array}$ & $\begin{array}{l}80,4 \\
19,6\end{array}$ & $\begin{array}{l}56,5 \\
43,5\end{array}$ & $X^{2}=4,53 ; p=0,104$ \\
\hline $\begin{array}{l}\text { Face } 52 \\
\text { Acerto }(\%) \\
\text { Erro }(\%)\end{array}$ & $\begin{array}{l}79,7 \\
20,3\end{array}$ & $\begin{array}{l}70,6 \\
29,4\end{array}$ & $\begin{array}{l}73,9 \\
26,1\end{array}$ & $X^{2}=1,90 ; p=0,386$ \\
\hline $\begin{array}{l}\text { Alta intensi } \\
\text { Face } 05 \\
\text { Acerto }(\%) \\
\text { Erro }(\%)\end{array}$ & $\begin{array}{l}59,4 \\
40,6\end{array}$ & $\begin{array}{l}51,0 \\
49,0\end{array}$ & $\begin{array}{l}60,9 \\
39,1\end{array}$ & $X^{2}=3,80 ; p=0,149$ \\
\hline $\begin{array}{l}\text { Face } 06 \\
\text { Acerto }(\%) \\
\text { Erro }(\%)\end{array}$ & $\begin{array}{l}51,0^{\mathrm{b}} \\
49,0\end{array}$ & $\begin{array}{l}62,7 \\
37,3\end{array}$ & $\begin{array}{l}73,9^{b} \\
26,1\end{array}$ & $X^{2}=6,66 ; p=0,036$ \\
\hline $\begin{array}{l}\text { Face } 07 \\
\text { Acerto }(\%) \\
\text { Erro }(\%)\end{array}$ & $\begin{array}{l}51,7 \\
48,3\end{array}$ & $\begin{array}{l}56,9 \\
43,1\end{array}$ & $\begin{array}{l}26,1 \\
73,9\end{array}$ & $X^{2}=5,63 ; p=0,060$ \\
\hline $\begin{array}{l}\text { Face } 08 \\
\text { Acerto }(\%) \\
\text { Erro }(\%)\end{array}$ & $\begin{array}{l}51,0 \\
49,0\end{array}$ & $\begin{array}{l}47,1 \\
52,9\end{array}$ & $\begin{array}{l}30,4 \\
69,6\end{array}$ & $X^{2}=3,39 ; p=0,183$ \\
\hline $\begin{array}{l}\text { Face } 53 \\
\text { Acerto }(\%) \\
\text { Erro }(\%)\end{array}$ & $\begin{array}{l}25,9 \\
74,1\end{array}$ & $\begin{array}{l}23,5 \\
76,5\end{array}$ & $\begin{array}{l}21,7 \\
78,3\end{array}$ & $\mathrm{X}^{2}=0,24 ; \mathrm{p}=0,884$ \\
\hline $\begin{array}{l}\text { Face } 54 \\
\text { Acerto }(\%) \\
\text { Erro }(\%)\end{array}$ & $\begin{array}{l}46,2 \\
53,8\end{array}$ & $\begin{array}{l}33,3 \\
66,7\end{array}$ & $\begin{array}{l}26,1 \\
73,9\end{array}$ & $\mathrm{X}^{2}=4,92 ; \mathrm{p}=0,085$ \\
\hline
\end{tabular}


Tabela 7 - Desempenho dos grupos em cada estímulo das expressões de raiva da tarefa de REFE.

(continuação)

\begin{tabular}{lllll}
\hline Variáveis & Controle & TNL & TNM & Estatística \\
\hline Face 55 & & & \\
Acerto (\%) & $74,8^{\mathrm{b}}$ & 62,7 & $47,8^{\mathrm{b}}$ & $\mathrm{X}^{2}=8,03 ; \mathrm{p}=0,018$ \\
Erro (\%) & 25,2 & 37,3 & 52,2 & \\
& & & \\
Face 56 & & 60,9 & $\mathrm{X}^{2}=5,28 ; \mathrm{p}=0,071$ \\
Acerto (\%) & 64,3 & 60,8 & 39,1 & \\
Erro (\%) & 35,7 & 39,2 & & \\
\hline TNL: Transtorno neurocognitivo leve; TNM: Transtorno neurocognitivo maior; ${ }^{\mathrm{a}} \mathrm{p}<0,05$ (controle e TNL); \\
\multicolumn{2}{l}{$\mathrm{p}<0,05$ (controle e TNM); ${ }^{\mathrm{c}} \mathrm{p}<0,05$ (TNL e TNM). }
\end{tabular}

Tabela 8 - Desempenho dos grupos em cada estímulo das expressões de nojo da tarefa de REFE.

\begin{tabular}{|c|c|c|c|c|}
\hline Variáveis & Controle & TNL & TNM & Estatística \\
\hline \multicolumn{5}{|c|}{ Baixa intensidade } \\
\hline \multicolumn{5}{|l|}{ Face 09} \\
\hline Acerto $(\%)$ & 18,2 & 13,7 & 13,0 & $X^{2}=0,77 ; p=0,679$ \\
\hline Erro (\%) & 81,8 & 86,3 & 87,0 & \\
\hline \multicolumn{5}{|l|}{ Face 10} \\
\hline Acerto $(\%)$ & 23,8 & 19,6 & 26,1 & $\mathrm{X}^{2}=0,50 ; p=0,778$ \\
\hline Erro (\%) & 76,2 & 80,4 & 73,9 & \\
\hline \multicolumn{5}{|l|}{ Face 11} \\
\hline Acerto $(\%)$ & 30,1 & 35,3 & 39,1 & $\mathrm{X}^{2}=1,02 ; \mathrm{p}=0,599$ \\
\hline Erro (\%) & 69,9 & 64,7 & 60,9 & \\
\hline \multicolumn{5}{|l|}{ Face 12} \\
\hline Acerto $(\%)$ & $67,1^{\mathrm{b}}$ & 54,9 & $43,5^{\mathrm{b}}$ & $X^{2}=6,01 ; p=0,049$ \\
\hline Erro (\%) & 32,9 & 45,1 & 56,5 & \\
\hline \multicolumn{5}{|l|}{ Face 57} \\
\hline Acerto $(\%)$ & $39,2^{\mathrm{b}}$ & 31,4 & $13,0^{\mathrm{b}}$ & $X^{2}=6,27 ; p=0,043$ \\
\hline Erro (\%) & 60,8 & 68,6 & 87,0 & \\
\hline \multicolumn{5}{|l|}{ Face 58} \\
\hline Acerto $(\%)$ & 14,7 & 5,9 & 8,7 & $\mathrm{X}^{2}=3,02 ; \mathrm{p}=0,220$ \\
\hline Erro (\%) & 85,3 & 94,1 & 91,3 & \\
\hline \multicolumn{5}{|l|}{ Face 59} \\
\hline Acerto (\%) & 60,8 & 49,0 & 43,5 & $X^{2}=3,83 ; p=0,147$ \\
\hline Erro (\%) & 39,2 & 51,0 & 56,5 & \\
\hline \multicolumn{5}{|l|}{ Face 60} \\
\hline Acerto $(\%)$ & 28,7 & 21,6 & 21,7 & $X^{2}=1,25 ; p=0,535$ \\
\hline Erro (\%) & 71,3 & 78,4 & 78,3 & \\
\hline \multicolumn{5}{|c|}{ Alta intensidade } \\
\hline Face 13 & & & & \\
\hline Acerto $(\%)$ & 5,6 & 5,9 & 8,7 & $\mathrm{X}^{2}=0,34 ; \mathrm{p}=0,844$ \\
\hline
\end{tabular}


Tabela 8 - Desempenho dos grupos em cada estímulo das expressões de nojo da tarefa de REFE.

(continuação)

\begin{tabular}{|c|c|c|c|c|}
\hline Variáveis & Controle & TNL & TNM & Estatística \\
\hline Erro (\%) & 94,4 & 94,1 & 91,3 & \\
\hline \multicolumn{5}{|l|}{ Face 14} \\
\hline Acerto (\%) & 29,4 & 17,6 & 34,8 & $X^{2}=3,35 ; p=0,186$ \\
\hline Erro $(\%)$ & 70,6 & 82,4 & 65,2 & \\
\hline \multicolumn{5}{|l|}{ Face 15} \\
\hline Acerto (\%) & 45,5 & 37,3 & 34,8 & $\mathrm{X}^{2}=1,64 ; \mathrm{p}=0,439$ \\
\hline Erro (\%) & 54,5 & 62,7 & 65,2 & \\
\hline \multicolumn{5}{|l|}{ Face 16} \\
\hline Acerto (\%) & 30,8 & 19,6 & 26,1 & $X^{2}=2,37 ; p=0,305$ \\
\hline Erro (\%) & 69,2 & 80,4 & 73,9 & \\
\hline \multicolumn{5}{|l|}{ Face 61} \\
\hline Acerto $(\%)$ & $70,6^{b}$ & 56,9 & $47,8^{b}$ & $X^{2}=6,45 ; p=0,040$ \\
\hline Erro (\%) & 29,4 & 43,1 & 52,2 & \\
\hline \multicolumn{5}{|l|}{ Face 62} \\
\hline Acerto (\%) & 12,6 & 7,8 & 4,3 & $X^{2}=1,95 ; p=0,376$ \\
\hline Erro (\%) & 87,4 & 92,2 & 95,7 & \\
\hline \multicolumn{5}{|l|}{ Face 63} \\
\hline Acerto $(\%)$ & 25,2 & 17,7 & 17,4 & $\mathrm{X}^{2}=2,29 ; \mathrm{p}=0,317$ \\
\hline Erro (\%) & 74,8 & 84,3 & 82,6 & \\
\hline \multicolumn{5}{|l|}{ Face 64} \\
\hline Acerto (\%) & 19,6 & 13,7 & 4,3 & $X^{2}=3,71 ; p=0,156$ \\
\hline Erro $(\%)$ & 80,4 & 86,3 & 95,7 & \\
\hline
\end{tabular}

Tabela 9 - Desempenho dos grupos em cada estímulo das expressões de medo da tarefa de REFE.

\begin{tabular}{lllll}
\hline Variáveis & Controle & TNL & TNM & Estatística \\
\hline Baixa intensidade & & & & \\
Face 17 & & & & \\
Acerto $(\%)$ & $78,3^{\mathrm{a}}$ & $58,8^{\mathrm{a}}$ & 65,2 & $\mathrm{X}^{2}=7,79 ; \mathrm{p}=0,020$ \\
Erro $(\%)$ & 21,7 & 41,2 & 34,8 & \\
Face 18 & & & & \\
Acerto $(\%)$ & $83,2^{\mathrm{b}}$ & $82,4^{\mathrm{c}}$ & $56,5^{\mathrm{b}, \mathrm{c}}$ & $\mathrm{X}^{2}=9,08 ; \mathrm{p}=0,011$ \\
Erro $(\%)$ & 16,8 & 17,6 & 43,5 & \\
& & & & \\
Face 19 & & & 78,3 & $\mathrm{X}^{2}=2,42 ; \mathrm{p}=0,297$ \\
Acerto $(\%)$ & 30,1 & 80,4 & 21,7 &
\end{tabular}


Tabela 9 - Desempenho dos grupos em cada estímulo das expressões de medo da tarefa de REFE.

(continuação)

\begin{tabular}{|c|c|c|c|c|}
\hline Variáveis & Controle & TNL & TNM & Estatística \\
\hline \multicolumn{5}{|l|}{ Face 20 } \\
\hline Acerto $(\%)$ & 7,0 & 13,7 & 4,3 & \multirow{2}{*}{$X^{2}=2,76 ; p=0,251$} \\
\hline Erro $(\%)$ & 93,0 & 86,3 & 95,7 & \\
\hline \multicolumn{5}{|l|}{ Face 65} \\
\hline Acerto $(\%)$ & $62,2^{\mathrm{a}}$ & $78,4^{\mathrm{a}, \mathrm{c}}$ & $52,2^{\mathrm{c}}$ & \multirow[t]{2}{*}{$X^{2}=6,18 ; p=0,045$} \\
\hline Erro (\%) & 37,8 & 21,6 & 47,8 & \\
\hline \multicolumn{5}{|l|}{ Face 66} \\
\hline Acerto (\%) & $47,6^{\mathrm{b}}$ & $47,1^{\mathrm{c}}$ & $13,0^{\mathrm{b}, \mathrm{c}}$ & \multirow[t]{2}{*}{$X^{2}=9,87 ; p=0,007$} \\
\hline Erro $(\%)$ & 52,4 & 52,9 & 87,0 & \\
\hline \multicolumn{5}{|l|}{ Face 67} \\
\hline Acerto (\%) & 67,8 & 60,8 & 52,2 & \multirow[t]{2}{*}{$X^{2}=2,52 ; p=0,283$} \\
\hline Erro $(\%)$ & 32,2 & 39,2 & 47,8 & \\
\hline \multicolumn{5}{|l|}{ Face 68} \\
\hline Acerto $(\%)$ & 44,1 & 41,2 & 39,1 & \multirow[t]{2}{*}{$X^{2}=0,27 ; p=0,872$} \\
\hline Erro $(\%)$ & 55,9 & 58,8 & 60,9 & \\
\hline \multicolumn{5}{|c|}{ Alta intensidade } \\
\hline \multicolumn{5}{|l|}{ Face 21} \\
\hline Acerto (\%) & $81,1^{\mathrm{b}}$ & 74,5 & $52,2^{b}$ & \multirow[t]{2}{*}{$X^{2}=9,38 ; p=0,009$} \\
\hline Erro (\%) & 18,9 & 25,5 & 47,8 & \\
\hline \multicolumn{5}{|l|}{ Face 22} \\
\hline Acerto $(\%)$ & $61,5^{\mathrm{b}}$ & $58,8^{\mathrm{c}}$ & $30,4^{b, c}$ & \multirow[t]{2}{*}{$\mathrm{X}^{2}=7,88 ; \mathrm{p}=0,019$} \\
\hline Erro $(\%)$ & 38,5 & 41,2 & 69,6 & \\
\hline \multicolumn{5}{|l|}{ Face 23} \\
\hline Acerto $(\%)$ & 86,0 & 82,4 & 65,2 & \multirow[t]{2}{*}{$X^{2}=6,07 ; p=0,048$} \\
\hline Erro $(\%)$ & 14,0 & 17,6 & 34,8 & \\
\hline \multicolumn{5}{|l|}{ Face 24} \\
\hline Acerto (\%) & 33,6 & 35,3 & 34,8 & \multirow[t]{2}{*}{$X^{2}=0,05 ; p=0,973$} \\
\hline Erro $(\%)$ & 66,4 & 64,7 & 65,2 & \\
\hline \multicolumn{5}{|l|}{ Face 69} \\
\hline Acerto (\%) & 86,0 & 82,4 & 69,6 & \multirow[t]{2}{*}{$X^{2}=3,92 ; p=0,140$} \\
\hline Erro $(\%)$ & 14,0 & 17,6 & 30,4 & \\
\hline \multicolumn{5}{|l|}{ Face 70} \\
\hline Acerto $(\%)$ & 81,1 & 84,3 & 65,2 & \multirow{2}{*}{$X^{2}=3,86 ; p=0,145$} \\
\hline Erro (\%) & 18,9 & 15,7 & 34,8 & \\
\hline \multicolumn{5}{|l|}{ Face 71} \\
\hline Acerto (\%) & 58,7 & 58,8 & 56,5 & \multirow[t]{2}{*}{$X^{2}=0,04 ; p=0,979$} \\
\hline Erro $(\%)$ & 41,3 & 41,2 & 43,5 & \\
\hline \multicolumn{5}{|l|}{ Face 72} \\
\hline Acerto (\%) & $77,6^{\mathrm{b}}$ & $76,5^{\mathrm{c}}$ & $39,1^{b, c}$ & $X^{2}=15,33 ; p<0,001$ \\
\hline Erro $(\%)$ & 22,4 & 23,5 & 60,9 & \\
\hline
\end{tabular}

TNL: Transtorno neurocognitivo leve; TNM: Transtorno neurocognitivo maior; ${ }^{a} \mathrm{p}<0,05$ (controle e TNL); ${ }^{\mathrm{b}} \mathrm{p}<0,05$ (controle e TNM); ${ }^{\mathrm{c}}<0,05$ (TNL e TNM). 
Tabela 10 - Desempenho dos grupos em cada estímulo das expressões de tristeza da tarefa de REFE

\begin{tabular}{|c|c|c|c|c|}
\hline Variáveis & Controle & TNL & TNM & Estatística \\
\hline \multicolumn{5}{|c|}{ Baixa intensidade } \\
\hline \multicolumn{5}{|l|}{ Face 41} \\
\hline Acerto (\%) & 41,3 & 47,1 & 39,1 & $X^{2}=0,63 ; p=0,730$ \\
\hline Erro $(\%)$ & 58,7 & 52,9 & 60,9 & \\
\hline \multicolumn{5}{|l|}{ Face 42} \\
\hline Acerto (\%) & 44,1 & 43,1 & 52,2 & $X^{2}=0,59 ; p=0,743$ \\
\hline Erro $(\%)$ & 55,9 & 56,9 & 47,8 & \\
\hline \multicolumn{5}{|l|}{ Face 43} \\
\hline Acerto (\%) & 58,7 & 58,8 & 43,5 & $X^{2}=1,96 ; p=0,375$ \\
\hline Erro $(\%)$ & 41,3 & 41,2 & 56,5 & \\
\hline \multicolumn{5}{|l|}{ Face 44} \\
\hline Acerto (\%) & 17,5 & 17,6 & 26,1 & $X^{2}=1,00 ; p=0,606$ \\
\hline Erro $(\%)$ & 82,5 & 82,4 & 73,9 & \\
\hline \multicolumn{5}{|l|}{ Face 89} \\
\hline Acerto (\%) & 31,5 & 29,4 & 43,5 & $X^{2}=1,55 ; p=0,460$ \\
\hline Erro $(\%)$ & 68,5 & 70,6 & 56,5 & \\
\hline \multicolumn{5}{|l|}{ Face 90} \\
\hline Acerto (\%) & 23,1 & 29,4 & 34,8 & $X^{2}=1,87 ; p=0,392$ \\
\hline Erro $(\%)$ & 76,9 & 70,6 & 65,2 & \\
\hline \multicolumn{5}{|l|}{ Face 91} \\
\hline Acerto (\%) & 32,9 & 31,4 & 34,8 & $X^{2}=0,08 ; p=0,957$ \\
\hline Erro $(\%)$ & 67,1 & 68,6 & 65,2 & \\
\hline \multicolumn{5}{|l|}{ Face 92} \\
\hline Acerto (\%) & 61,5 & 58,8 & 43,5 & $X^{2}=2,67 ; p=0,263$ \\
\hline Erro $(\%)$ & 38,5 & 41,2 & 56,5 & \\
\hline \multicolumn{5}{|c|}{ Alta intensidade } \\
\hline \multicolumn{5}{|l|}{ Face 45} \\
\hline Acerto (\%) & 74,1 & 78,4 & 60,9 & $X^{2}=2,55 ; p=0,278$ \\
\hline Erro $(\%)$ & 25,9 & 21,6 & 31,9 & \\
\hline \multicolumn{5}{|l|}{ Face 46} \\
\hline Acerto (\%) & 45,5 & 31,4 & 30,4 & $\mathrm{X}^{2}=4,18 ; \mathrm{p}=0,123$ \\
\hline Erro $(\%)$ & 54,5 & 68,6 & 69,6 & \\
\hline \multicolumn{5}{|l|}{ Face 47} \\
\hline Acerto (\%) & 68,5 & 62,7 & 56,5 & $X^{2}=1,56 ; p=0,457$ \\
\hline Erro $(\%)$ & 31,5 & 37,3 & 43,5 & \\
\hline \multicolumn{5}{|l|}{ Face 48} \\
\hline Acerto (\%) & 75,5 & 64,7 & 73,9 & $X^{2}=2,23 ; p=0,327$ \\
\hline Erro $(\%)$ & 24,5 & 35,3 & 26,1 & \\
\hline \multicolumn{5}{|l|}{ Face 93} \\
\hline Acerto (\%) & 52,4 & 70,6 & 56,5 & $X^{2}=5,05 ; p=0,080$ \\
\hline Erro $(\%)$ & 47,6 & 29,4 & 43,5 & \\
\hline
\end{tabular}


Tabela 10 - Desempenho dos grupos em cada estímulo das expressões de tristeza da tarefa de REFE

(continuação)

\begin{tabular}{|c|c|c|c|c|}
\hline Variáveis & Controle & TNL & TNM & Estatística \\
\hline \multicolumn{5}{|l|}{ Face 94} \\
\hline Acerto $(\%)$ & 49,7 & 47,1 & 47,8 & $\mathrm{X}^{2}=0,11 ; \mathrm{p}=0,946$ \\
\hline Erro (\%) & 50,3 & 52,9 & 52,2 & \\
\hline \multicolumn{5}{|l|}{ Face 95} \\
\hline Acerto $(\%)$ & 59,4 & 62,7 & 47,8 & $X^{2}=1,49 ; p=0,474$ \\
\hline Erro $(\%)$ & 40,6 & 37,3 & 52,2 & \\
\hline \multicolumn{5}{|l|}{ Face 96} \\
\hline Acerto (\%) & 32,2 & 29,4 & 26,1 & $X^{2}=0,41 ; p=0,815$ \\
\hline Erro $(\%)$ & 67,8 & 70,6 & 73,9 & \\
\hline
\end{tabular}

Tabela 11 - Desempenho dos grupos em cada estímulo da expressão neutro da tarefa de REFE

\begin{tabular}{lllll}
\hline Variáveis & Controle & TNL & TNM & Estatística \\
\hline Face 33 & & & & \\
Acerto (\%) & 72,7 & 56,9 & 56,5 & $\mathrm{X}^{2}=5,65 ; \mathrm{p}=0,059$ \\
Erro (\%) & 27,3 & 43,1 & 43,5 & \\
& & & \\
Face 34 & & $47,1^{\mathrm{a}}$ & $34,8^{\mathrm{b}}$ & $\mathrm{X}^{2}=9,83 ; \mathrm{p}=0,007$ \\
Acerto (\%) & $64,3^{\mathrm{a}, \mathrm{b}}$ & 52,9 & 65,2 & \\
Erro (\%) & 35,7 & & &
\end{tabular}

\section{Face 35}

Acerto $(\%)$

Erro $(\%)$

Face 36

Acerto $(\%)$

Erro $(\%)$

Face 37

Acerto (\%)

Erro (\%)

Face 38

Acerto (\%)

Erro (\%)

Face 39

Acerto (\%)

Erro (\%)

\section{$65,0^{\mathrm{b}}$}

35,0

$65,0^{\mathrm{a}, \mathrm{b}}$

35,0

$51,7^{\mathrm{a}, \mathrm{b}}$

48,3

56,6

43,4

$68,5^{\mathrm{a}, \mathrm{b}}$

31,5 $60,8^{\circ}$

39,2

$49,0^{\mathrm{a}}$

51,0

$35,3^{\mathrm{a}}$

64,7

47,1

52,9

$51,0^{\mathrm{a}}$

49,0 $34,8^{\mathrm{b}, \mathrm{c}}$

65,2

$39,1^{\mathrm{b}}$

60,9

$X^{2}=7,95 ; p=0,019$

$X^{2}=7,61 ; p=0,022$

$26,1^{b}$

$\mathrm{X}^{2}=7,88 ; \mathrm{p}=0,019$

73,9

39,1

60,9

$X^{2}=2,47 ; p=0,291$

$39,1^{\mathrm{b}}$

60,9
$X^{2}=11,09 ; p=0,004$ 
Tabela 11 - Desempenho dos grupos em cada estímulo da expressão neutro da tarefa de REFE

(continuação)

\begin{tabular}{|c|c|c|c|c|}
\hline Variáveis & Controle & TNL & TNM & Estatística \\
\hline \multicolumn{5}{|l|}{ Face 40 } \\
\hline Acerto $(\%)$ & $70,6^{a, b}$ & $52,9^{\mathrm{a}}$ & $43,5^{b}$ & \multirow[t]{2}{*}{$X^{2}=9,57 ; p=0,008$} \\
\hline Erro (\%) & 29,4 & 47,1 & 56,5 & \\
\hline \multicolumn{5}{|l|}{ Face 81} \\
\hline Acerto (\%) & $74,8^{a, b}$ & $56,9^{\mathrm{a}}$ & $39,1^{\mathrm{b}}$ & \multirow[t]{2}{*}{$X^{2}=14,36 ; p<0,001$} \\
\hline Erro (\%) & 25,2 & 43,1 & 60,9 & \\
\hline \multicolumn{5}{|l|}{ Face 82} \\
\hline Acerto $(\%)$ & $68,5^{\mathrm{a}, \mathrm{b}}$ & $52,9^{\mathrm{a}}$ & $43,5^{b}$ & \multirow[t]{2}{*}{$\mathrm{X}^{2}=7,72 ; \mathrm{p}=0,021$} \\
\hline Erro (\%) & 31,5 & 47,1 & 56,5 & \\
\hline \multicolumn{5}{|l|}{ Face 83} \\
\hline Acerto (\%) & 45,5 & 39,2 & 30,4 & \multirow{2}{*}{$\mathrm{X}^{2}=2,10 ; \mathrm{p}=0,349$} \\
\hline Erro (\%) & 54,5 & 60,8 & 69,6 & \\
\hline \multicolumn{5}{|l|}{ Face 84} \\
\hline Acerto (\%) & $72,7^{\mathrm{a}, \mathrm{b}}$ & $52,9^{\mathrm{a}}$ & $30,4^{b}$ & \multirow[t]{2}{*}{$X^{2}=18,57 ; p<0,001$} \\
\hline Erro (\%) & 27,3 & 47,1 & 69,6 & \\
\hline \multicolumn{5}{|l|}{ Face 85} \\
\hline Acerto $(\%)$ & $70,6^{a, b}$ & $54,9^{\mathrm{a}}$ & $47,8^{b}$ & \multirow{2}{*}{$X^{2}=7,19 ; p=0,027$} \\
\hline Erro (\%) & 29,4 & 45,1 & 52,2 & \\
\hline \multicolumn{5}{|l|}{ Face 86} \\
\hline Acerto $(\%)$ & $63,6^{a, b}$ & $37,3^{\mathrm{a}}$ & $30,4^{b}$ & \multirow[t]{2}{*}{$X^{2}=16,24 ; p<0,001$} \\
\hline Erro (\%) & 36,4 & 62,7 & 69,6 & \\
\hline \multicolumn{5}{|l|}{ Face 87} \\
\hline Acerto $(\%)$ & $60,1^{b}$ & $51,0^{c}$ & $26,1^{b, c}$ & \multirow{2}{*}{$X^{2}=9,57 ; p=0,008$} \\
\hline Erro (\%) & 39,9 & 49,0 & 73,9 & \\
\hline \multicolumn{5}{|l|}{ Face 88} \\
\hline Acerto (\%) & 50,3 & 37,3 & 39,1 & \multirow{2}{*}{$X^{2}=3,09 ; p=0,213$} \\
\hline Erro $(\%)$ & 49,7 & 62,7 & 60,9 & \\
\hline
\end{tabular}

A Figura 3, por sua vez, apresenta a curva ROC relativa à tarefa de REFE (Penn Emotion Recognition Test), considerando-se os grupos controle e com TNM. A área da curva foi de 0,78 (IC95\%: 0,68-0,88), sendo considerada regular (Metz, 1978). 


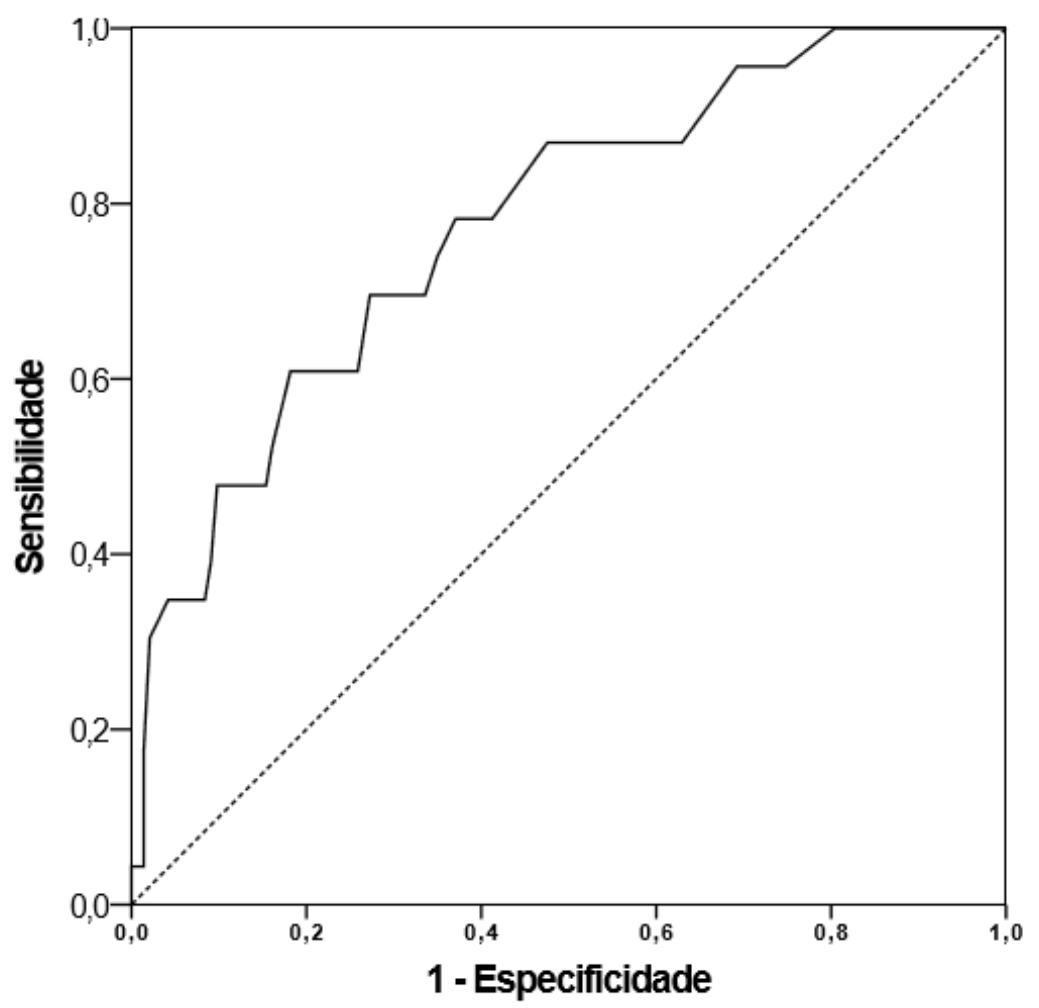

Figura 3 - Curva ROC tarefa de REFE (Penn Emotion Recognition Test) tendo-se como referência os grupos controle e com TNM.

A Tabela 12 apresenta a sensibilidade e especificidade referente aos pontos de corte da bateria de REFE (Penn Emotion Recognition Test). Pode-se notar que a nota de 47 apresenta o melhor equilíbrio entre a sensibilidade e especificidade, no entanto, apresenta elevada especificidade e baixa sensibilidade, o que não é adequado para um teste. Por isso, a nota de corte de 52 seria considerada com um melhor equilíbrio entre a sensibilidade e especificidade.

Tabela 12 - Valores de sensibilidade e especificidade por escore na tarefa de REFE (Penn Emotion Recognition Test).

\begin{tabular}{lcc}
\hline Pontos de corte & Sensibilidade & Especificidade \\
\hline$<\mathbf{4 2}$ & $47,8 \%$ & $84,6 \%$ \\
$<\mathbf{4 3}$ & $52,2 \%$ & $83,9 \%$ \\
$<\mathbf{4 4}$ & $60,9 \%$ & $81,8 \%$ \\
$<\mathbf{4 5}$ & $60,9 \%$ & $79,0 \%$ \\
$<\mathbf{4 6}$ & $60,9 \%$ & $76,2 \%$ \\
$<\mathbf{4 7}$ & $60,9 \%$ & $74,1 \%$ \\
$<\mathbf{4 8}$ & $69,6 \%$ & $72,7 \%$ \\
$<\mathbf{4 9}$ & $69,6 \%$ & $69,9 \%$
\end{tabular}


Tabela 12 - Valores de sensibilidade e especificidade por escore na tarefa de REFE (Penn Emotion Recognition Test).

(continuação)

\begin{tabular}{lcc}
\hline Pontos de corte & Sensibilidade & Especificidade \\
\hline$<\mathbf{5 0}$ & $69,6 \%$ & $68,5 \%$ \\
$<\mathbf{5 1}$ & $69,6 \%$ & $66,4 \%$ \\
$<\mathbf{5 2}$ & $73,9 \%$ & $65,0 \%$ \\
$<\mathbf{5 3}$ & $78,3 \%$ & $62,9 \%$ \\
$<\mathbf{5 4}$ & $78,3 \%$ & $58,7 \%$ \\
$<\mathbf{5 5}$ & $87,0 \%$ & $52,4 \%$ \\
$<\mathbf{5 6}$ & $87,0 \%$ & $49,0 \%$ \\
$<\mathbf{5 7}$ & $87,0 \%$ & $43,4 \%$ \\
$<\mathbf{5 8}$ & $87,0 \%$ & $39,9 \%$ \\
$<\mathbf{5 9}$ & $87,0 \%$ & $37,1 \%$ \\
$<\mathbf{6 0}$ & $95,7 \%$ & $30,8 \%$ \\
$<\mathbf{6 1}$ & $95,7 \%$ & $25,2 \%$ \\
$<\mathbf{6 2}$ & $100,0 \%$ & $19,6 \%$ \\
\hline
\end{tabular}

(conclusão)

A Tabela 13 apresenta uma proposta de uma escala reduzida composta por questões escolhidas da Bateria de Tarefas de ToM e as faces da tarefa de REFE (Penn Emotion Recognition Test), bem como o percentual de acerto de cada item, conforme já apontado nas tabelas anteriores. No instrumento que avalia a ToM, foram selecionadas as questões que apresentaram diferença estatisticamente significativa entre os grupos após aplicado o teste post hoc de Bonferroni (questões 1, 5 e 10). Já na tarefa de REFE, como algumas emoções (ex: medo) apresentaram várias faces com p menor ou igual a 0,05, optou-se pela seleção de duas faces de cada emoção, não necessariamente sendo uma de alta intensidade e a outra de baixa intensidade, mas sim optando por aquelas que apresentavam maior significância estatística.

É importante ressaltar que nenhuma das faces com expressão de tristeza apresentou significância estatística. No entanto, foram selecionadas duas faces dessa emoção apenas para que o instrumento fosse composto de todas as faces propostas de avaliação inicial.

Tabela 13 - Desempenho dos grupos na Bateria Breve de Cognição Social

\begin{tabular}{lllll}
\hline Variáveis & Controle & TNL & TNM & Estatística \\
\hline ToM & & & & \\
& & & & \\
Questão 1 & 69,4 & 57,7 & 38,1 & $\mathrm{X}^{2}=8,81 ; \mathrm{p}=0,012$ \\
Acerto (\%) & 30,6 & 21,4 & 61,9 & \\
Erro (\%) & & &
\end{tabular}


Tabela 13 - Desempenho dos grupos na Bateria Breve de Cognição Social

(continuação)

\begin{tabular}{lllll}
\hline Variáveis & Controle & TNL & TNM & Estatística \\
\hline Questão 5 & & & & \\
Acerto (\%) & 87,1 & 71,2 & 71,4 & $\mathrm{X}^{2}=8,23 ; \mathrm{p}=0,016$ \\
Erro (\%) & 12,9 & 28,8 & 28,6 & \\
& & & \\
Questão 10 & & & 28,6 & $\mathrm{X}^{2}=22,42 ; \mathrm{p}<0,001$ \\
Acerto (\%) & 75,5 & 53,8 & 71,4 & \\
Erro (\%) & 24,5 & 46,2 & &
\end{tabular}

\section{REFE}

\section{Alegria}

Face 28

Acerto $(\%)$

Erro (\%)

71,3

28,7

37,3

62,7

53,5

43,5

$X^{2}=7,27 ; p=0,026$

\section{Face 79}

Acerto (\%)

Erro $(\%)$

96,5

3,5

90,2

9,8

78,3

21,7
$X^{2}=11,11 ; p=0,004$

\section{Raiva}

Face 06

Acerto (\%)

Erro (\%)

51,0

49,0

37,3

\section{Nojo}

\section{Face 57}

73,9

26,1
62,7

Acerto (\%)

Erro $(\%)$

74,8

25,2

37,3

Acerto (\%)

Erro (\%)

39,2

60,8

31,4

68,6

13,0

87,0

Face 61

Acerto (\%)

Erro (\%)

70,6

29,4

56,9

43,1

47,8

52,2
47,8

52,2

$$
X^{2}=8,03 ; p=0,018
$$

Medo

Face 66

Acerto (\%)

Erro (\%)

47,6

52,4

47,1

52,9

13,0

87,0

Face 72

Acerto (\%)

Erro (\%)

77,6

76,5

23,5

39,1

60,9

$$
X^{2}=6,27 ; p=0,043
$$

$X^{2}=6,45 ; p=0,040$

\section{Neutro}

Face 84

Acerto (\%)

Erro $(\%)$
52,9

47,1
30,4

69,6
$X^{2}=18,57 ; p<0,001$ 
Tabela 13 - Desempenho dos grupos na Bateria Breve de Cognição Social

(continuação)

\begin{tabular}{|c|c|c|c|c|}
\hline Variáveis & Controle & TNL & TNM & Estatística \\
\hline \multicolumn{5}{|l|}{ Face 86} \\
\hline Acerto $(\%)$ & 63,6 & 37,3 & 30,4 & \multirow{2}{*}{$X^{2}=16,24 ; p<0,001$} \\
\hline Erro $(\%)$ & 36,4 & 62,7 & 69,6 & \\
\hline \multicolumn{5}{|l|}{ Tristeza } \\
\hline \multicolumn{5}{|l|}{ Face 46} \\
\hline Acerto (\%) & 45,5 & 31,4 & 30,4 & \multirow{2}{*}{$X^{2}=4,18 ; p=0,123$} \\
\hline Erro (\%) & 54,5 & 68,6 & 69,6 & \\
\hline \multicolumn{5}{|l|}{ Face 93} \\
\hline Acerto $(\%)$ & 52,4 & 70,6 & 56,5 & \multirow{2}{*}{$X^{2}=5,05 ; p=0,080$} \\
\hline Erro (\%) & 47,6 & 29,4 & 43,5 & \\
\hline
\end{tabular}

O instrumento proposto acima possui 15 itens e sua pontuação varia de 0 a 15 pontos. A partir disto, calculou-se a média de acertos, as curvas ROC, a sensibilidade e a especificidade para cada grupo com base nos dados colhidos previamente.

A Tabela 14 apresenta a média de acertos do instrumento proposto de cognição social reduzido, o qual foi nomeado de Bateria Breve de Cognição Social (Anexo A), em relação ao grupo controle e os grupos clínicos.

Tabela 14 - Média de acertos dos grupos na Bateria Breve de Cognição Social

\begin{tabular}{lllll}
\hline Escala & $\begin{array}{l}\text { Controle } \\
\bar{X}(\mathrm{DP}: \pm)\end{array}$ & $\begin{array}{l}\text { TNL } \\
\overline{\mathrm{X}}(\mathrm{DP}: \pm)\end{array}$ & $\begin{array}{l}\text { TNM } \\
\overline{\mathrm{X}}(\mathrm{DP}: \pm)\end{array}$ & Estatística \\
\hline ToM reduzida & $2,31( \pm 0,81)$ & $1,82( \pm 0,96)$ & $1,38( \pm 0,92)$ & $\mathrm{F}_{2,219}=14,74 ; \mathrm{p}<0,001$ \\
REFE reduzida & $7,89( \pm 2,11)$ & $6,86( \pm 2,34)$ & $5,08( \pm 1,95)$ & $\mathrm{F}_{2,216}=18,49 ; \mathrm{p}<0,001$ \\
$\begin{array}{l}\text { Bateria Breve } \\
\text { de Cognição Social }\end{array}$ & $10,22( \pm 2,51)$ & $8,70( \pm 2,67)$ & $6,42( \pm 2,35)$ & $\mathrm{F}_{2,214}=23,67 ; \mathrm{p}<0,001$ \\
\hline
\end{tabular}

TNL: Transtorno neurocognitivo leve; TNM: Transtorno neurocognitivo maior; ${ }^{\mathrm{a}} \mathrm{p}<0,05$ (controle e TNL); ${ }^{\mathrm{b}} \mathrm{p}<0,05$ (controle e TNM); ${ }^{\mathrm{c}} \mathrm{p}<0,05$ (TNL e TNM). 
A Figura 4 apresenta a curva ROC relativa à Bateria Breve de Cognição Social apresentando a validade discriminativa entre os grupos controle e com TNL. A área da curva foi de 0,66 (IC95\%: 0,58-0,75), sendo considerada ruim (Metz, 1978).

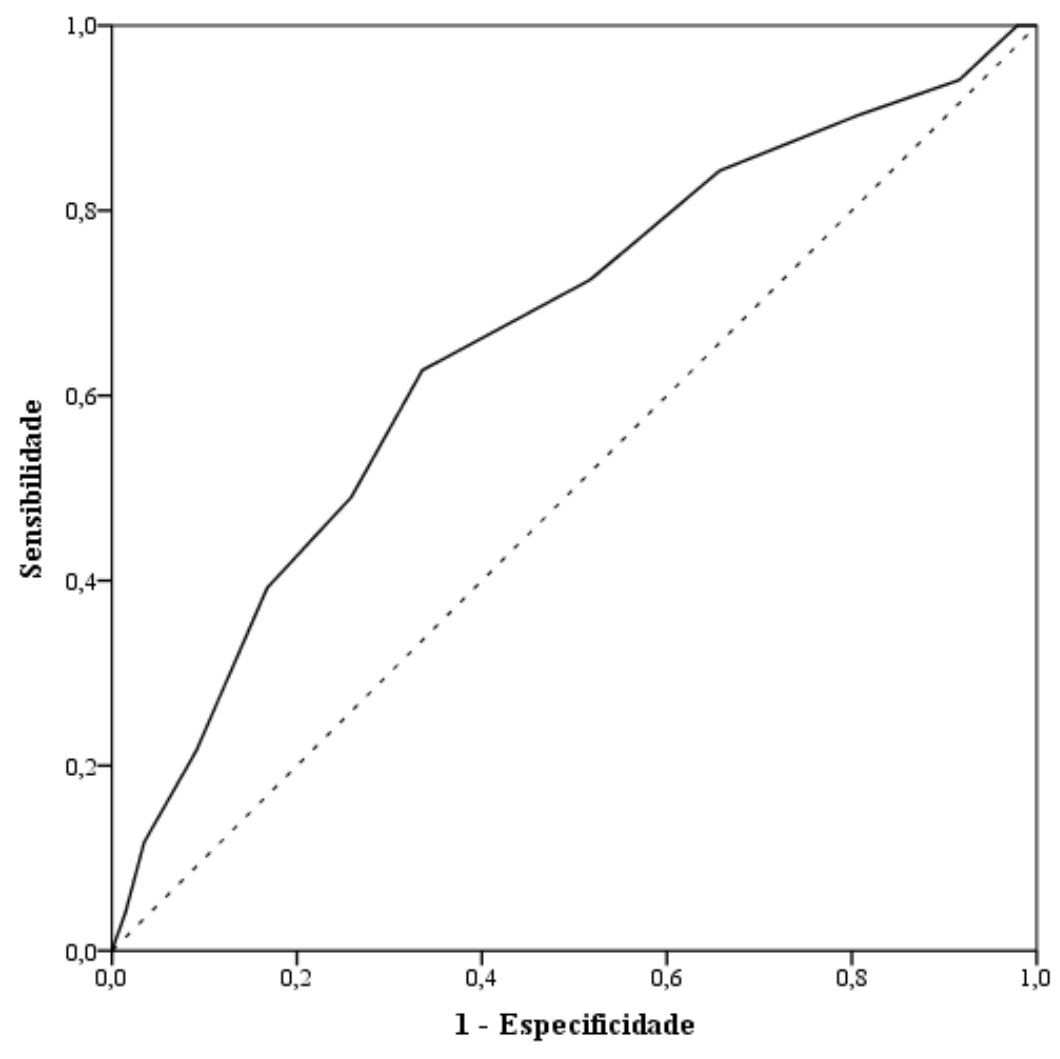

Figura 4 - Curva ROC da Bateria Breve de Cognição Social tendo-se como referência os grupos controle e com TNL.

A Tabela 15 apresenta os valores de sensibilidade e especificidade referente a diferentes pontos de corte da Bateria Breve de Cognição Social entre os grupos controle e com TNL. O ponto de corte que apresenta melhor equilíbrio entre a sensibilidade e especificidade foi nove. Isto implica em considerar a presença do TNL em sujeitos que apresentem uma pontuação abaixo ou igual a nove.

Tabela 15 - Valores de sensibilidade e especificidade por escore na Bateria Breve de Cognição Social entre os grupos controle e TNL

\begin{tabular}{lll}
\hline Pontos de corte & Sensibilidade & Especificidade \\
\hline$<\mathbf{4}$ & $0,0 \%$ & $100,0 \%$ \\
$<\mathbf{5}$ & $3,9 \%$ & $98,6 \%$
\end{tabular}


Tabela 15 - Valores de sensibilidade e especificidade por escore na Bateria Breve de Cognição Social entre os grupos controle e TNL

(continuação)

\begin{tabular}{lll}
\hline Pontos de corte & Sensibilidade & Especificidade \\
\hline$<\mathbf{6}$ & $11,8 \%$ & $96,5 \%$ \\
$<\mathbf{7}$ & $21,6 \%$ & $90,9 \%$ \\
$<\mathbf{8}$ & $39,2 \%$ & $83,2 \%$ \\
$<\mathbf{9}$ & $49,0 \%$ & $74,1 \%$ \\
$<\mathbf{1 0}$ & $62,7 \%$ & $66,4 \%$ \\
$<\mathbf{1 1}$ & $72,5 \%$ & $48,3 \%$ \\
$<\mathbf{1 2}$ & $84,3 \%$ & $34,3 \%$ \\
$<\mathbf{1 3}$ & $90,2 \%$ & $19,6 \%$ \\
$<\mathbf{1 4}$ & $94,1 \%$ & $8,4 \%$ \\
$<\mathbf{1 5}$ & $100,0 \%$ & $2,1 \%$ \\
\hline
\end{tabular}

(conclusão)

A figura 5, por sua vez, apresenta a curva ROC relativa à Bateria Breve de Cognição Social apresentando a validade discriminativa entre os grupos controle e com TNM. A área da curva foi de 0,86 (IC95\%: 0,77-0,94), sendo considerada boa (Metz, 1978).

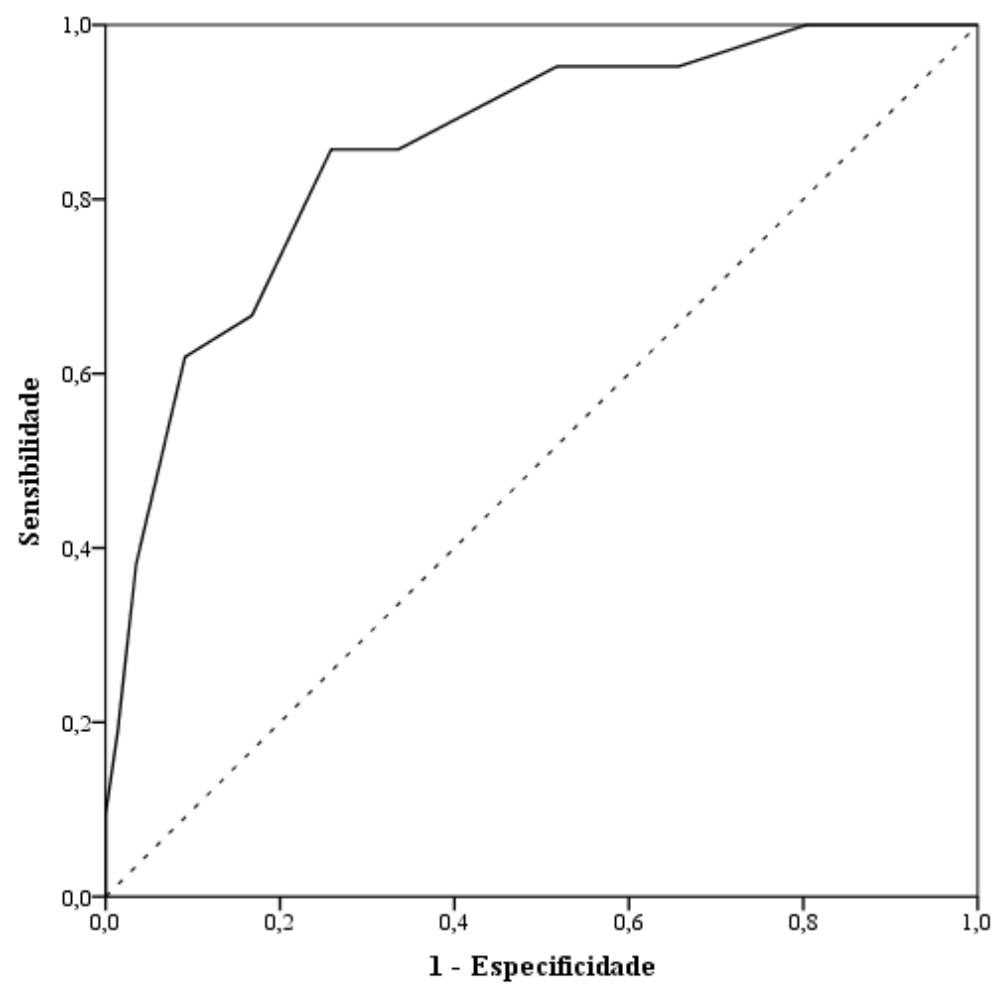

Figura 5 - Curva ROC da Bateria Breve de Cognição Social tendo-se como referência os grupos controle e com TNM. 
A tabela 16 apresenta os valores de sensibilidade e especificidade referente a diferentes pontos de corte da Bateria Breve de Cognição Social entre os grupos controle e com TNM. O ponto de corte que apresenta melhor equilíbrio entre a sensibilidade e especificidade foi oito, sendo que uma pontuação igual ou maior que nove, seria mantida a sensibilidade e diminuiria a especificidade em cerca de $7 \%$ e um ponto de corte menor ou igual a sete, teria uma perda de $19 \%$ na sensibilidade do teste.

Tabela 16 - Valores de sensibilidade e especificidade por escore na Bateria Breve de Cognição Social entre o controle e o TNM

\begin{tabular}{lll}
\hline Pontos de corte & Sensibilidade & Especificidade \\
\hline$<\mathbf{3}$ & $0,0 \%$ & $100,0 \%$ \\
$<\mathbf{4}$ & $9,5 \%$ & $100,0 \%$ \\
$<\mathbf{5}$ & $19,0 \%$ & $98,6 \%$ \\
$<\mathbf{6}$ & $38,1 \%$ & $96,5 \%$ \\
$<\mathbf{7}$ & $61,9 \%$ & $90,9 \%$ \\
$\mathbf{<}$ & $66,7 \%$ & $83,2 \%$ \\
$<\mathbf{9}$ & $85,7 \%$ & $74,1 \%$ \\
$\mathbf{<}$ & $85,7 \%$ & $66,4 \%$ \\
$\mathbf{1 0}$ & $95,2 \%$ & $48,3 \%$ \\
$\mathbf{1 1 2}$ & $95,2 \%$ & $34,3 \%$ \\
$\mathbf{1 1 3}$ & $100,0 \%$ & $19,6 \%$ \\
$<\mathbf{1 4}$ & $100,0 \%$ & $8,4 \%$ \\
$\mathbf{1 1 5}$ & $100,0 \%$ & $2,1 \%$ \\
\hline
\end{tabular}

A figura 6 apresenta a curva ROC relativa à Bateria Breve de Cognição Social apresentando a validade discriminativa entre os grupos com TNL e TNM. A área da curva foi de 0,74 (IC95\%: 0,61-0,87), sendo considerada regular (Metz, 1978). 


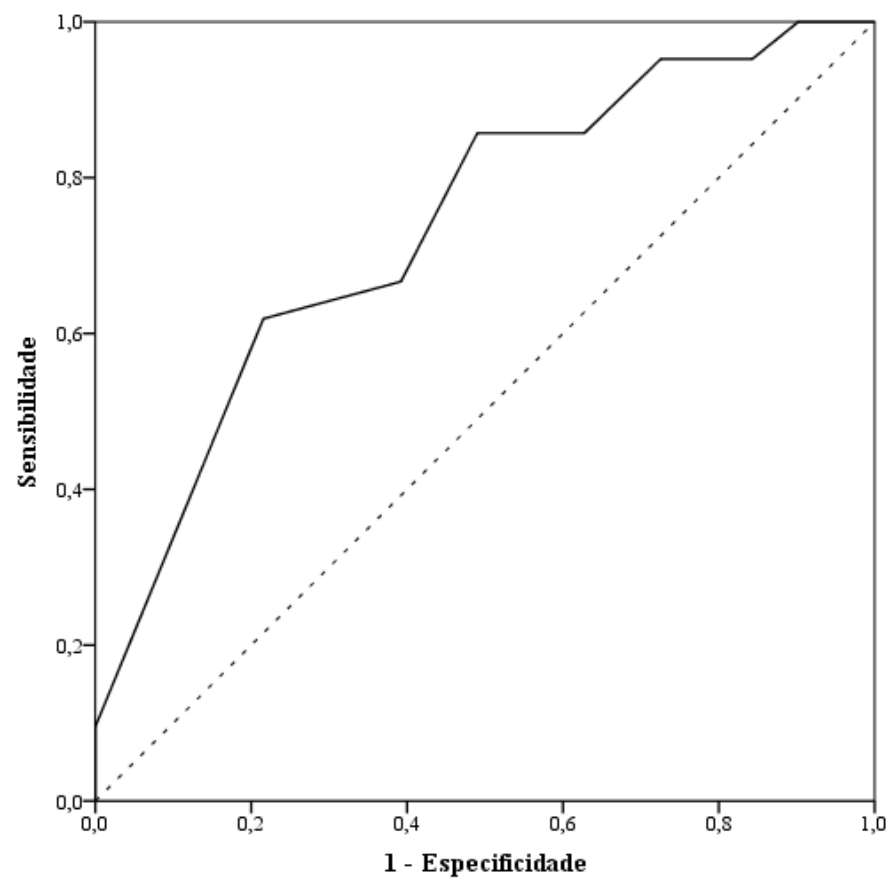

Figura 6 - Curva ROC da Bateria Breve de Cognição Social tendo-se como referência os grupos com TNL e com TNM.

A Tabela 17 apresenta os valores de sensibilidade e especificidade referente a diferentes pontos de corte da escala de cognição social reduzida entre os grupos com TNL e TNM. O ponto de corte que apresenta melhor equilíbrio entre a sensibilidade e especificidade também foi oito, assim como entre o grupo controle e com TNM. Uma pontuação menor que sete apresenta uma diminuição em $14 \%$ da sensibilidade e acima de nove, uma diminuição em $13 \%$ da especificidade.

Tabela 17 - Valores de sensibilidade e especificidade por escore na Bateria Breve de Cognição Social entre o os grupos TNL e o TNM

\begin{tabular}{lll}
\hline Pontos de corte & Sensibilidade & Especificidade \\
\hline$<\mathbf{3}$ & $0,0 \%$ & $100,0 \%$ \\
$<\mathbf{4}$ & $9,5 \%$ & $100,0 \%$ \\
$<\mathbf{5}$ & $19,0 \%$ & $96,1 \%$ \\
$<\mathbf{6}$ & $38,1 \%$ & $88,2 \%$ \\
$<\mathbf{7}$ & $61,9 \%$ & $78,4 \%$ \\
$<\mathbf{8}$ & $66,7 \%$ & $60,8 \%$ \\
$<\mathbf{9}$ & $85,7 \%$ & $51,0 \%$ \\
$<\mathbf{1 0}$ & $85,7 \%$ & $37,3 \%$ \\
$<\mathbf{1 1}$ & $95,2 \%$ & $27,5 \%$ \\
$<\mathbf{1 2}$ & $95,2 \%$ & $15,7 \%$ \\
$<\mathbf{1 3}$ & $100,0 \%$ & $9,8 \%$ \\
$<\mathbf{1 4}$ & $100,0 \%$ & $5,9 \%$ \\
$<\mathbf{1 5}$ & $100,0 \%$ & $0,0 \%$ \\
\hline
\end{tabular}


A figura 7, por sua vez, apresenta a curva ROC relativa à Breve de Cognição Social apresentando a validade discriminativa entre os grupos controle e TNL com TNM. A área da curva foi de 0,83 (IC95\%: 0,74-0,92), sendo considerada boa (Metz, 1978).

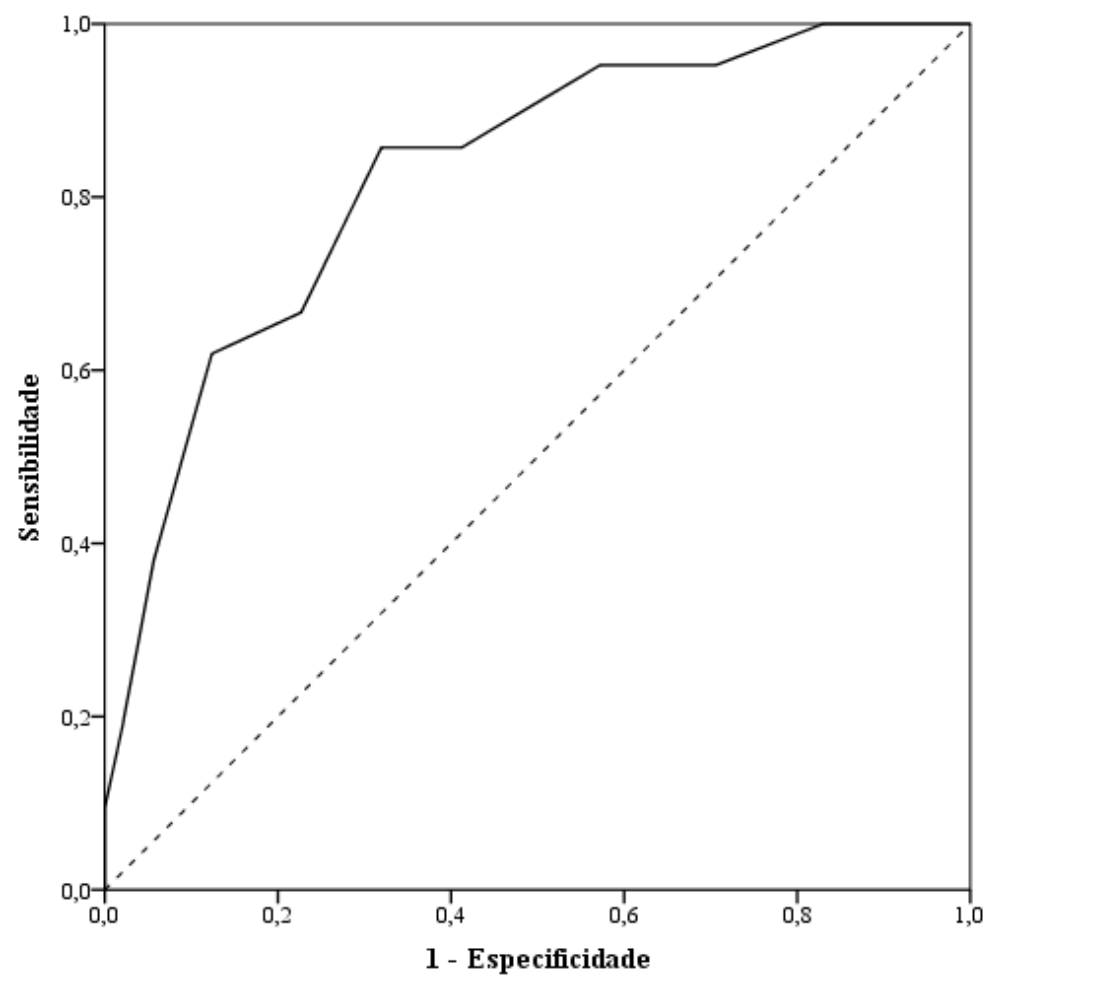

Figura 7 - Curva ROC da Bateria Breve de Cognição Social tendo-se como referência os grupos controle e TNL em relação ao grupo com TNM.

A Tabela 18 apresenta os valores de sensibilidade e especificidade referente a diferentes pontos de corte da Bateria Breve de Cognição Social entre os grupos controle e TNL com TNM. O ponto de corte que apresenta melhor equilíbrio entre a sensibilidade e especificidade foi oito.

Tabela 18 - Valores de sensibilidade e especificidade por escore na Breve de Cognição Social entre os grupos controle e TNL em relação ao grupo com TNM

\begin{tabular}{lll}
\hline Pontos de corte & Sensibilidade & Especificidade \\
\hline$<\mathbf{3}$ & $0,0 \%$ & $100,0 \%$ \\
$<\mathbf{4}$ & $9,5 \%$ & $100,0 \%$ \\
$<\mathbf{5}$ & $19,0 \%$ & $97,9 \%$ \\
$<\mathbf{6}$ & $38,1 \%$ & $94,3 \%$ \\
$<\mathbf{7}$ & $61,9 \%$ & $87,6 \%$
\end{tabular}


Tabela 18 - Valores de sensibilidade e especificidade por escore na Breve de Cognição Social entre os grupos controle e TNL em relação ao grupo com TNM

(continuação)

\begin{tabular}{lll}
\hline Pontos de corte & Sensibilidade & Especificidade \\
\hline$<\mathbf{8}$ & $66,7 \%$ & $77,3 \%$ \\
$<\mathbf{9}$ & $85,7 \%$ & $68,0 \%$ \\
$<\mathbf{1 0}$ & $85,7 \%$ & $58,8 \%$ \\
$<\mathbf{1 1}$ & $95,2 \%$ & $42,8 \%$ \\
$<\mathbf{1 2}$ & $95,2 \%$ & $29,4 \%$ \\
$<\mathbf{1 3}$ & $100,0 \%$ & $17,0 \%$ \\
$<\mathbf{1 4}$ & $100,0 \%$ & $7,7 \%$ \\
$<\mathbf{1 5}$ & $100,0 \%$ & $1,5 \%$ \\
\hline
\end{tabular}

(conclusão)

Em relação à validade convergente, o coeficiente de correlação de Spearman entre a Bateria Breve de Cognição Social e os escores totais da Bateria de tarefas de ToM foi moderado $(r=0,617 ; \mathrm{p}<0,001)$ e o coeficiente entre a Bateria Breve de Cognição Social e o escore total da tarefa de REFE foi alto $(r=0,811 ; p<0,001)$. 


\section{DISCUSSÃO}

No presente estudo, foram utilizadas duas tarefas para avaliação da cognição social em sujeitos de uma população geral com idade superior a 60 anos de idade com objetivo de avaliar a capacidade psicométrica das mesmas, sobretudo para rastreio do Transtorno neurocognitivo. Além da avaliação individual de cada instrumento, propôs-se um instrumento único de rastreio que englobou as questões de ambas as ferramentas com maior poder discriminativo. O poder discriminativo desse instrumento combinado e reduzido fora também aferido, tendo-se como parâmetro a coleta de dados original.

Este estudo tem seu mérito, uma vez que com o envelhecimento populacional e o conseqüente aumento de quantidade de casos de sujeitos com Transtorno neurocognitivo, a necessidade de rastreio cognitivo será cada vez mais necessária, uma vez que esta patologia é uma das principais causas de incapacidade e morbimortalidade em idosos (Machado et al., 2012).

Apesar da ampla diversidade, a maioria dos testes cognitivos foi desenvolvida em outros países, sendo elaborados para avaliar sujeitos com alto grau de escolaridade e com aspectos culturais distintos, não se assemelhando à população do Brasil que se apresenta com grande heterogeneidade cultural e educacional. Devido a este fato, estes instrumentos podem não ser indicados para aplicação em nosso meio.

A falta de instrumentos para rastreio cognitivo adequados à população brasileira pode ser considerada um dos motivos de uma grande parcela de sujeitos com Transtorno neurocognitivo permanecerem sem o diagnóstico correto, acarretando em uma falta de intervenção precoce. Este fato traz a necessidade de um instrumento de rastreio cognitivo com acurácia adequada, que seja de fácil interpretação e que não interfira no tempo disponível para os atendimentos de rotina, principalmente na atenção primária.

Este estudo trouxe uma forma de avaliação inédita no que diz respeito ao rastreio do Transtorno neurocognitivo, uma vez que sugere o uso de um instrumento reduzido para análise da cognição social para aventar a hipótese desse transtorno, domínio que foi incorporado recentemente no DSM-5 (APA, 2013). O principal achado é a capacidade do instrumento de discriminar os grupos como previsto com índices relativamente adequados de sensibilidade e especificidade, já que a hipótese era de que grupos com Transtorno neurocognitivo terão mais prejuízo. Os achados desse estudo evidenciaram, como previsto, que os idosos com Transtorno apresentaram pior desempenho nas tarefas de cognição social 
assim como demonstrado na literatura (Gregory et al., 2002; Kumfor et al;. 2017; Schroeter et al ., 2018), reforçando a inclusão desse domínio nos critérios do DSM-5.

Até o momento, não há uma definição exata de quantos seriam os componentes que melhor descrevem a cognição social. No entanto, um estudo realizado por Pinkman et al. (2014) descreveu quatro domínios principais que englobariam todos os aspectos a serem considerados na avaliação da cognição social, a saber: processamento de emoções, percepção social, atribuição do estado mental (Teoria da Mente - ToM) e viés de atribuição.

O construto cognição social é visto como um domínio complexo e multifacetado e a utilização de uma medida única seria totalmente inadequado. Com o aumento no número de estudos nesta área e a criação de diferentes tarefas, surgiu a necessidade de um estudo que reunisse em um único instrumento diferentes tarefas que abordam a investigação de diferentes domínios desse construto.

Dos instrumentos utilizados no presente estudo, a Bateria de tarefas de ToM em sua versão original (Hutchins, Prelock e Chace, 2008) foi proposta para avaliação da ToM em crianças com Transtorno do Espectro Autista, porém fora realizado um estudo apenas da avaliação de confiabilidade teste-reteste e a consistência interna do instrumento proposto, sem avaliar validade discriminativa. Como parte do atual estudo, ela foi traduzida e adaptada para o português do Brasil e seu uso em uma população acima de 60, sendo testada e demonstrando-se adequada. Este foi o primeiro estudo a propor e avaliar as qualidades psicométricas de uma bateria de ToM especificamente para avaliação em idosos. Esta tarefa foi escolhida porque é de fácil entendimento e de aplicação rápida (Chagas, Chagas e Osório, 2017).

Na Bateria de tarefas de ToM, as amostras demonstraram diferença na média de acertos entre os grupos controle e TNM, com uma melhor performance do grupo controle em relação ao grupo com TNM. Também foi observada diferença entre os grupos controle e TNL, com uma média de acertos levemente maior do grupo sem transtorno. No entanto, não foram encontradas diferenças significativas entre os grupos clínicos, ou seja, entre o TNL e o TNM.

Um estudo clínico realizado por Schroeter et al. (2018) com pacientes com e sem TNM demonstrou uma diferença na média de acertos entre os dois grupos quando aplicado uma tarefa de ToM (RMET), com uma performance superior dos sujeitos saudáveis, reforçando a idéia de que instrumentos para avaliação da cognição social são bons métodos de rastreio para esta condição. Em outro estudo também com características clínicas, realizado por Kumfor et al. (2017), utilizou-se uma versão reduzida do The Awareness of Social 
Inference Test (TASIT) como instrumento para a avaliação da ToM com o objetivo de identificar e diferenciar sujeitos saudáveis de sujeitos com TNM, e também apresentou um resultado semelhante ao encontrado em nosso estudo, com o grupo controle apresentando média de acertos maior que os demais indivíduos com TNM. Gregory et al. (2002) apresentaram o desempenho da avaliação da ToM em indivíduos com diagnóstico de demência de Alzheimer através da ferramenta Faux Pas, sendo encontrado diferença na média de acertos do grupo com TNM em relação ao grupo controle, sugerindo que estes sujeitos teriam dificuldades em realizar atividades que envolvem tarefas de memória, e que a cognição social encontra-se prejudicada em indivíduos com déficit cognitivo.

Além disso, este estudo conseguiu diferenciar o grupo controle e TNL através da Bateria de tarefas de ToM. Isso torna esta ferramenta interessante, pois consegue identificar estágios mais precoces da alteração cognitiva, uma vez que já foi demonstrado que a ToM já encontra-se alterada em estágios iniciais do comprometimento cognitivo (Baglio et al., 2012; Bora e Yener, 2017; Yi et al., 2020). Este dado é de importante conhecimento, pois uma vez detectado o TNL e sabendo que em cerca de 10 a 15\% desses casos, por ano, se convertem para um TNM (Petersen et al., 1999; Rountree et al., 2007), pode-se agir através de medidas preventivas e tarefas de estimulação cognitiva para a fim de reduzir as chances dessa evolução.

No entanto, diferentemente da metanálise apresentada por Yi et al. (2017) em que sujeitos com TNM apresentaram desempenho inferior aos sujeitos com TNL na tarefa RMET, este estudo não conseguiu discriminar os grupos clínicos entre si. Isto pode ser devido ao fato de que o desempenho no RMET é afetado não apenas pelo gênero, idade e psicopatologia dos sujeitos, mas também pela valência emocional dos estímulos das pessoas retratadas nesse instrumento (Kynast e Schroeter, 2018). Além disso, estudos relataram que o TNL pode ser diferenciado de acordo com o acometimento em "domínio único" ou "múltiplos domínios", assim indivíduos com TNL afetando múltiplos domínios apresentariam comprometimento cognitivo social mais significativo do que sujeitos com acometimento em um único domínio (Bediou et al., 2009; Serrano et al., 2013; Michaelian et al., 2019). Isso sugere análises de subgrupos mais precisas são necessárias, com base em variáveis de controle correspondentes, como sexo, idade e raça, além de considerar o tamanho da amostra.

Diante dos resultados obtidos, assim como relatado por Choong e Doody (2013), pode-se considerar que ainda é difícil avaliar a ToM como um fenômeno isolado em populações com comprometimento cognitivo global, pois as tarefas utilizadas até o momento não são padronizadas para tal população. 
A diferença dos achados citados em outros estudos com o presente foi que a Bateria de tarefas de ToM é uma compilação das tarefas utilizadas para avaliação da ToM, organizada de forma crescente de dificuldade, possibilitando a avaliação de reconhecimento de emoções simples até as falsas crenças de segunda ordem. Os instrumentos citados acima trazem limitações, como no caso do Faux Pas e do TASIT, que necessitam de conhecimento de um vocabulário rebuscado e possuir memória de trabalho preservada, não sendo ferramentas apropriadas para a investigação de desordens clínicas cognitivas. Outroassim, a maioria dos estudos com esta finalidade foi executado em idosos com alto nível educacional, o que deve ser levado em conta na escolha da ferramenta utilizada. Uma outra diferença desses estudos citados com o presente estudo é que a utilização da Bateria de tarefas de ToM apresentou avanços apresentando características psicométricas do instrumento, determinando indicadores de sensibilidade e especificidade, além de apresentar dados sobre a validade convergente.

Desta forma, para o estudo da validade discriminativa, calculou-se a área sob a curva ROC para a comparação entre o grupo controle e sujeitos com TNM, a qual fora de 0,70, sendo considerada intermediária (Metz, 1978). Ademais, a nota de corte que apresentou maior equilíbrio entre a sensibilidade e especificidade foi oito, sendo 0,81 e 0,50, respectivamente. Esse resultado indica que a Bateria de tarefas de ToM apresenta uma boa sensibilidade para rastreio de declínio cognitivo, no entanto, a especificidade deixa a desejar. Todavia, considerando que esse instrumento foi desenvolvido com o objetivo de rastreio, é importante que ele tenha uma alta sensibilidade. Por isso, para que seja valorizado a especificidade do teste, uma outra nota de corte deve ser adotada, sugerindo-se a nota seis (sensibilidade 0,52 e especificidade 0,67).

Uma outra qualidade psicométrica avaliada da Bateria de tarefas de ToM foi a validade convergente, foi utilizado como parâmetro diferentes instrumentos para avaliação da cognição, considerados construtos correlatos, a saber: Lista de Figuras da Bateria Breve de Rastreio Cognitivo (BBRC), o teste de Fluência Verbal, o Teste do Desenho do Relógio (TDR), o Teste de nomeação de Boston e o MEEM. As correlações obtidas foram significativas e variaram entre 0,27 e 0,46, classificadas como fracas/moderadas, em acordo com o esperado. A correlação com a tarefa de REFE, que avalia um subdomínio diferente do mesmo construto (cognição social), foi mais expressiva $r=0,54$ ), reforçando a adequação psicométrica.

O estudo original da Bateria de Tarefas de ToM (Hutchins, Prelock e Chace, 2008) realizado com uma amostra clínica diferente (crianças com diagnóstico de autismo), 
apresentou consistência interna excelente (alpha de cronbach de 0,94) e uma boa confiabilidade teste-reteste.

O outro único estudo, além do estudo original, que realizou avaliação das propriedades psicométricas da Bateria de tarefas de ToM foi o realizado por Rezende et al. (2018), onde foi realizada a análise da validade convergente da Bateria de tarefas de Tom com o RMET em uma amostra de idosos sem comorbidades, com coeficiente de Pearson de 0,71 ( $p<0,00$. Os dados aqui apresentados somam evidências a essa qualidade psicométrica da escala, que deverá ser aprofundada em estudos futuros, sobretudo em relação a outros estudos instrumentos de avaliação da ToM.

O outro instrumento utilizado para avaliar a cognição social foi o Penn Emotion Recognition Test, ferramenta utilizada para avaliar o REFE.

No presente estudo, a análise das médias de acerto geral do instrumento citado demonstrou diferença estatística significativa entre os grupos controle, com TNL e com TNM, com maior prejuízo identificado nesse último grupo.

Por sua vez, a área sob a curva ROC em relação ao grupo controle e TNM foi considerada regular $(0,78)$ de acordo com Metz (1978). Esse instrumento, diferentemente da Bateria de tarefas de ToM, demonstrou índices mais altos de especificidade. A nota de corte que apresenta o maior equilíbrio entre a sensibilidade e especificidade foi a nota 47 e caso seja considerado esse ponto de corte, o instrumento apresentará uma boa sensibilidade $(69,6 \%)$ e uma especificidade alta $(72,7 \%)$, não favorecendo a proposta de rastreio para o instrumento. Desta forma, para estas situações, a nota de corte 52 pode ampliar essa capacidade discriminativa, apresentando uma sensibilidade de 0,78 e especificidade de 0,63 , considerada razoável para se evitar falsos positivos.

O instrumento demonstrou-se sensível para avaliar os prejuízos dos sujeitos com Transtorno neurocognitivo em relação à sujeitos saudáveis, mas pouco adequada para discriminar os grupos com declínio cognitivo leve e maior. Quando as expressões emocionais são avaliadas separadamente, apenas entre o grupo controle e com TNM foi encontrado diferença no reconhecimento das emoções de alegria, medo, nojo, raiva e neutra, e entre os grupos clínicos, apenas a emoção medo apresentou diferença.

Ressalta-se que a alegria foi a emoção com maior porcentagem de acerto em todos os grupos. Isso vai ao encontro de resultados obtidos por Kessels et al (2014) que observaram que emoções negativas (raiva, tristeza e medo) têm maior grau de dificuldade para o reconhecimento em comparação à alegria. Além disso, a expressão emocional medo foi a única que apresentou diferença entre os grupos que apresentam declínio cognitivo, assim 
como as expressões neutras foram as únicas capazes de diferenciar o grupo saudável do grupo com declínio cognitivo leve. Esse dado pode ser explicado através de uma perspectiva cognitiva, onde tanto a atrofia hipocampal quanto a amígdala são encontradas no declínio cognitivo, o que pode explicar o déficit no reconhecimento de emoções negativas, como o medo, que depende desse circuito cerebral (Adolphs, Baron-Cohen e Tranel, 2002; Jicha et al., 2006).

Em relação à intensidade das emoções, houve diferença entre os grupos controle e com TNM na identificação das emoções alegria e medo em baixa intensidade, assim como nas emoções medo e raiva em alta intensidade.

Weiss et al., (2008) utilizaram uma versão do Penn Emotion Recognition Test composta de 40 fotografias com as cinco emoções básicas, exceto surpresa. Foi demonstrado que pacientes saudáveis apresentaram maior capacidade de reconhecimento de todas as emoções, inclusive emoção neutra, em relação ao grupo com TNL e com TNM. As emoções que mostraram maior diferença estatística entre os grupos foram a de medo, tristeza e a neutra. Ademais, comparando sujeitos saudáveis com TNL, este último grupo quando apresentada prejuízo em apenas um domínio cognitivo e não em múltiplos domínios, não diferiram significativamente dos indivíduos controles. Bediou et al. (2009), utilizando o Facial Expression Task e o Eye Gaze Direction Task, e Henry et al. (2009) utilizando o Danger Rating Task Faces, apresentaram resultados apenas próximo da significância em relação à diferença no desempenho entre sujeitos saudáveis e com TNL na tarefa de REFE. Ou seja, sujeitos com TNL sem comprometimento de múltiplos domínios, podem não apresentar prejuízo claramente identificável no REFE.

Spolettini et al. (2008) relataram que sujeitos com TNL diferiam dos controles apenas na emoção medo de baixa intensidade, ao contrário do que foi encontrada neste estudo, que demonstrou essa diferença apenas na alta intensidade da mesma emoção. Uma das explicações possíveis para as discrepâncias encontradas entre os estudos é que, embora as emoções sejam consideradas universais (Ekman e Friesen, 1971), pode ser que o subconjunto de fotografias utilizadas se diferencie em relação à etnia, idade dos sujeitos das fotos, cor da pele, além das tarefas apresentarem níveis de complexidade diferentes, assim como discrepância no uso das fotos e isto pode ser desfavorável na identificação das faces.

Quanto a emoção medo ter sido a emoção capaz de discriminar sujeitos saudáveis de sujeitos TNL, como já descrito anteriormente, pode ser devido ao fato de que esta emoção está relacionada à estrutura cerebral amígdala. Esta região é responsável pelo processamento emocional, porém principalmente associada ao medo, uma das emoções mais primitivas 
encontradas no ser humano, relacionando-se à sobrevivência. O medo possibilita uma resposta a uma ameaça conhecida, tendo sido fundamental para a perpetuação da espécie (Kaplan et al., 1997). Além disso, a amígdala também está relacionada a estágios iniciais de processamento de informações, função importante para manter a cognição global íntegra (Phelps, 2006).

A validade convergente da tarefa de REFE mostrou-se adequada, tendo-se como parâmetro outros instrumentos para avaliação de aspectos específicos da cognição, como a Lista de Figuras da Bateria Breve de Rastreio Cognitivo (BBRC), o teste de Fluência Verbal, o Teste do Desenho do Relógio (TDR), o Teste de nomeação de Boston e o MEEM. As correlações mostram-se significativas, positivas e com magnitude de fraca a moderada $(0,29$ a 0,49), conforme esperado. Quando a correlação é avaliada em relação à Bateria de tarefas de ToM, como já referido acima, as correlações ficam mais expressivas ( $r=0,54)$, atestando a validade convergente do instrumento.

Com base nos resultados obtidos positivamente, procurou-se identificar os itens mais discriminativos de cada tarefa a fim de compor um instrumento único, com menor número de itens, que pudesse ser de fácil e rápida aplicação e que tivesse bom potencial discriminativo. Para isto, foi desenvolvido um instrumento de rastreio nomeado de Bateria Breve de Cognição Social, cujo objetivo foi avaliar a cognição social de sujeitos com declínio cognitivo. A ferramenta possui 15 itens e foi composta utilizando três questões de ToM e doze questões de REFE. Utilizou-se os itens que apresentaram diferença estatisticamente significativa entre os grupos, após de aplicado o teste post hoc de Bonferroni, para a ToM, e na tarefa de REFE, foi feito a seleção de duas faces de cada emoção que apresentaram maior significância estatística $(\mathrm{p}<0,005)$, exceto a emoção tristeza, que não apresentou significância estatística em nenhuma das faces utilizadas no teste. Para estas, foram escolhidas duas faces aleatoriamente apenas para que o instrumento fosse composto de todas as faces propostas pela avaliação inicial.

Até o momento, nenhuma ferramenta isolada no domínio experimental ou clínico fornece uma breve avaliação de uma gama representativa de habilidades sociais usando tarefas projetadas para idosos. Para isto, a sugestão de uma ferramenta breve adequada para triagem de adultos mais velhos, utilizando uma variedade de habilidades sociais fornecerá uma visão geral das deficiências nas habilidades sociais, permitindo um melhor atendimento.

Recentemente, Kelly e McDonald (2019) desenvolveram uma ferramenta que pudesse brevemente avaliar vários componentes principais de habilidades sociais, incluindo a cognição social. A Brief Assessment of Social Skills-Dementia (BASS-D) foi composta por 
uma compilação de itens provenientes da literatura que eram simples e projetados para medir diferentes facetas das habilidades sociais. A BASS-D compreendeu sete tarefas, abrangendo seis domínios, levando aproximadamente 25 minutos para ser concluído. Apesar desse instrumento ter apresentado boa validade convergente e discriminar sujeitos saudáveis com TNM, apresenta várias limitações. Uma delas é que o tempo de aplicação é longo, não sendo ideal para um teste de rastreio. Outra questão apontada é que a amostra utilizada tinha nível educacional elevado, sendo sujeitos saudáveis com média de 14 anos de escolaridade e sujeitos com TNM, com 11 anos. Devido a isto, a Bateria Breve de Cognição Social apresenta-se como uma ferramenta que se aproxima mais da realidade do país, além de ser mais rápida (média de 5 a 10 minutos).

Kumfor et al. (2017) utilizaram uma versão reduzida TASIT, inicialmente desenvolvido para avaliação de sujeitos com traumatismo craniano, para avaliar sujeitos saudáveis e com declínio cognitivo. Seus achados identificaram que o teste apresentou discriminação entre dois tipos de TNM (Alzheimer e Frontotemporal), porém não discriminou controles do Alzheimer. Diante disso, este teste seria mais especifico para direcionar o tipo de TNM após já realizado um teste de rastreio, como a Bateria Breve de Cognição Social

Na Bateria Breve de Cognição Social, a média de acertos do grupo controle foi maior que a do grupo com TNL, que por sua vez, foi maior que a do grupo com TNM. Assim, é possível considerar que este instrumento consegue diferenciar sujeitos saudáveis de sujeitos com declínio cognitivo, o que fazia parte dos objetivos iniciais. A Bateria Breve de Cognição Social apresentou parâmetros psicométricos adequados e mostrou capacidade de rastrear e detectar sujeitos tanto com declínio cognitivo leve quanto mais acentuado. Este instrumento apresentou uma boa validade discriminativa quando considerado o grupo controle e TNL em relação ao grupo com TNM, com área sob a curva de 0,83 e entre o grupo controle e com TNM, com área sob a curva de 0,86. Foi identificado como melhor ponto de corte para rastreio do TNM em relação o grupo controle a nota oito, com sensibilidade de 0,86 e especificidade de 0,74 . Já a melhor nota de corte para diferenciar os sujeitos saudáveis e com TNL dos sujeitos com TNM também foi de oito, mantendo a sensibilidade, porém apresentando uma diminuição de $6 \%$ na especificidade.

Ademais, apesar desta bateria apresentar uma área sob a curva ROC considerada regular $(0,74)$, é possível realizar o rastreio entre sujeitos com TNL e TNM, uma vez que a nota de corte oito apresenta uma sensibilidade de 85,7\%. No entanto, apresenta baixa especificidade $(51,0 \%)$. Este é um limite a ser superado, pois o que diferencia um grupo do 
outro em termos de cognição social ainda não está claro, pois as tarefas não são específicas, aventando-se a possibilidade de que no futuro, as tarefas possam melhorar esse indicador.

Outroassim, embora fosse esperado encontrar diferença entre saudáveis e sujeitos com TNL, esta bateria não foi considerada sensível e específica o suficiente para discriminar as especificidades dos déficits dos grupos clínicos, apresentando uma área sob a curva ROC de 0,66, considerada ruim diante dos padrões de Metz (1978). Weiss et al. (2008) já haviam apontado em estudo anterior que pode-se considerar a existência de subtipos de TNL, onde aquele que apresentou prejuízo em apenas um domínio cognitivo, não diferiu no desempenho das tarefas em relação ao grupo controle, enquanto aqueles que apresentavam prejuízo em múltiplos domínios, tiveram pior desempenho em relação aos saudáveis.

Em relação à validade convergente, o coeficiente de correlação de Spearman entre a Bateria Breve de Cognição Social e a Bateria de tarefas de ToM foi de 0,617 ( $<<0,001)$, sendo considerado moderado. Já a correlação entre a Bateria Breve e o Penn Emotion Recognition Test foi de 0,811 ( $\mathrm{p}<0,001)$, considerado alto. Os resultados obtidos indicam evidências de validade convergente adequada, e assim como observado para os instrumentos isoladamente, é possível dizer baseado na área sob a curva $\operatorname{ROC}(0,86)$ e pelos valores de sensibilidade especificidade encontradas para a nota de corte proposta $(85,7 \%$ e $74,1 \%$, respectivamente), que a Bateria Breve de Cognição Social possui melhor capacidade discriminativa para fazer o rastreio diagnóstico de TNM que os demais instrumentos, provavelmente devido ao fato de incluir avaliação de duas diferentes áreas da cognição social em uma única ferramenta.

De modo geral, o presente estudo cumpriu com os objetivos propostos, possibilitando a utilização de um único instrumento que aborda dois domínios da cognição social (ToM e REFE). O modelo final resultou em um instrumento adequado para ser utilizado como rastreio cognitivo, pois o mesmo apresenta-se como uma tarefa com poucos itens, de rápida aplicação e fácil interpretação que merece ser testado mais amplamente.

Contudo, faz necessário apontar algumas limitações do estudo. A princípio, deve-se considerar a particularidade da amostra, que embora tenha contado com um número relativamente expressivo de sujeitos, foi composta apenas por idosos de uma área de abrangência de uma cidade do interior do estado de São Paulo. Dessa forma, deve-se ter cuidado na generalização indiscriminada dos dados para outra população com diferente nível socioeducacional, principalmente devido à variedade da população brasileira.

Outra limitação apontada é o ponto de que o instrumento Bateria Breve de Cognição Social não foi aplicado de fato na população após ter sido gerado, tendo sido utilizado os dados da coleta original. Para isso, são necessários estudos futuros a fim de que o mesmo seja 
aplicado na população e observado sua replicabilidade e comparação com os resultados inicialmente encontrados. Além disso, seria importante a aplicação de técnicas estatisticamente mais requintadas para a aprimoração do instrumento, como por exemplo, a Teoria de Resposta ao Item (Araujo, Andrade e Bortolotti, 2009).

No entanto, tais limitações descritas acima pareceram não interferir significativamente na condução e desfecho do estudo.

Salienta-se ainda que a Bateria Breve de Cognição Social é proposta como um instrumento de rastreio breve para identificação de Transtornos neurocognitivos em atenção primária, limitando-se apenas à triagem de possíveis casos. Esse instrumento não substitui de forma alguma a consulta com profissional especializado e a avaliação diagnóstica realizada por este.

Por fim, como contribuição, o presente estudou trouxe a proposta de um novo instrumento para rastreio de Transtornos neurocognitivos utilizando o domínio de cognição social como forma de avaliação única, trazendo uma inovação e preenchendo inicialmente uma lacuna na literatura em relação à disponibilização de instrumentos com tais características em cenário de cuidado em atenção primária da saúde do país. 
CONCLUSÃo 


\section{CONCLUSÃO}

O presente estudo avaliou a capacidade de rastreio de prejuízos na cognição social de indivíduos com Transtornos neurocognitivos com mais de 60 anos na atenção básica através de dois instrumentos com bom poder discriminativo, disponíveis na literatura previamente.

Com base nesses achados, foi proposto um novo instrumento com menor número de itens, integrando dois domínios da cognição social (REFE e ToM), sendo nomeado de Bateria Breve de Cognição Social. Esta ferramenta também demonstrou bons índices psicométricos de validade.

Esse instrumento tem potencial para atender à recomendações do DSM-5 sobre a avaliação da cognição social como parte do diagnóstico de Transtorno neurocognitivo. Além disso, esta ferramenta pode ter utilidade na prática clínica e parece ser uma boa forma de rastreio, uma vez que é de fácil entendimento e demanda apenas de alguns minutos para sua execução. 


\section{REFERÊNCIAS}




\section{REFERÊNCIAS}

Adolphs R, Baron-Cohen S, Tranel D. Impaired recognition of social emotions following amygdala damage. J Cogn Neurosci. 2002 Nov 15;14(8):1264-74.

American Psychiatric Association (1987). Diagnosis and statistical manual of mental disorders (3.a ed. revista). Washington, DC: American Psychiatric Press

American Psychiatric Association. Diagnostic and statistical manual of mental disorders. 5th ed. Washington DC: American Psychiatric Press; 2013.

Apperly IA. What is "theory of mind"? Concepts, cognitive processes and individual differences. Q J Exp Psychol (Hove). 2012;65(5):825-39.

Aprahamian I, Martinelli JE, Neri AL, Yassuda MS. The accuracy of the Clock Drawing Test compared to that of standard screening tests for Alzheimer's disease: results from a study of Brazilian elderly with heterogeneous educational backgrounds. IntPsychogeriatr. 2010 Feb;22(1):64-71

Araújo EAC, Andrade DF, Bortolotti SLV. Teoria da resposta ao item. Rev Esc Enferm. 2009;43(Esp):1000-8.

Baglio F, Castelli I, Alberoni M, Blasi V, Griffanti L, Falini A, Nemni R,

Marchetti A. Theory of mind in amnestic mild cognitive impairment: an FMRI study. J Alzheimers Dis. 2012;29(1):25-37.

Baron-Cohen S, Leslie AM, Frith U. Does the autistic child have a "theory of mind"? Cognition. 1985 Oct;21(1):37-46.

Baron-Cohen S, O'Riordan, M, Jones, R, Stone, V., \& Plaisted, K. (1999). A new test of social sensitivity: Detection of faux pas in normal children and children with Asperger syndrome. Journal of Autism and Developmental Disorders, 29, 407-418

Baron-Cohen S, Wheelwright S, Hill J, Raste Y, Plumb I. The "Reading the Mind in the Eyes" Test revised version: a study with normal adults, and adults with Asperger syndrome or high-functioning autism. J Child Psychol Psychiatry. 2001 Feb;42(2):241-51. 
Bediou B, Ryff I, Mercier B, Milliery M, Hénaff MA, D'Amato T, Bonnefoy M, Vighetto A, Krolak-Salmon P. Impaired social cognition in mild Alzheimer disease. J Geriatr Psychiatry Neurol. 2009 Jun;22(2):130-40

Bertolucci PH, Okamoto IH, Brucki SM, Siviero MO, TonioloNeto J, Ramos LR. Applicability of the CERAD neuropsychological battery to Brazilian elderly.ArqNeuropsiquiatr. 2001 Sep;59(3-A):532-6.

Bomfim AJL, Ribeiro RADS, Chagas MHN. Recognition of dynamic and static facial expressions of emotion among older adults with major depression. Trends Psychiatry Psychother. 2019 Apr-Jun;41(2):159-166.

Bora E, Yener GG. Meta-Analysis of Social Cognition in Mild Cognitive Impairment. J Geriatr Psychiatry Neurol. 2017 Jul;30(4):206-213

Bottino CM, Azevedo D Jr, Tatsch M, et al. Estimate of dementia prevalence in a community sample from Sao Paulo, Brazil. Dement Geriatr Cogn Disord 2008; 26: 291-99.

Brucki SMD, Nitrini R, Caramelli P, Bertolucci PHF., Okamoto IH. Sugestões para o uso do Mini-Exame do Estado Mental no Brasil, Arquivos de Neuropsiquiatria, 2003, vol. 61 (pg. 777-781)

Brucki SMD, Rocha MSG. Category fluency test: effects of age, gender and education on total scores, clustering and switching in Brazilian Portuguese-speaking subjects. Braz J Med Biol Res. 2004 Dec;37(12):1771-7.

Brüne M, Brüne-Cohrs U. Theory of mind--evolution, ontogeny, brain mechanisms and psychopathology. Neurosci Biobehav Rev. 2006;30(4):437-55. Epub 2005 Oct 18. Review.

Burnham, H, Hogervorst, E. (2004). Recognition of facial expressions of emotion by patients with dementia of the Alzheimer type. Dementia and Geriatric Cognitive Disorders, 18(1), 7579.

Castro-Costa E, Fuzikawa C, Uchoa E, Firmo JOA, Lima-Costa MF. Norms for the minimental state examination: adjustment of the cut-off point in population-based studies (evidences from the Bambuí health aging study). Arq Neuropsiquiatr. 2008 Sep;66(3A):5248. 
Chagas MHNC, Chagas NMS, Osorio FL. Translation and transcultural adaptation to Brazilian Portuguese of the Theory of Mind Task Battery for assessment of social cognition in the elderly. Arch Clin Psychiatry. 2017;44(1):30-1.

Choong CS, Doody GA. Can theory of mind deficits be measured reliably in people with mild and moderate Alzheimer's dementia? BMC Psychol. 2013 Dec 5;1(1):28.

Corcoran CM, Keilp JG, Kayser J, Klim C, Butler PD, Bruder GE, Gur RC, Javitt DC. Emotion recognition deficits as predictors of transition in individuals at clinical high risk for schizophrenia: a neurodevelopmental perspective. Psychol Med. 2015 Oct;45(14):2959-73.

Darwin, C. The expression of the emotions in man and animals. Chicago: University of Chicago Press, 1965. (Original work published 1872).

Ekman P, Friesen WV. Constants across cultures in the face and emotion. J Pers Soc Psychol. 1971 Feb;17(2):124-9

Ekman P, Friesen W. Pictures of facial affect. Palo Alto: Consulting Psychologists; 1976.

Feldman H, Gauthier S, Hecker J, Vellas B, Hux M, Xu Y, et al. Economic evaluation of donepezil in moderate to severe Alzheimer disease. Neurology 2004 Aug 24;63(4):644-50.

Feshbach ND, Feshbach S. Affective processes and academic achievement. Child Dev. 1987 Oct;58(5):1335-47.

Fiske, S. T. \& Taylor, S. E. (1991). Social cognition (2a ed). Nova York: McGrawHill.

Folstein MF, Folstein SE, McHugh PR. "Mini-mental state".A practical method for grading the cognitive state of patients for the clinician. J Psychiatr Res. 1975 Nov;12(3):189-98.

Fuzikawa C, Lima-Costa MF, Uchoa E, Barreto SM, Shulman K. A population based study on the intra and inter-rater reliability of the clock drawing test in Brazil: the Bambuí Health and Ageing Study. Int J Geriatr Psychiatry. 2003 May;18(5):450-6.

Garrido, MV, Azevedo, C, Palma, T. (2011). Cognição social: Fundamentos, formulações actuais e perspectivas futuras. Psicologia, 25(1), 113-157. 
Gur RC, Sara R, Hagendoorn M, et al. A method for obtaining 3-dimensional facial expressions and its standardization for use in neurocognitive disorders. J Neurosci Methods 2002; 115: 137-143

Grainger SA, Henry JD, Phillips LH, Vanman EJ, Allen R. Age Deficits in Facial Affect Recognition: The Influence of Dynamic Cues. J Gerontol B PsycholSciSoc Sci. 2015 Nov 2.

Green MF, Penn DL, Bentall R, Carpenter WT, Gaebel W, Gur RC, Kring AM, Park S, Silverstein SM, Heinssen R. Social cognition in schizophrenia: an NIMH workshop on definitions, assessment, and research opportunities. Schizophr Bull. 2008 Nov;34(6):1211-20.

Gregory CA, Lough S, Stone V, Erzinclioglu S, Martin L, Baron-Cohen S, et al. Theory of mind in patients with frontal variant frontotemporal dementia and Alzheimer's disease: theoretical and practical implications, Brain, 2002, vol. 125 (pg. 752-64).

Han JW, So Y, Kim TH, Lee DY, Ryu SH, Kim SY, et al. Prevalence rates of dementia and mild cognitive impairment are affected by the diagnostic parameter changes for neurocognitive disorders in the DSM-5 in a Korean population. Dement Geriatr Cogn Disord. 2017;43:193-203.

Hargrave, R, Maddock, RJ, Stone, V. (2002). Impaired recognition of facial expressions of emotion in Alzheimer's disease. Journal of Neuropsychiatry Clinical Neuroscience, 14(1), 6471.

Henry JD, Thompson C, Ruffman T, Leslie F, Withall A, Sachdev P, Brodaty H. Threat perception in mild cognitive impairment and early dementia. J Gerontol B Psychol Sci Soc Sci. 2009 Sep;64(5):603-7.

Henry JD, von Hippel W, Molenberghs P, Lee T, Sachdev PS. Clinical assessment of social cognitive function in neurological disorders. Nat Ver Neurol. 2016 Jan;12(1):28-39.

Hoffman ML. How automatic and representational is empathy, and why. Behavioral and Brain Sciences. Cambridge University Press; 2002;25(1):38-9.

Hughes, C. (2011). Social Understanding and Social Lives. London: Psychology Press

Hugo J, Ganguli M. Dementia and cognitive impairment: epidemiology, diagnosis, and treatment. Clin Geriatr Med. 2014 Aug;30(3):421-42. 
Hutchins, TL, Prelock, PA, Chace, W. (2008). Test-Retest Reliability of a Theory of Mind Task Battery for Children With Autism Spectrum Disorders. Focus on Autism and Other Developmental Disabilities, 23(4), 195-206.

IBGE - Instituto Brasileiro de Geografia e estatística. Diponível na internet via WWW URL: http://www.ibge.gov.br

Jicha GA, Parisi JE, Dickson DW et al. Neuropathological outcome of mild cognitive impairment following progression to clinical dementia. Arch Neurol 2006;63 (5) 674- 681.

Kaplan E, Goodglass H, Weintraub S. The Boston naming test.2 ${ }^{\mathrm{a}}$ ed. Philadelphi: Lea \& Febiger; 1983.

Kaplan, H.I.; Sadock, B.J.; Greeb, J.A. Compêndio de Psiquiatria- Ciências do comportamento e Psiquiatria Clínica. 7 ed.Porto Alegre: Artemed, 1997

Kelly M, McDonald S. Assessing social cognition in people with a diagnosis of dementia: Development of a novel screening test, the Brief Assessment of Social Skills (BASS-D). J Clin Exp Neuropsychol. 2019 Dec 12:1-14.

Kemp J, Després O, Sellal F, Dufour A. Theory of Mind in normal ageing and neurodegenerative pathologies. Ageing Res Rev. 2012 Apr;11(2):199-219.

Kessels RP, Montagne B, Hendriks AW, Perrett DI, de Haan EH. Assessment of perception of morphed facial expressions using the Emotion Recognition Task: normative data from healthy participants aged 8-75. J Neuropsychol. 2014 Mar;8(1):75-93.

Kumfor F, Sapey-Triomphe LA, Leyton CE, Burrell JR, Hodges JR, Piguet O. Degradation of emotion processing ability in corticobasal syndrome and Alzheimer's disease. Brain. 2014 Nov;137(Pt 11):3061-72.

Kumfor F, Honan C, McDonald S, Hazelton JL, Hodges JR, Piguet O. Assessing the "social brain" in dementia: Applying TASIT-S. Cortex. 2017 Aug;93:166-177.

Kynast J, Schroeter ML (2018) Sex, age, and emotional valence: revealing possible biases in the 'reading the mind in the eyes' task. Front Psychol 9:570.

Ladislau R, Guimarães JG, Souza, WC (2015). Percepção de Expressões Faciais Emocionais em Idosos com Doença de Alzheimer. Psicologia: Reflexão e Crítica, 28(4), 804-812. 
Leime, JL, Rique Neto J, Alves SM, Torro-Alves N. (2013). Recognition of facial expression in children, young adults and elderly people. Estudos de Psicologia, 30, 161-167.

Machado JCB. Doença de Alzheimer. In: Freitas EV, Py L, Neri AL, Cançado FAX, Gorzoni ML, Rocha SM, editores. Tratado de Geriatria e Gerontologia. Rio de Janeiro: Editora Guanabara Koogan; 2006. p. 260-80.

Martins C, Barreto AL, Castiajo P. (2013). Teoria da mente ao longo do desenvolvimento normativo: Da idade escolar até à idade adulta. Análise Psicológica, 31(4), 377-392.

McCade D, Savage G, Naismith SL. Review of emotion recognition in mild cognitive impairment. Dement Geriatr Cogn Disord. 2011;32(4):257-66.

Metz CE. Basic principles of ROC analysis. Sem Nuc Med, 1978,8: 283-298.

Michaelian JC, Mowszowski L, Guastella AJ, Henry JD, Duffy S, McCade D, Naismith SL (2019) Theory of mind in mild cognitive impairment - relationship with limbic structures and behavioural change. J Int Neuropsychol Soc:1-12.

Miotto EC, Sato J, Lucia MCS, Camargo CHP, Scaff M. Development of an adapted version of the Boston Naming Test for Portuguese speakers. Rev Bras Psiquiatr. 2010 Sep;32(3):27982.

Morgan JK, Izard CE, King KA (2009). Construct Validity of the Emotion Matching Task: Preliminary Evidence for Convergent and Criterion Validity of a New Emotion Knowledge Measure for Young Children. Social development (Oxford, England), 19(1), 52-70.

Mukaka MM. Statistics corner: A guide to appropriate use of correlation coefficient in medical research. Malawi Med J. 2012 Sep;24(3):69-71.

Nitrini R, Caramelli P, Bottino CMC, Damasceno BP, Brucki SMD, Anghinah R. Diagnóstico de doença de Alzheimer no Brasil. Avaliação cognitiva e funcional: Departamento Científico de Neurologia Cognitiva e do Envelhecimento da Academia Brasileira de Neurologia. Arq Neuropsiquiatr. 2005;63:720-727.

Nussbaum, AM. Guia para o exame diagnóstico Segundo o DSM-5. Porto Alegre: Artmed, 2015. $273 \mathrm{p}$. 
Pavarini G, Souza DH (2010). Teoria da mente, empatia e motivação pró-social em crianças pré-escolares. Psicologia em Estudo, 15(3), 613-622.

Perner J, Wimmer H (1985). John thinks that Mary thinks that...: Atribution of second-order beliefs by 5- to 10-year-old children. Journal of Experimental Child Psychology, 39, 437-471.

Petersen RC, Smith GE, Waring SC, Ivnik RJ, Tangalos EG, Kokmen E. Mild cognitive impairment: clinical characterization and outcome. Arch Neurol. 1999 Mar;56(3):303-8. Erratum in: Arch Neurol 1999 Jun;56(6):760.

Petersen RC, Jack Jr CR, Xu YC. et al. Memory and MRI-based hippocampal volumes in aging and AD. Neurology.2000;54:581-587.

Peterson CC, Slaughter VP (2006), Telling the story of theory of mind: Deaf and hearing children's narratives and mental state understanding. British Journal of Developmental Psychology, 24: 151-179.

Phelps EA. Emotion and cognition: insights from studies of the human amygdala. Annu Rev Psychol. 2006;57:27-53. Review.

Pinkham AE. Social cognition in schizophrenia. J Clin Psychiatry. 2014;75Suppl 2:149.

Premack D, Woodruff G. Does the chimpanzee have a theory of mind? .Behavioral and Brain Sciences. 1978. p. 515-26.

Preston SD, de Waal FB. Empathy: Its ultimate and proximate bases. Behav Brain Sci. 2002 Feb;25(1):1-20; discussion 20-71.

Prince M, Bryce R, Albanese E, Wimo A, Ribeiro W, Ferri CP. The global prevalence of dementia: a systematic review and metaanalysis. Alzheimers Dement. 2013 Jan;9(1):6375.e2.

Rezende TF, Bomfim AJL, Chagas NMS, Osório FL, Chagas MHN (2018). Convergent validity of the Brazilian version of the Theory of Mind Task Battery for the assessment of social cognition in older adults. Archives of Clinical Psychiatry, 45(3), 75-76.

Rountree SD, Waring SC, Chan WC, Lupo PJ, Darby EJ, Doody RS. Importance of subtle amnestic and nonamnestic deficits in mild cognitive impairment: prognosis and conversion to dementia. Dement Geriatr Cogn Disord. 2007;24(6):476-82. 
Sanvicente-Vieira B, Kluwe-Schiavon B, Wearick-Silva LE, Piccoli GL, Scherer L, Tonelli HA, et al. Revised Reading the Mind in the Eyes Test (RMET) - Brazilian version. Ver Bras Psiquiatr. 2014 Jan;36(1):60-7.

Scazufca M, Menezes PR, Vallada HP, Crepaldi AL, Pastor-Valero M, Coutinho LMS, et al. High prevalence of dementia among older adults from poor socioeconomic backgrounds in São Paulo, Brazil.Int Psychogeriatr. 2008 Apr;20(2):394-405.

Schroeter ML, Pawelke S, Bisenius S, Kynast J, Schuemberg K, Polyakova M, et al. (2018). A modified reading the mind in the eyes test predicts behavioral variant frontotemporal dementia better than executive function tests. Front. Aging Neurosci. 10:11.

Sergi MJ, Green MF. Social perception and early visual processing in schizophrenia. Schizophr Res. 2003 Feb 1;59(2-3):233-41.

Serrano CM, Dillon C, Leis A, Taragano FE, Allegri RF (2013) Mild cognitive impairment: risk of dementia according to subtypes. Actas Esp Psiquiatr 41(6):330-339

Shamay-Tsoory SG, Harari H, Aharon-Peretz J, Levkovitz Y. The role of the orbitofrontal cortex in affective theory of mind deficits in criminal offenders with psychopathic tendencies. Cortex. 2010 May;46(5):668-77.

Sosa-Ortiz AL, Acosta-Castillo I, Prince MJ. Epidemiology of dementias and Alzheimer's disease. Arch Med Res. 2012 Nov;43(8):600-8.

De Souza W, Feitosa M, Eifuku S, Tamura R, Ono T. Face perception in its neurobiological and social context. Psychol Neurosci. 2008;1:15-20.

Spoletini I, Marra C, Du Lulio F, et al. Facial emotion recognition deficit in amnestic mild cognitive impairment and Alzheimer disease. Am J Geriatr Psychiatry 2008;16:389-98.

Sze JA, Goodkind MS, Gyurak A, Levenson RW. Aging and emotion recognition: not just a losing matter. Psychol Aging. 2012 Dec;27(4):940-950.

Takenoshita S, Terada S, Yokota O, Kutoku Y, Wakutani Y, Nakashima M, et al. Sally-Anne test in patients with Alzheimer's Disease Dementia. J Alz Dis(2018) 61(3):1029-36. 
Tonelli H, Alvarez CE (2009). Cognição social na esquizofrenia: um enfoque em habilidades teoria da mente. Revista de Psiquiatria do Rio Grande do Sul, 31(3, Suppl. )

Torres B, Santos RL, Sousa MF, Simões Neto JP, Nogueira MM, Belfort TT, et al. (2015). Facial expression recognition in Alzheimer's disease: a longitudinal study. Arq. Neuropsiquiatr. 73, 383-389.

Varjassyová A, Hořínek D, Andel R, Amlerova J, Laczó J, Sheardová K, et al. Recognition of facial emotional expression in amnestic mild cognitive impairment. J Alzheimers Dis. 2013;33:273-80.

Weiss EM, Kohler CG, Vonbank J, et al. Impairment in emotion recognition abilities in patients with mild cognitive impairment, early and moderate Alzheimer disease compared with healthy comparison subjects. Am J Geriatr Psychiatry 2008;16:974e80.

Wimmer H, Perner J (1983). Beliefs about beliefs: Representation and constraining function of wrong beliefs in young childrens understanding of deception. Cognition, 13, 103-128.

Yi Z, Zhao P, Zhang H. et al. Theory of mind in Alzheimer's disease and amnestic mild cognitive impairment: a meta-analysis. Neurol Sci (2020). 
APÊNDICES 


\section{Apêndice A -Termo de Consentimento Livre e Esclarecido}

NOME DA PESQUISA: Cognição social e comparação dos critérios de demência do DSMIV e DSM-5 entre idosos atendidos na atenção básica

\section{PESQUISADOR REPONSÁ VEL: Marcos Hortes N. Chagas (contato: 16 98145- 2367/setroh@ hotmail.com)}

Você está sendo convidado a participar do estudo: "Cognição social e comparação dos critérios de demência do DSM-IV e DSM-5 entre idosos atendidos na atenção básica”.

1. Objetivos e Justificativa: Essa pesquisa tem como objetivo estudar a frequência de pessoas com mais de 60 anos com demência que moram na sua região. Este quadro inclui pessoas que têm perda de memória, que se perdem com facilidade, que trocam as coisas de lugar e o nome das pessoas muitas vezes, que não conseguem mais fazer compras, entre outras atividades do dia-a-dia. Vamos também comparar duas maneiras que são usadas pelos profissionais de saúde para saber se você tem a demência. Além disso, queremos saber como está sua capacidade de reconhecer algumas emoções no rosto de outras pesssoas. A demência é um problema de saúde que acontece com certa frequência principalmente com as pessoas que possuem 60 anos ou mais. Ela pode prejudicar de maneira importante a realização das atividades do dia-a-dia, o relacionamento com as pessoas e tornar a pessoa dependente de cuidados. Por isso, há a necessidade de observar se isso pode estar acontecendo, para que medidas preventivas sejam tomadas.

2. Participação na Pesquisa: Sua participação na pesquisa será responder as perguntas feitas por um pesquisador sobre sua saúde e realizar alguns testes como tarefas para testar sua memória, sua capacidade de nomear objetos, fazer algumas contas e alguns desenhos, reconhecer faces de algumas emoções, entre outros.

3. Riscos e Benefícios: Como possíveis riscos do estudo, cita-se o possível desconforto e cansaço em realizar os testes e responder às perguntas propostas, que exigem engajamento do participante e podem demandar cerca de 50 minutos. Além disso, mesmo que pequena, há possibilidade de outras pessoas terem acesso às informações que você ofereceu. Deve-se considerar também que o diagnóstico de demência pode causar sofrimento psicológico, principalmente para participantes que não saibam do diagnóstico.

Você não terá necessidade de se deslocar para outro local para participar da pesquisa, pois a pesquisa será realizada em sua casa, no local que se sentir mais confortável. 
Como benefícios de sua participação na pesquisa, poderemos obter informações sobre como identificar pessoas que possuem o quadro de demência. Também poderemos obter dados importantes sobre memória, atenção, prejuízo nas atividades do dia-a-dia e emoções sentidas da população estudada. De acordo com estas perguntas e testes, alguns participantes poderão ser identificados com o quadro de demência. Caso algumas perguntas e testes estejam alterados e exista a suspeita de demência, você será encaminhado para avaliação adequada na unidade de saúde do município.

Caso você aceite participar da pesquisa, você precisa saber que:

Somente você e os pesquisadores terão acesso às informações e aos testes e que é garantido o sigilo sobre todos os dados coletados e mantida a privacidade dos participantes na pesquisa. Estas informações serão utilizadas exclusivamente para este estudo e as análises serão realizadas de forma geral, sem a identificação individual dos participantes. O material coletado na pesquisa será arquivado no Departamento de Gerontologia da Universidade Federal de São Carlos.

Os resultados finais da pesquisa poderão ser divulgados em publicações ou eventos científicos, sendo que os dados pessoais dos participantes do estudo não serão revelados, o que garante o completo anonimato.

A sua participação é voluntária e caso você se sinta desconfortável para responder às perguntas ou aos testes, a sua não participação ou a interrupção em qualquer momento do estudo não lhe causará qualquer problema ou dificuldade com relação a seu atendimento no serviço de saúde do município ou às visitas que a agente comunitária faz durante o ano.

Nesse estudo não haverá despesas financeiras para os participantes, e serão garantidos esclarecimentos, antes e durante o curso da pesquisa sobre a metodologia e resultados obtidos.

O pesquisador responsável pela pesquisa poderá ser contatado pelo telefone (16) 98145-2367.

Você ficará com uma das duas vias originais desse Termo de Consentimento e a outra via será arquivada pelo pesquisador.

$\mathrm{Eu}$, , RG

tendo sido esclarecido sobre as condições do estudo, especialmente no que diz respeito ao objetivo da pesquisa, aos procedimentos a que serei submetido, aos riscos e benefícios do trabalho, declaro que tenho pleno conhecimento dos direitos e condições que me foram assegurados e manifesto livremente minha vontade de participar do referido estudo.

São Carlos, de de 


\section{Apêndice B - Aprovação pelo Comitê de Ética}

Conclusôes ou Pendências e Lista de Inadequações:

Projeto aprovado. O pesquisador atendeu a todas as pendências do Parecer 1 .

Este parecer foi elaborado baseado nos documentos abaixo relacionados:

\begin{tabular}{|c|c|c|c|c|}
\hline Tipo Documento & Arquivo & Postagem & Autor & Situação \\
\hline $\begin{array}{l}\text { Informações Básicas } \\
\text { do Projeto }\end{array}$ & $\begin{array}{l}\text { PB_INFORMACCOES_BASICAS_DO_P } \\
\text { ROJETO 550432.pdf }\end{array}$ & $\begin{array}{c}08 / 09 / 2015 \\
21: 22: 02\end{array}$ & & Aceito \\
\hline $\begin{array}{l}\text { Recurso Anexado } \\
\text { pelo Pesquisador }\end{array}$ & carta_ao_cep.pdf & $\begin{array}{c}08 / 09 / 2015 \\
21: 20: 03 \\
\end{array}$ & \begin{tabular}{|l|} 
Marcos Hortes \\
Nisihara Chagas \\
\end{tabular} & Aceito \\
\hline $\begin{array}{l}\text { TCLE / Termos de } \\
\text { Assentimento / } \\
\text { Justificativa de } \\
\text { Ausência } \\
\end{array}$ & TCLE_CEP_versao_2.pdf & $\begin{array}{l}08 / 09 / 2015 \\
21: 19: 40\end{array}$ & $\begin{array}{l}\text { Marcos Hortes } \\
\text { Nisihara Chagas }\end{array}$ & Aceito \\
\hline Outros & $\begin{array}{l}\text { Reconhecimento de Emoções } \\
\text { Faciais.pdf }\end{array}$ & $\begin{array}{c}20 / 07 / 2015 \\
11: 07: 12\end{array}$ & & Aceito \\
\hline Outros & RMET.pdf & $\begin{array}{c}20 / 07 / 2015 \\
11: 06: 58\end{array}$ & & Aceito \\
\hline Outros & Protocolo ¿ quest socio e escalas.pdf & $\begin{array}{c}20 / 07 / 2015 \\
11: 06: 28\end{array}$ & & Aceito \\
\hline Outros & Autorizacao prefeitura.pdf & $\begin{array}{c}20 / 07 / 2015 \\
11: 05: 59\end{array}$ & & Aceito \\
\hline
\end{tabular}


Anexo A - Bateria Breve de Cognição Social

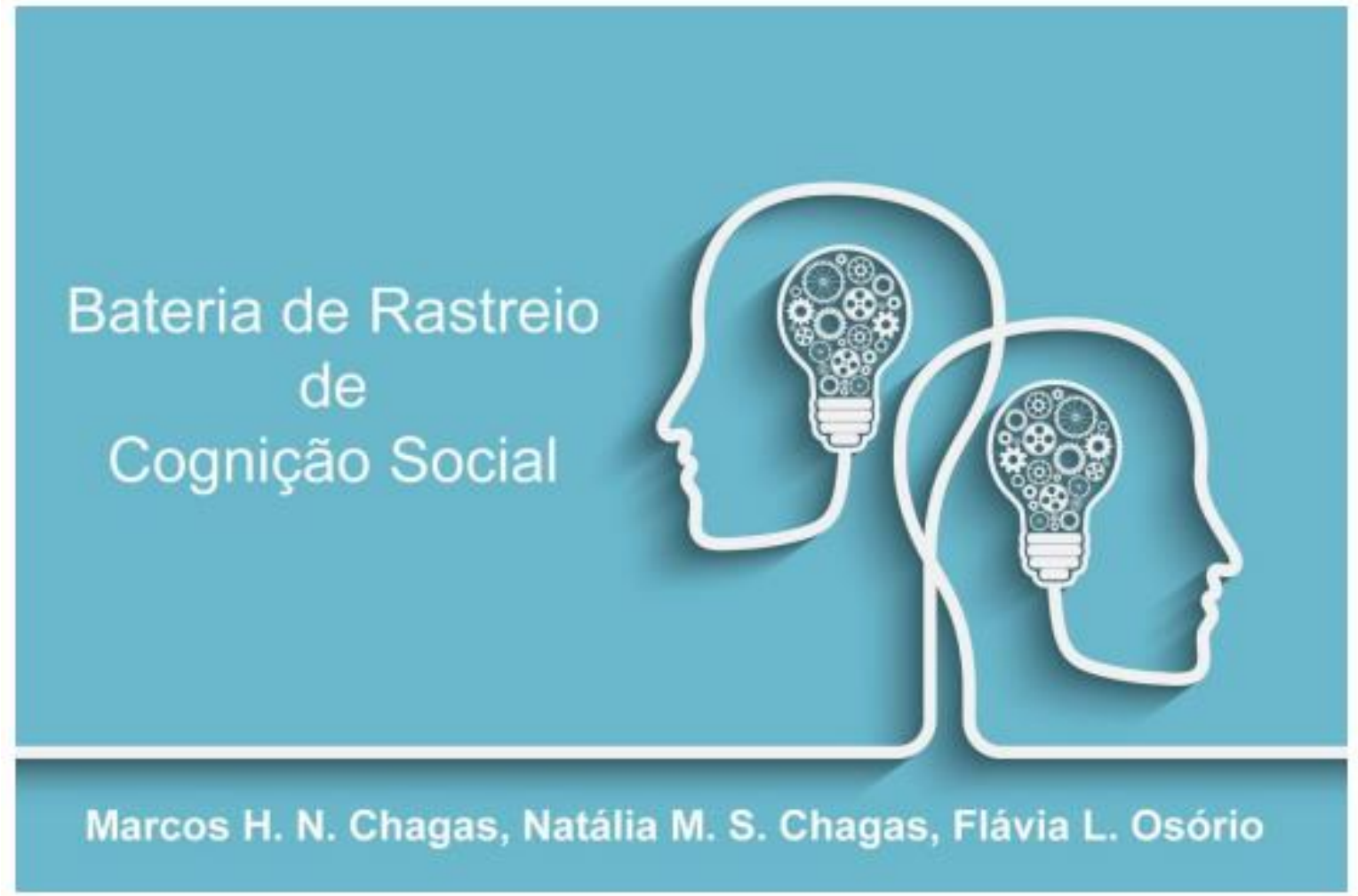




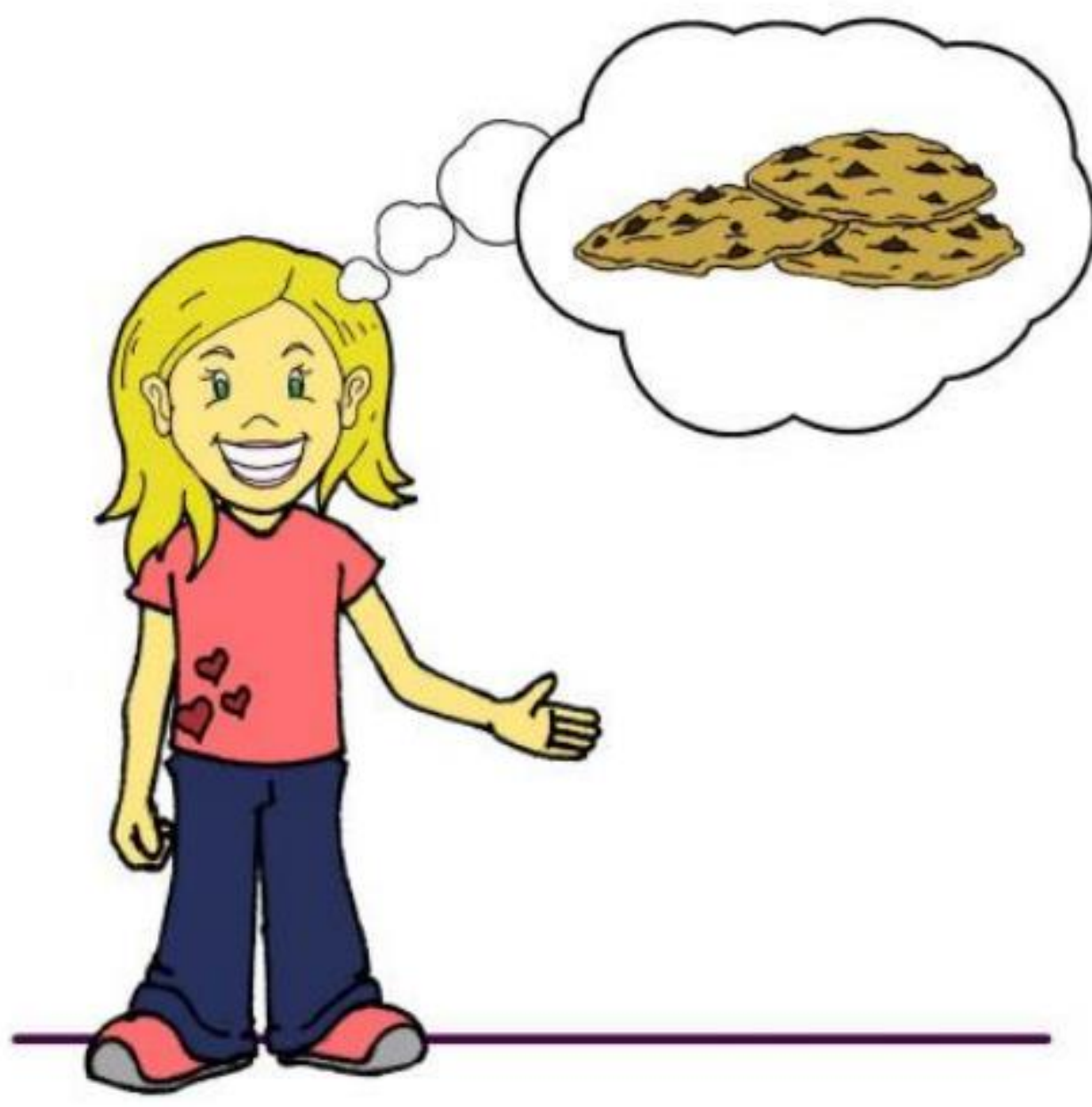

Esta é Bia.

Bia quer uma bolacha para comer. 

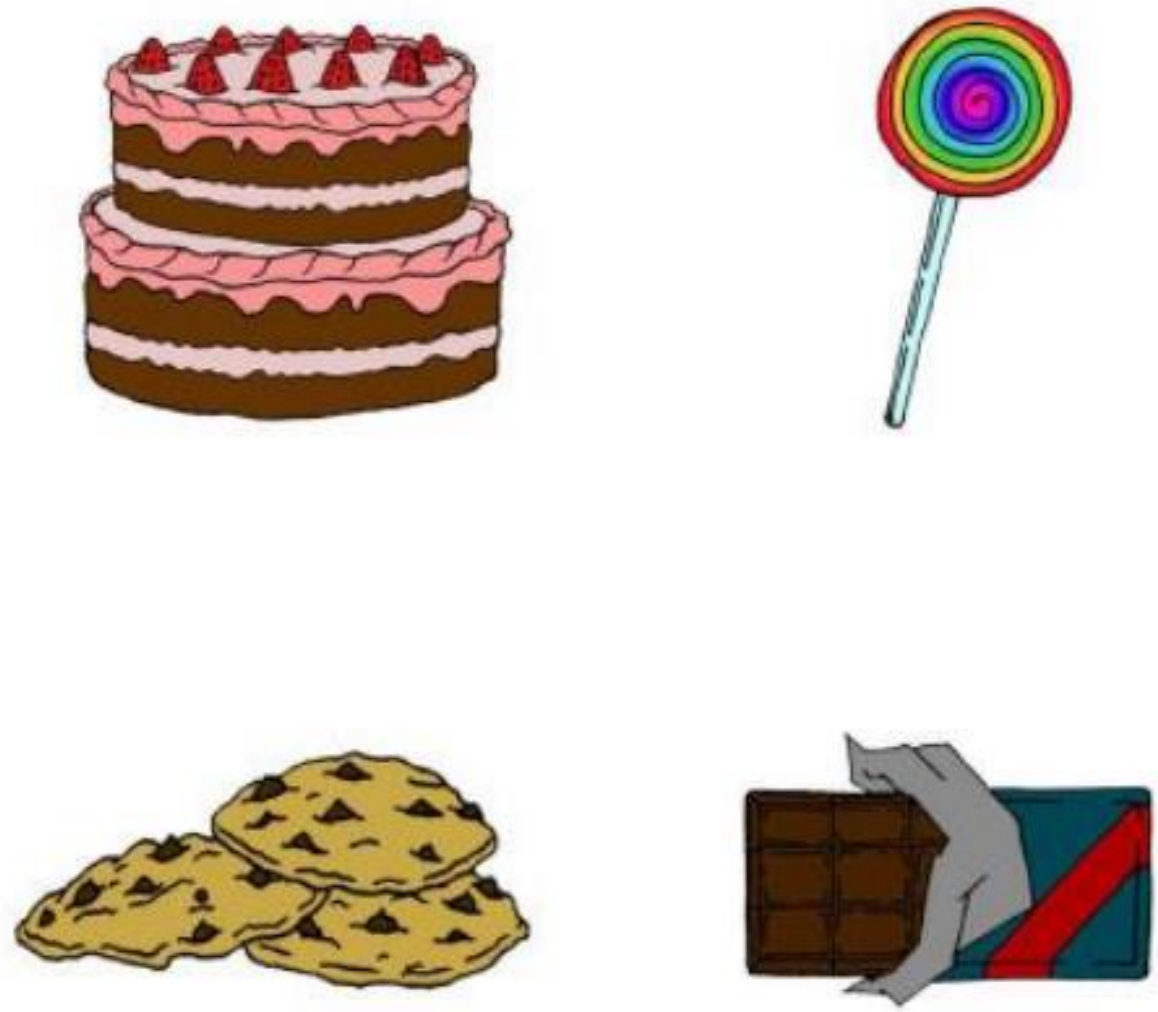

O que Bia quer? 

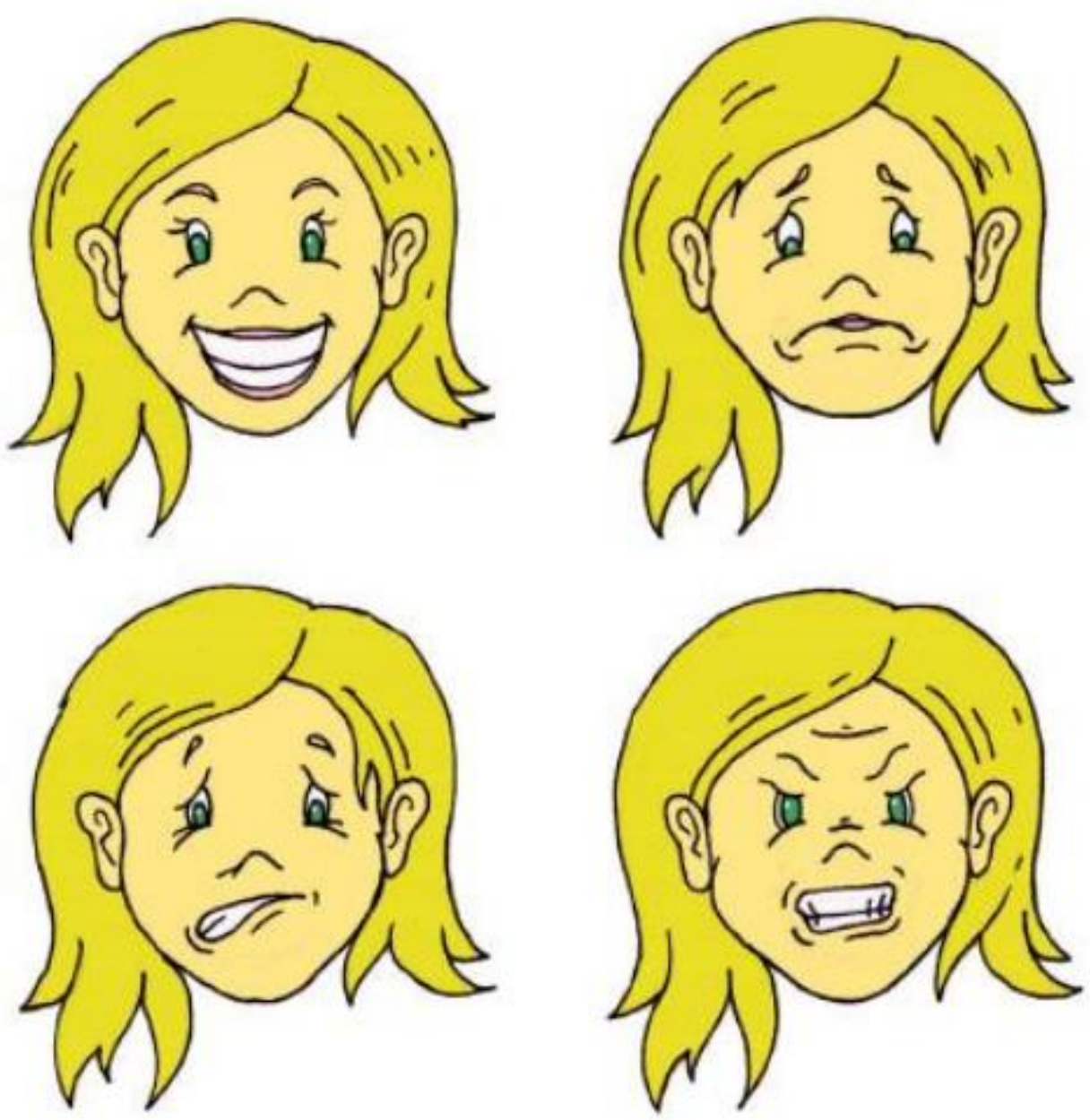

Como Bia vai se sentir

se ela conseguir uma bolacha? 


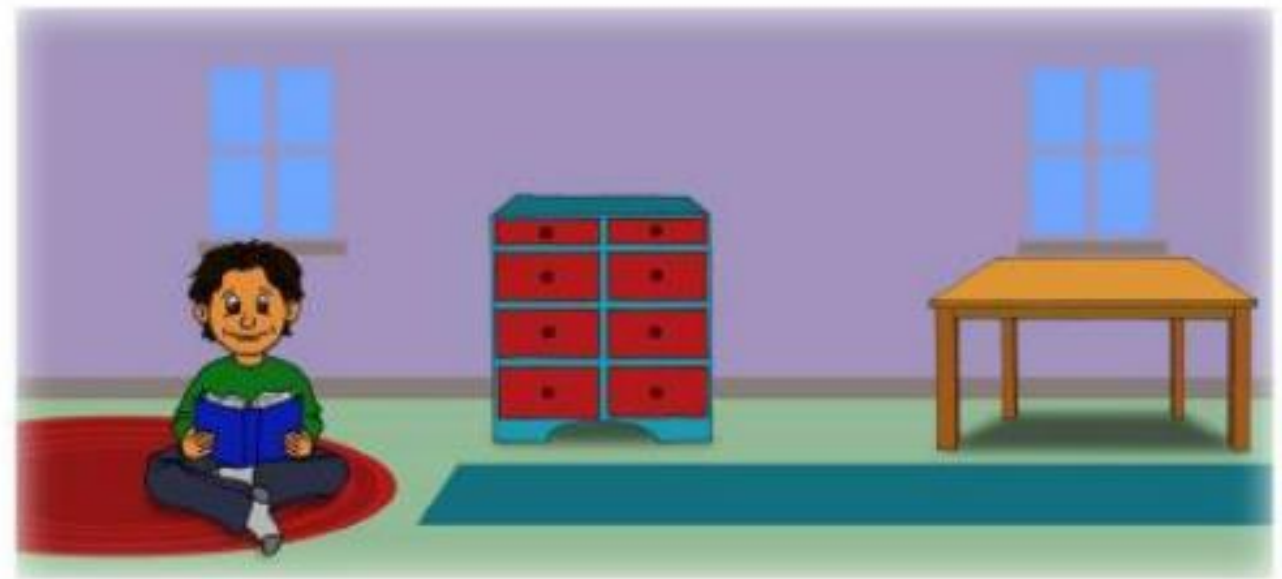

Este é Antônio. Antônio está lendo um livro.

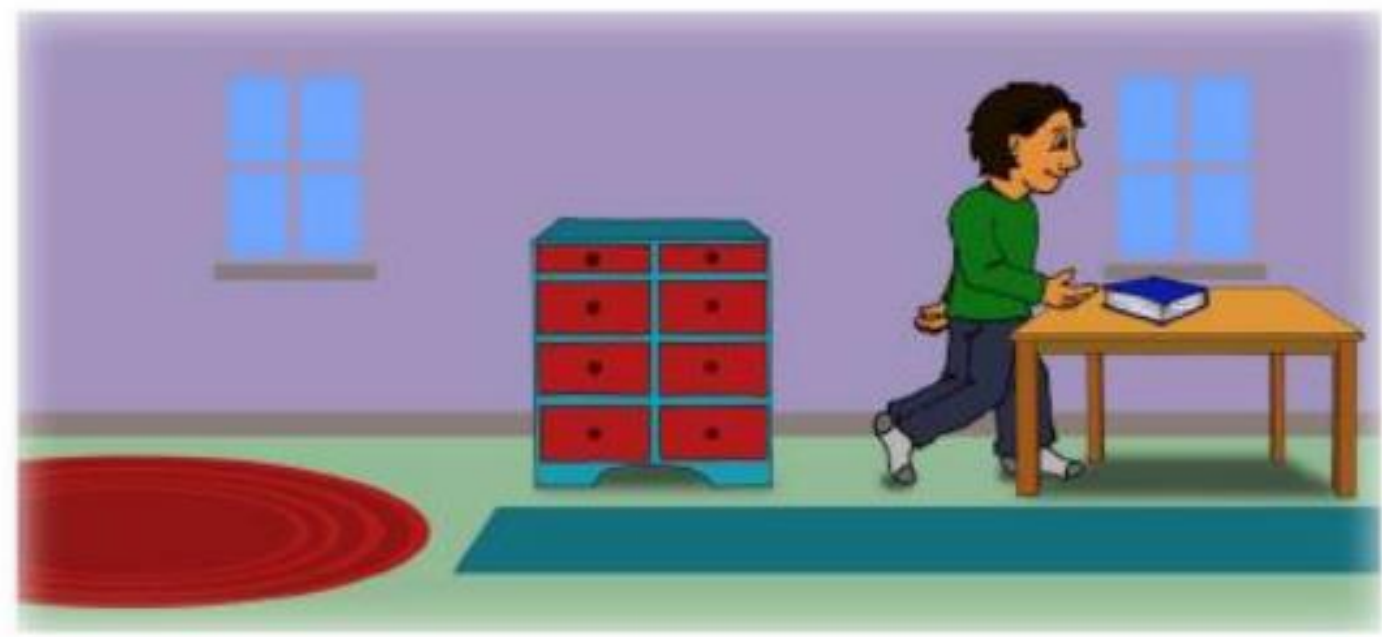

Quando ele termina, Antônio coloca o livro em cima da mesa. 


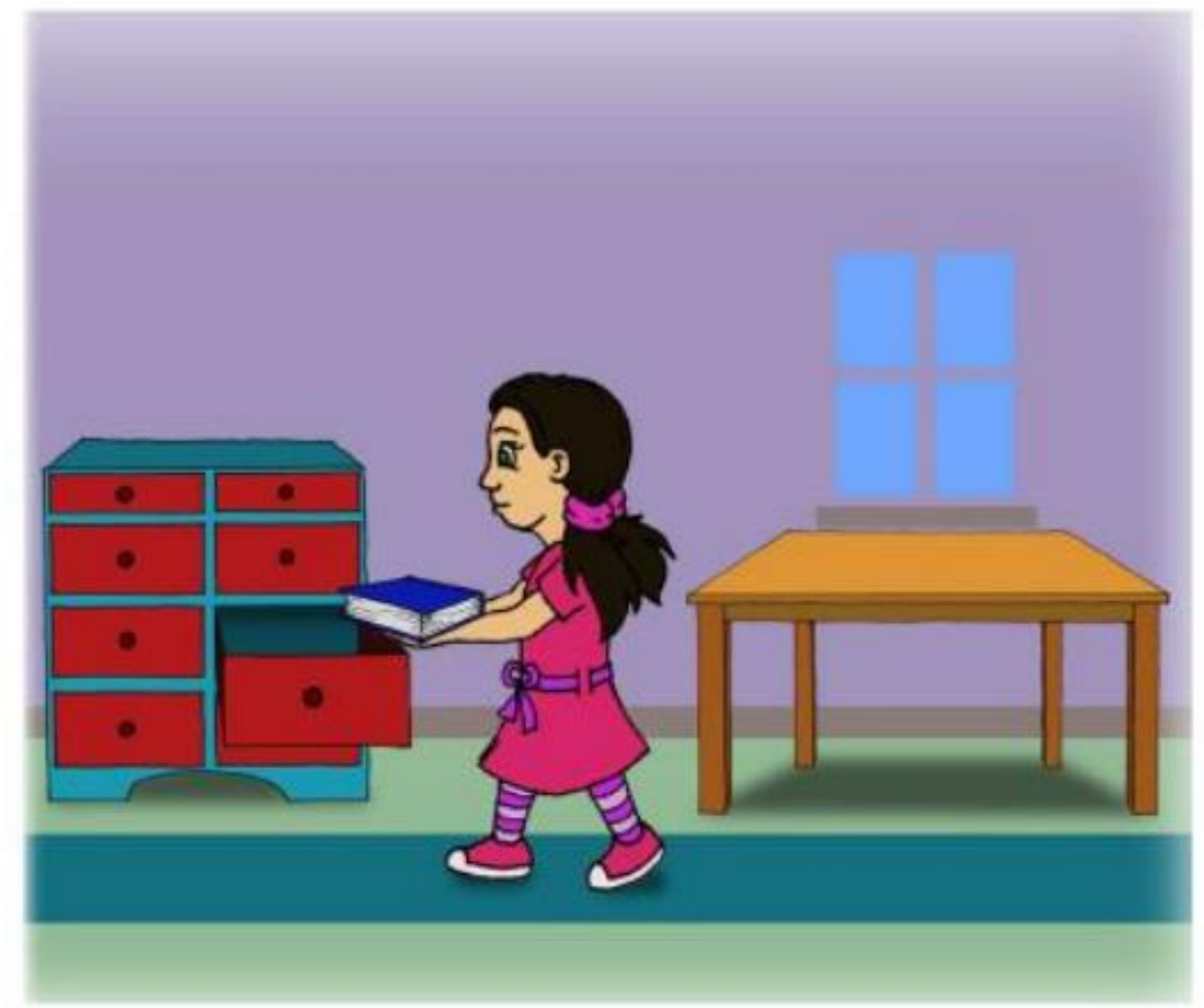

Veja, Sonia chega e muda o livro da mesa para uma gaveta. 


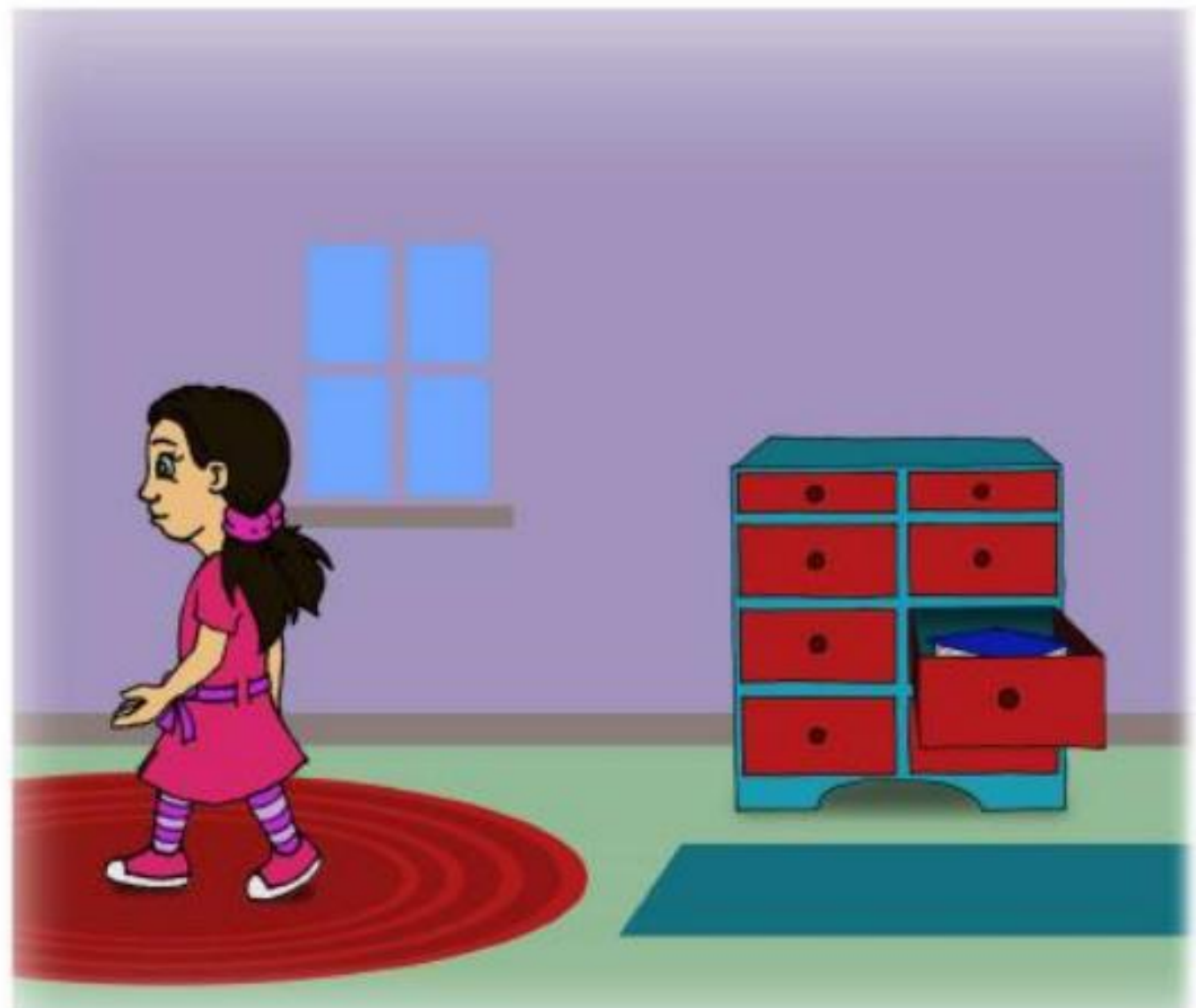

Em seguida Sonia sai. 


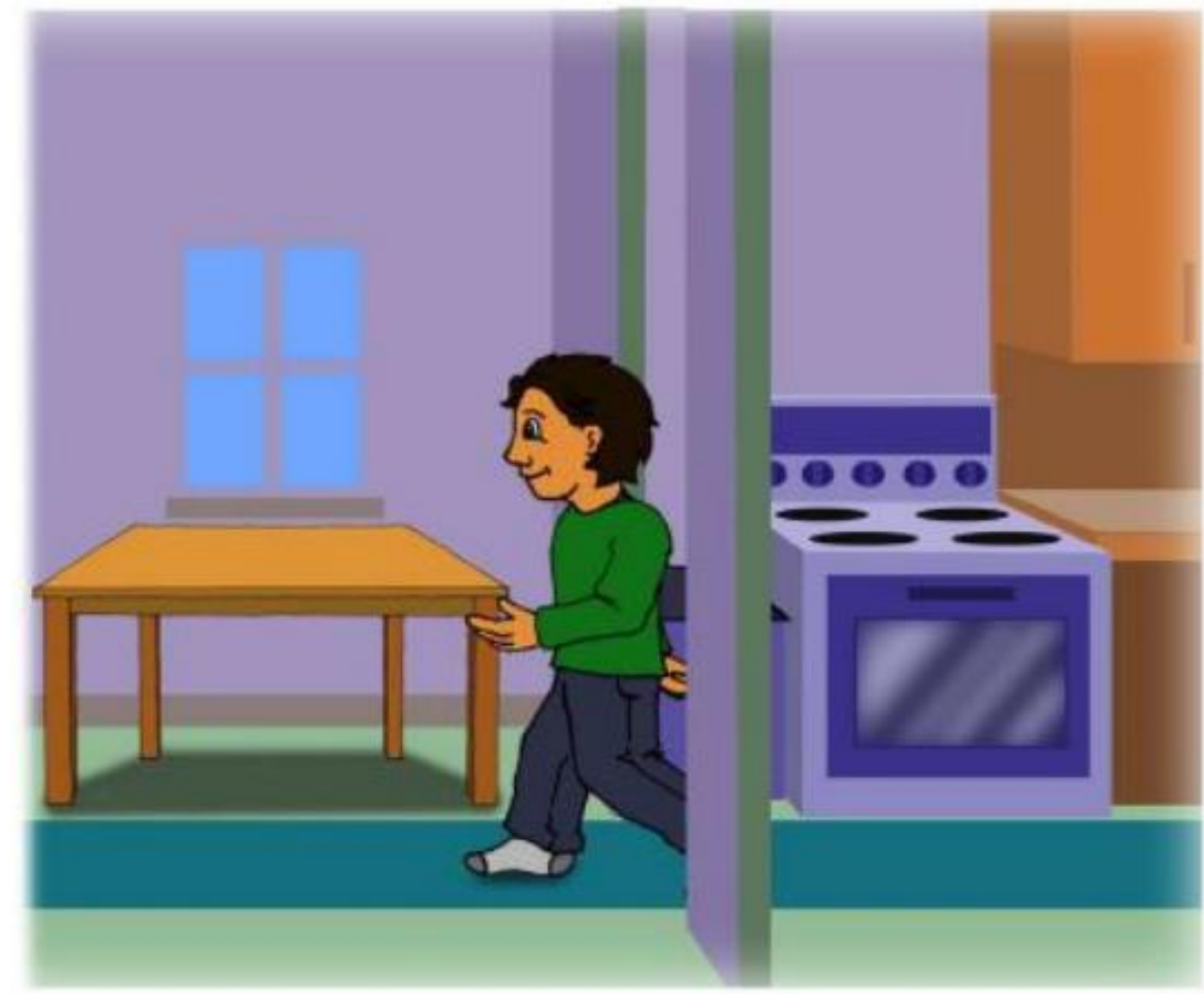

Veja, Antônio volta para ler mais um pouco. 

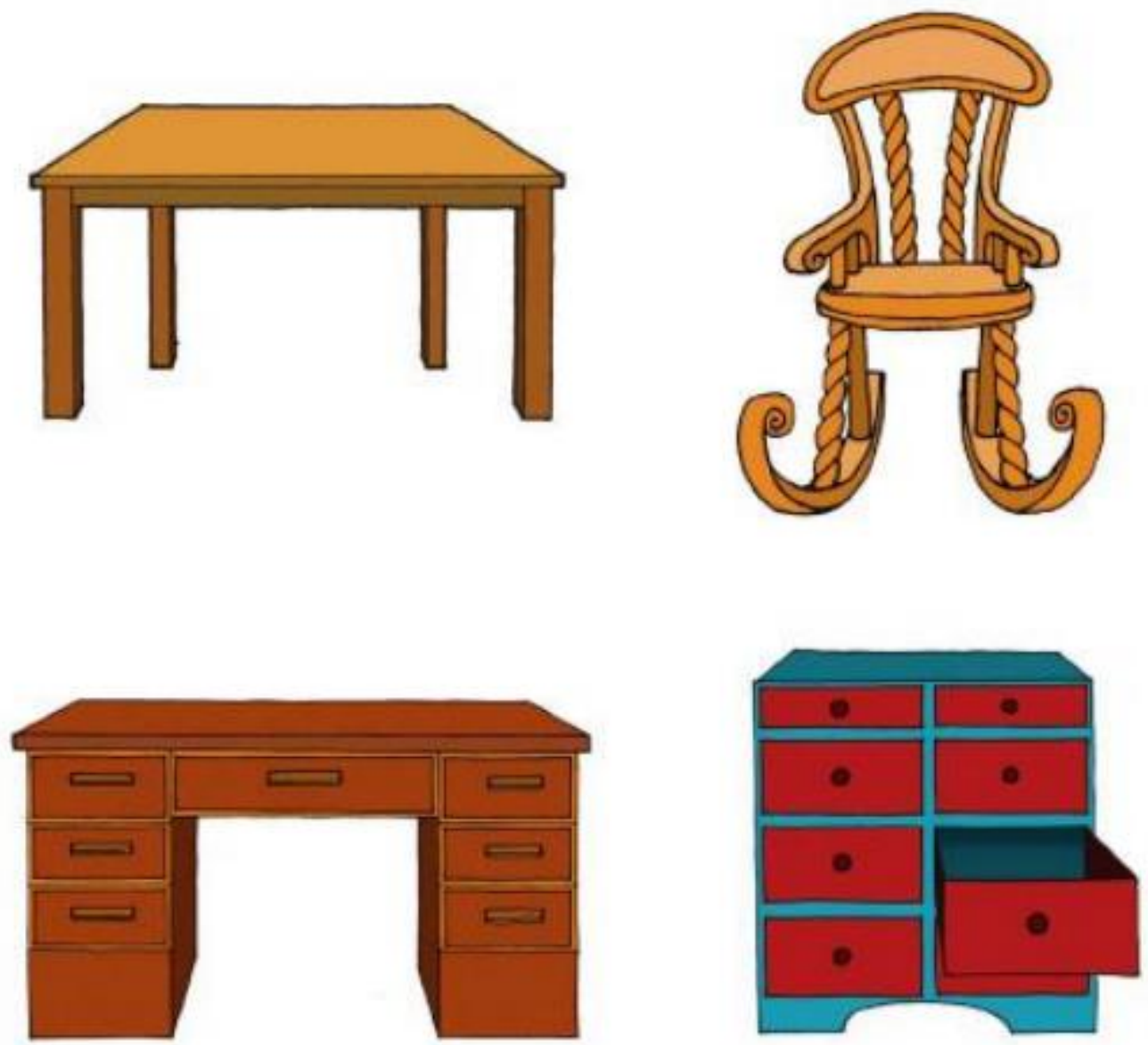

Onde Antônio colocou o livro? Onde o livro está agora?

Onde Antônio irá procurar o livro primeiro? 

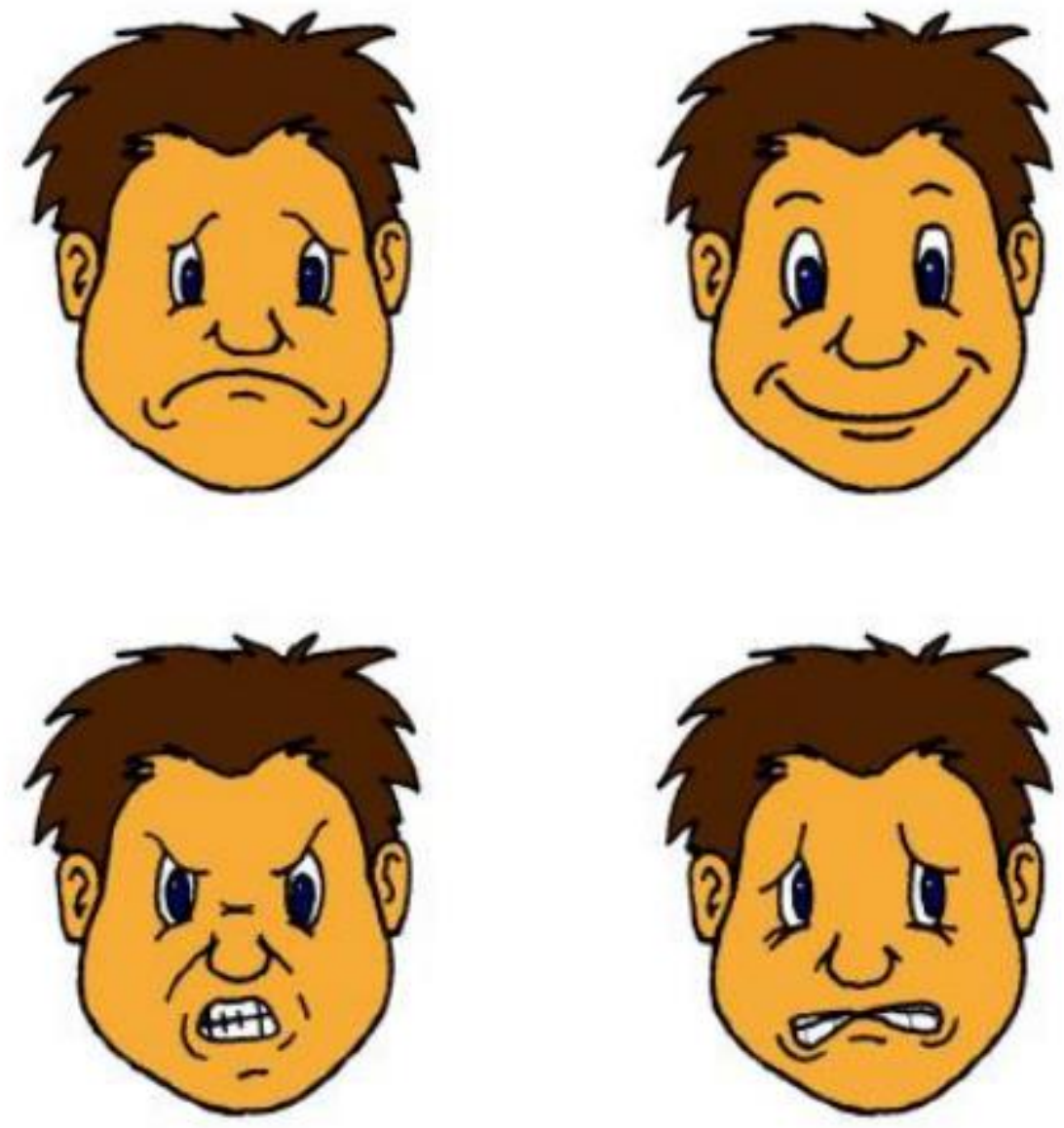

Aponte para a face que está feliz. 
Qual a emoção dessa face?

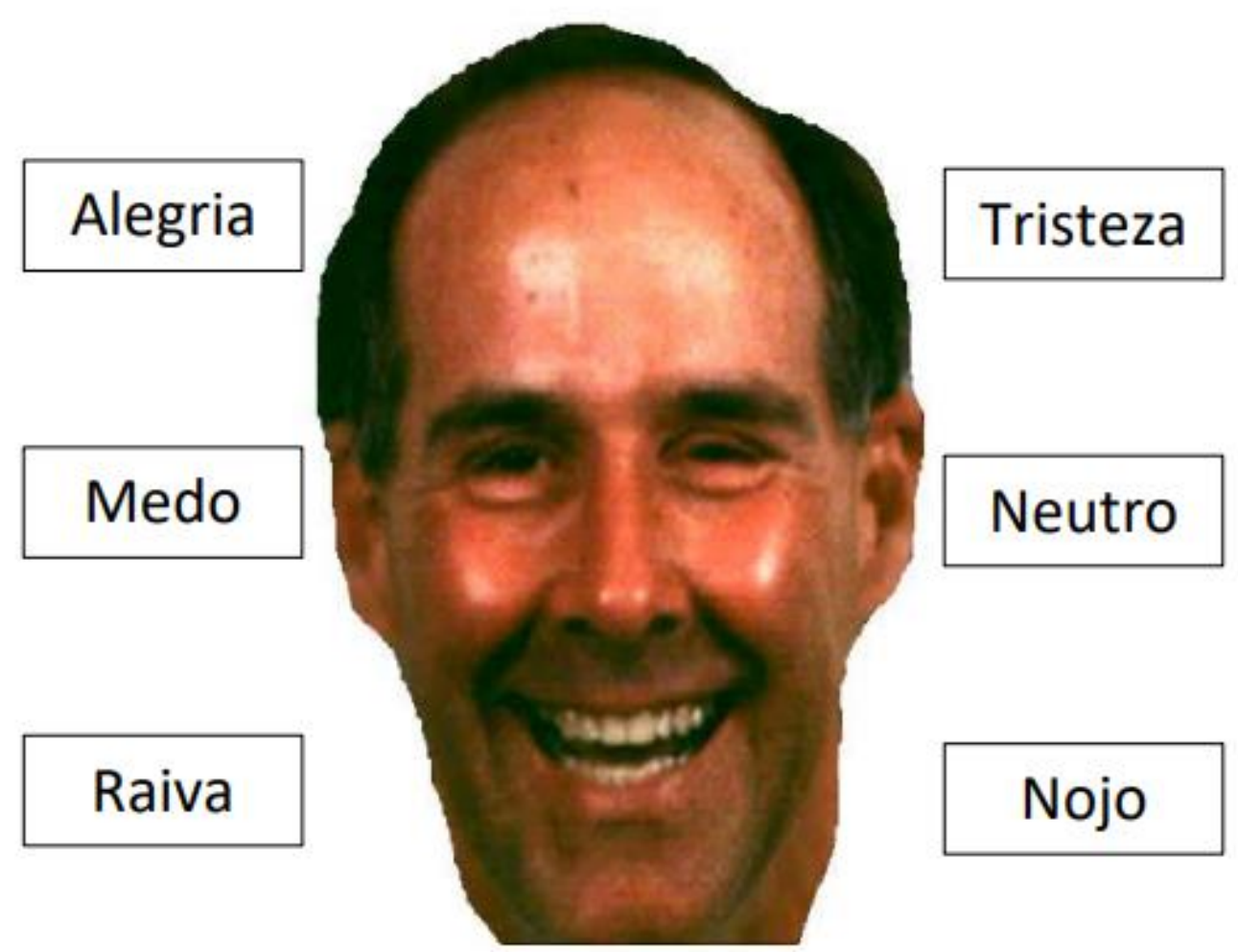


Qual a emoção dessa face?

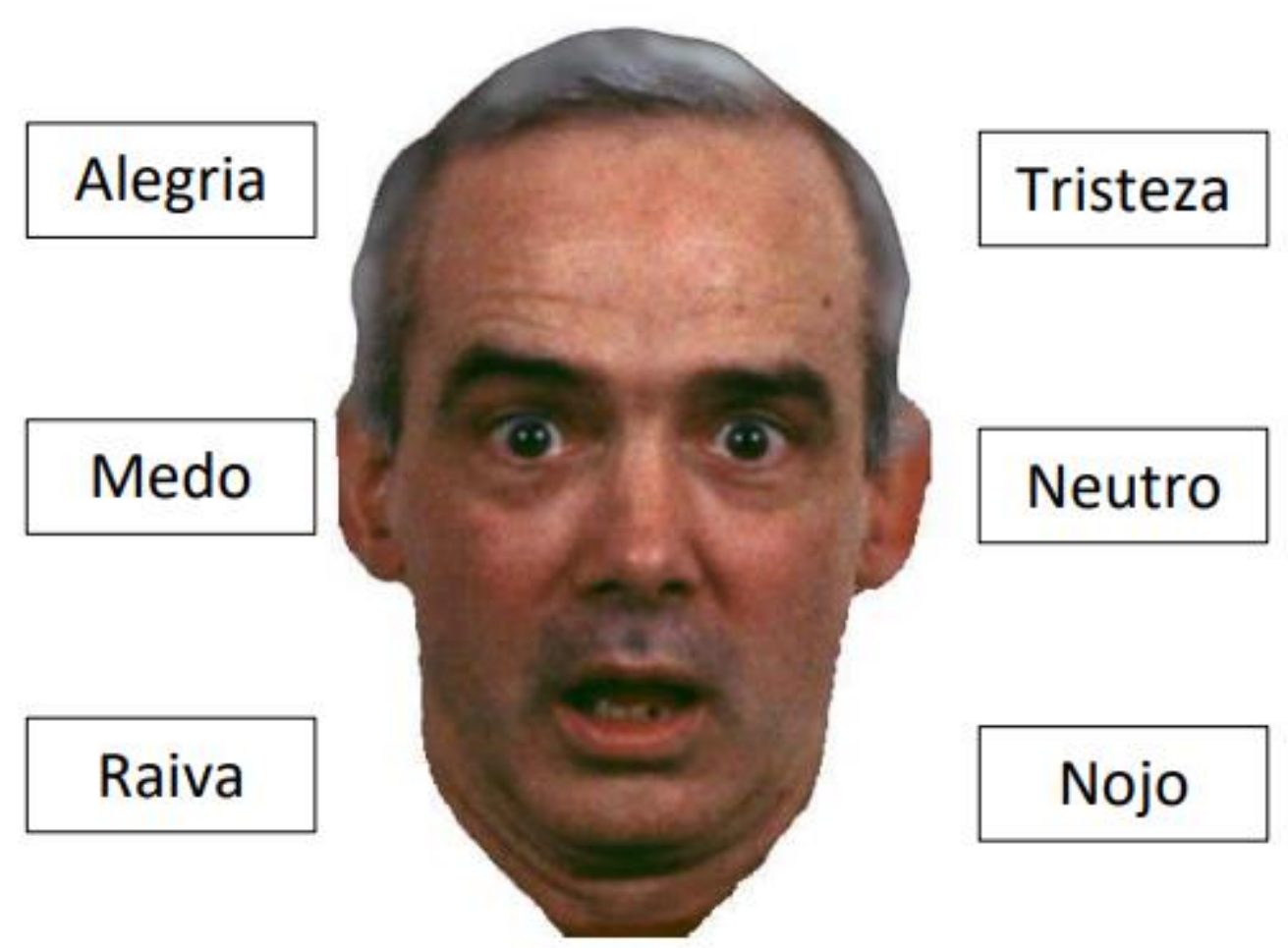


Qual a emoção dessa face?
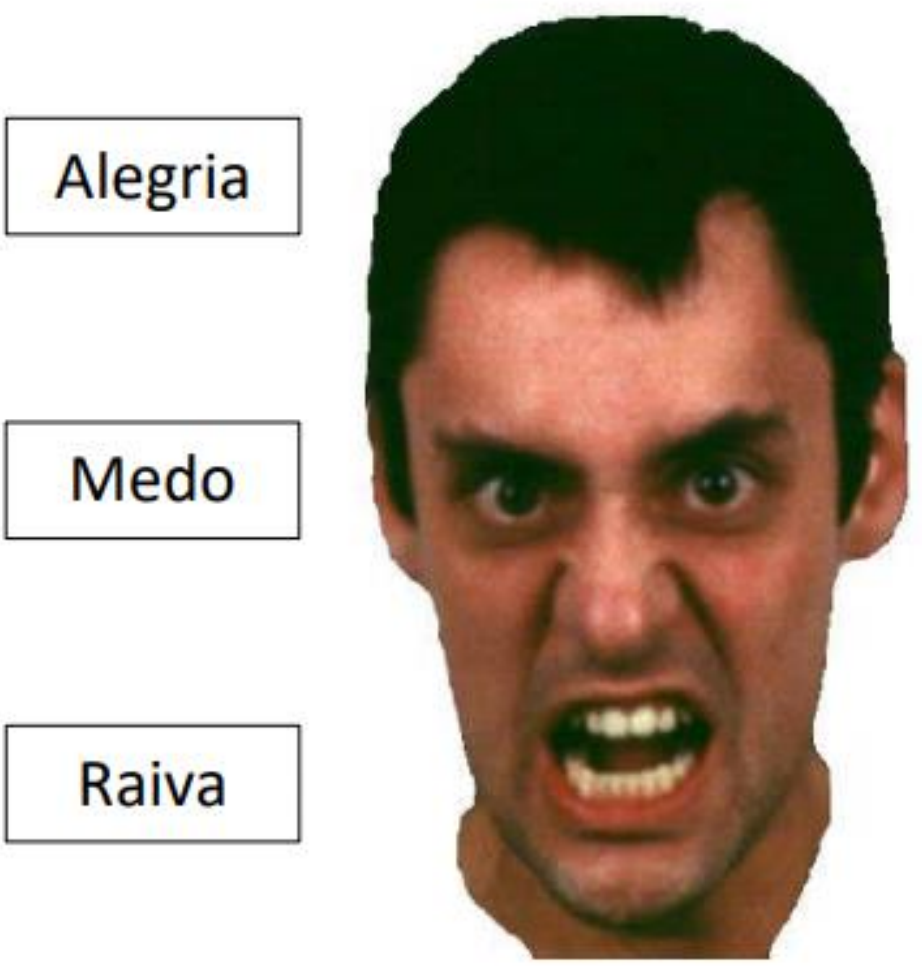

Tristeza

Neutro

Nojo 
Qual a emoção dessa face?
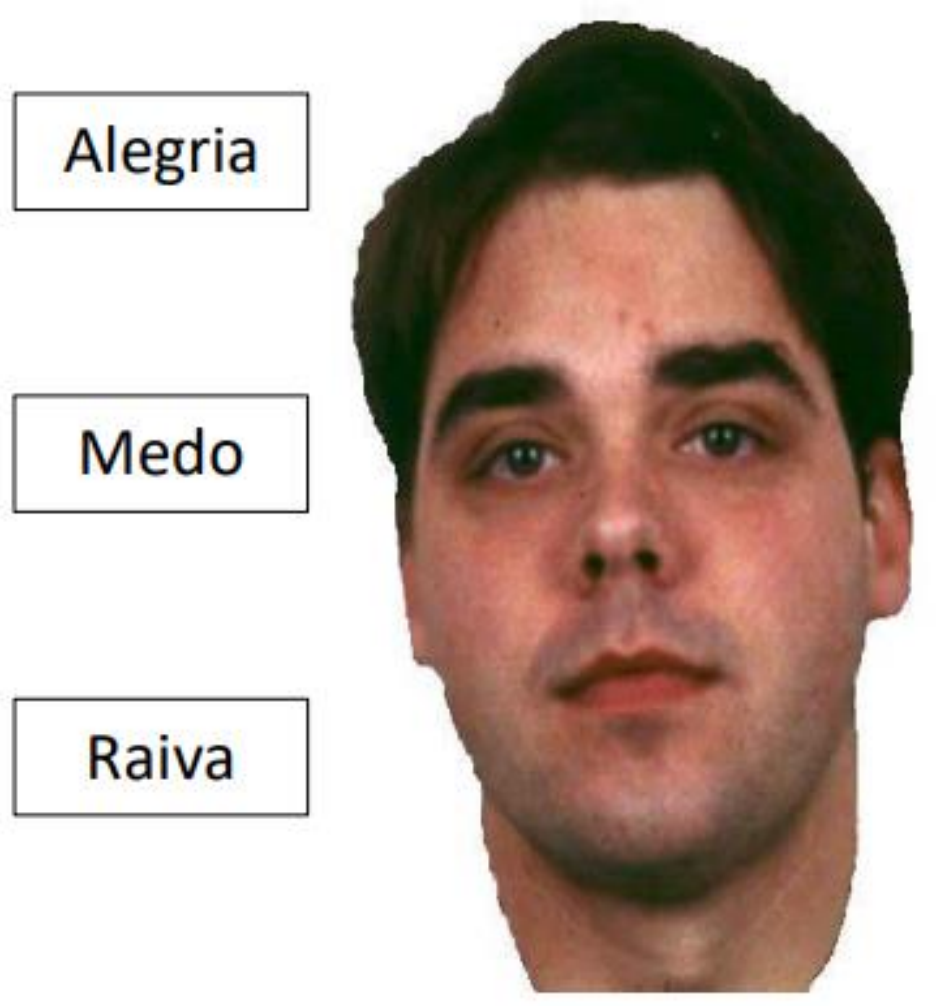

\section{Tristeza}

Neutro

Nojo 
Qual a emoção dessa face?

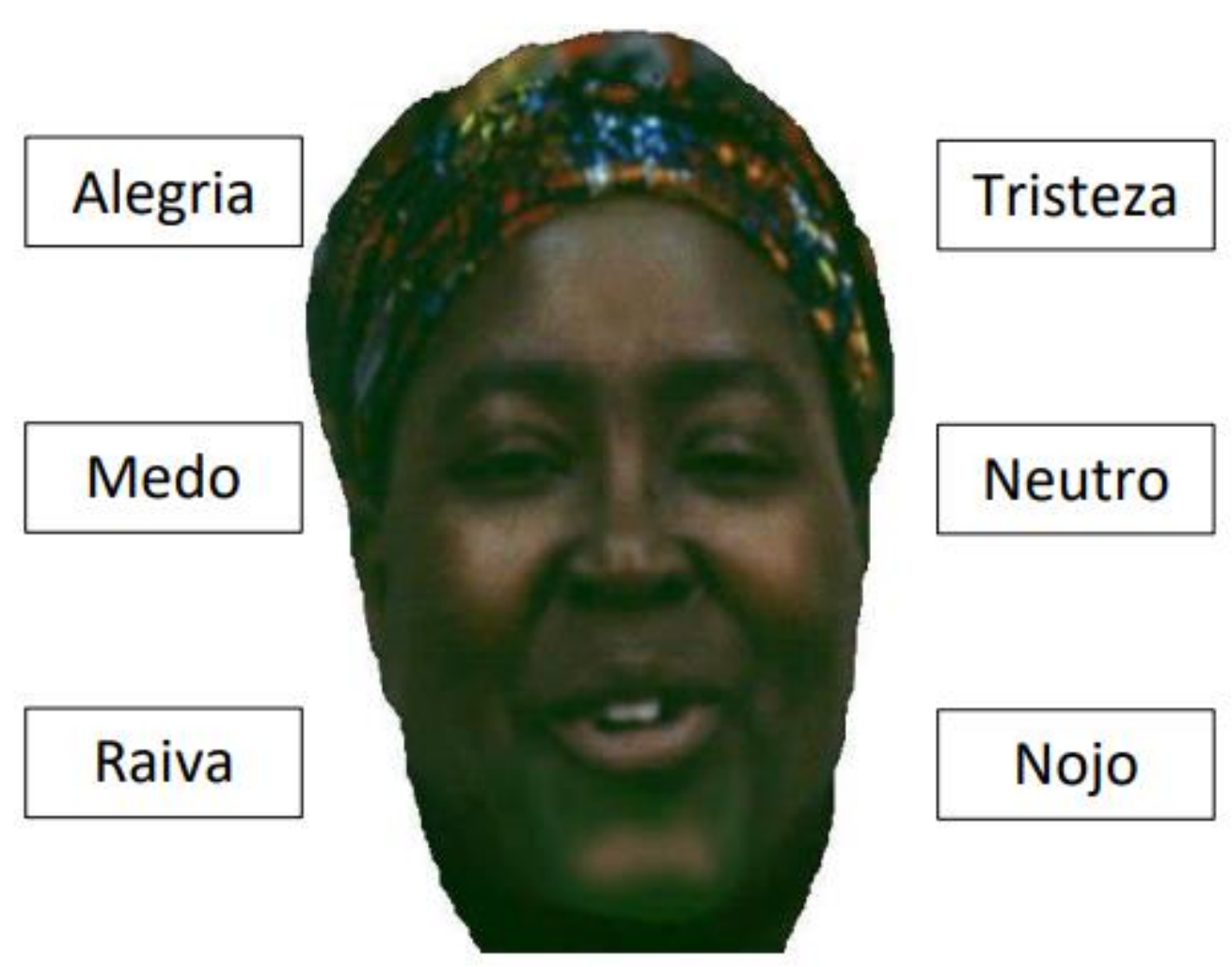


Qual a emoção dessa face?

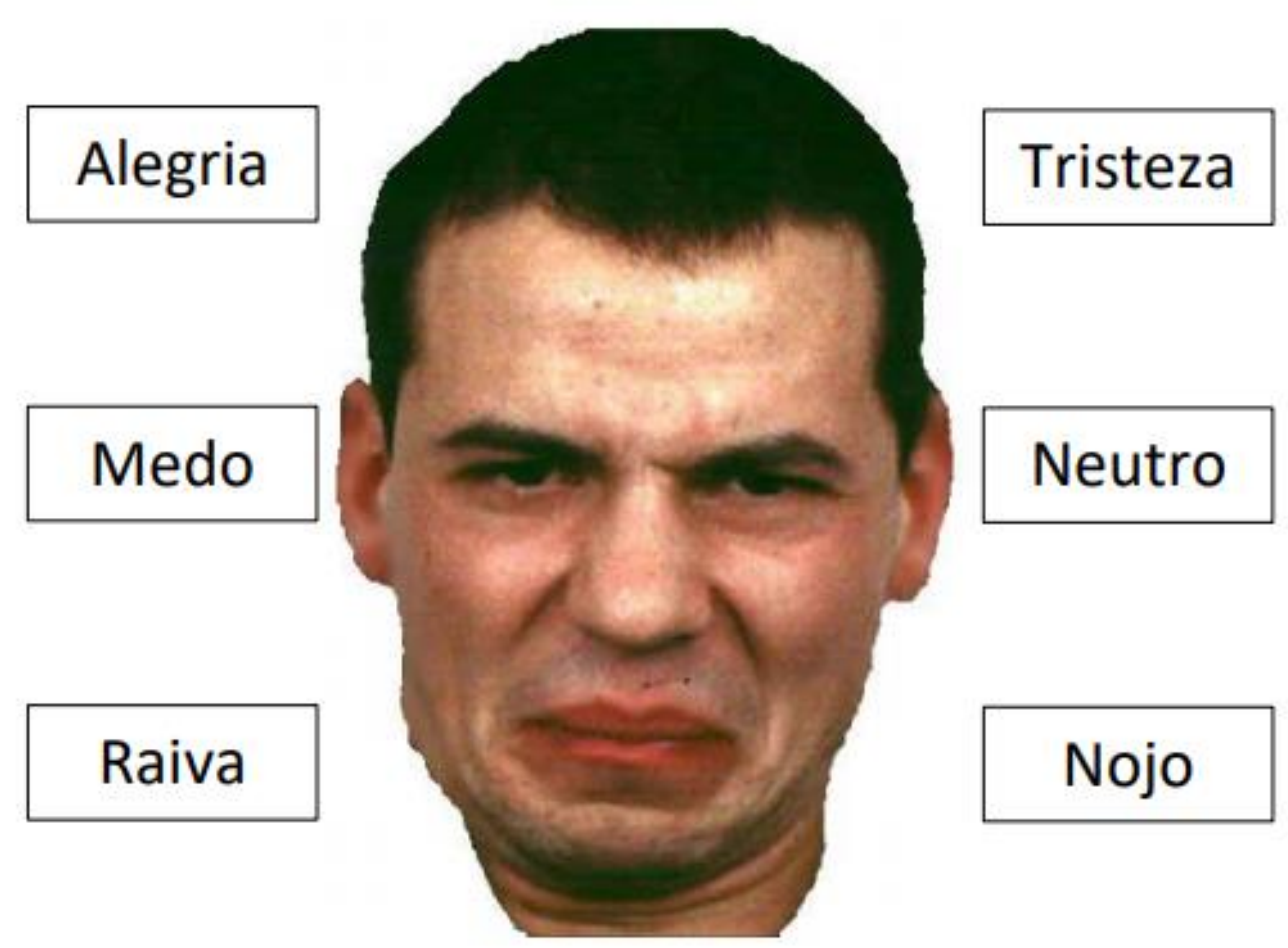


Qual a emoção dessa face?
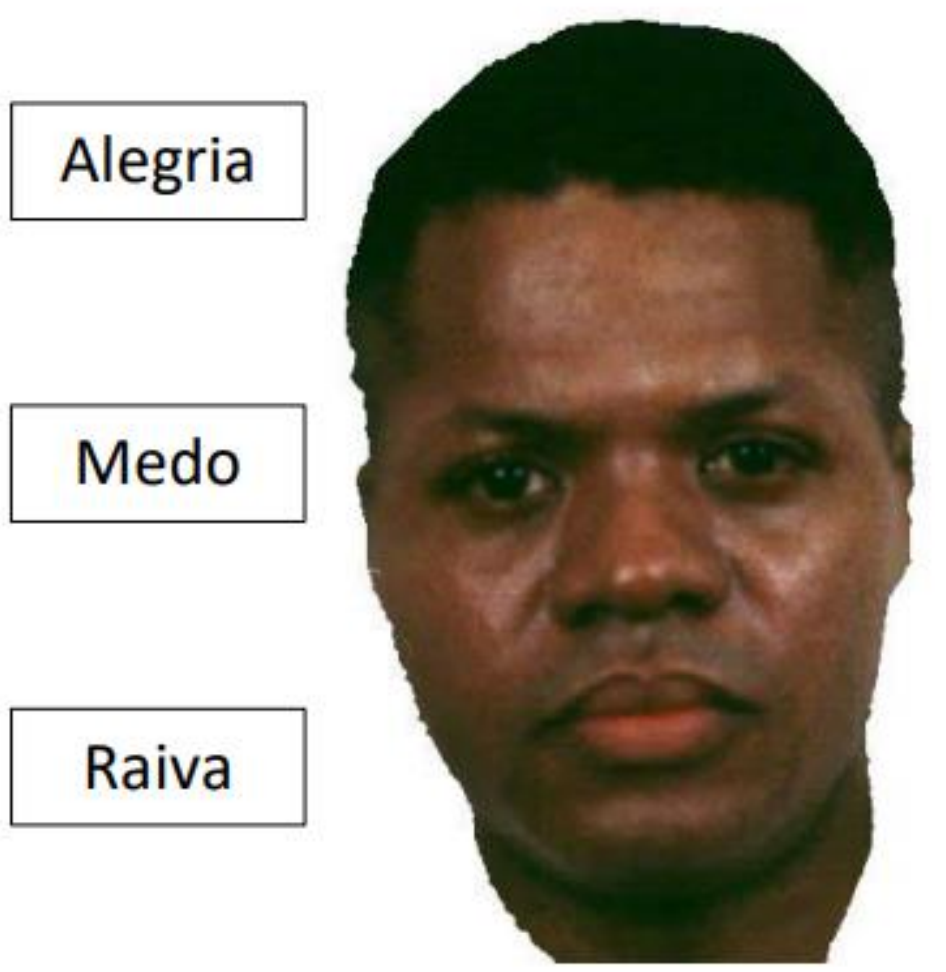

Tristeza

Neutro

Nojo 
Qual a emoção dessa face?
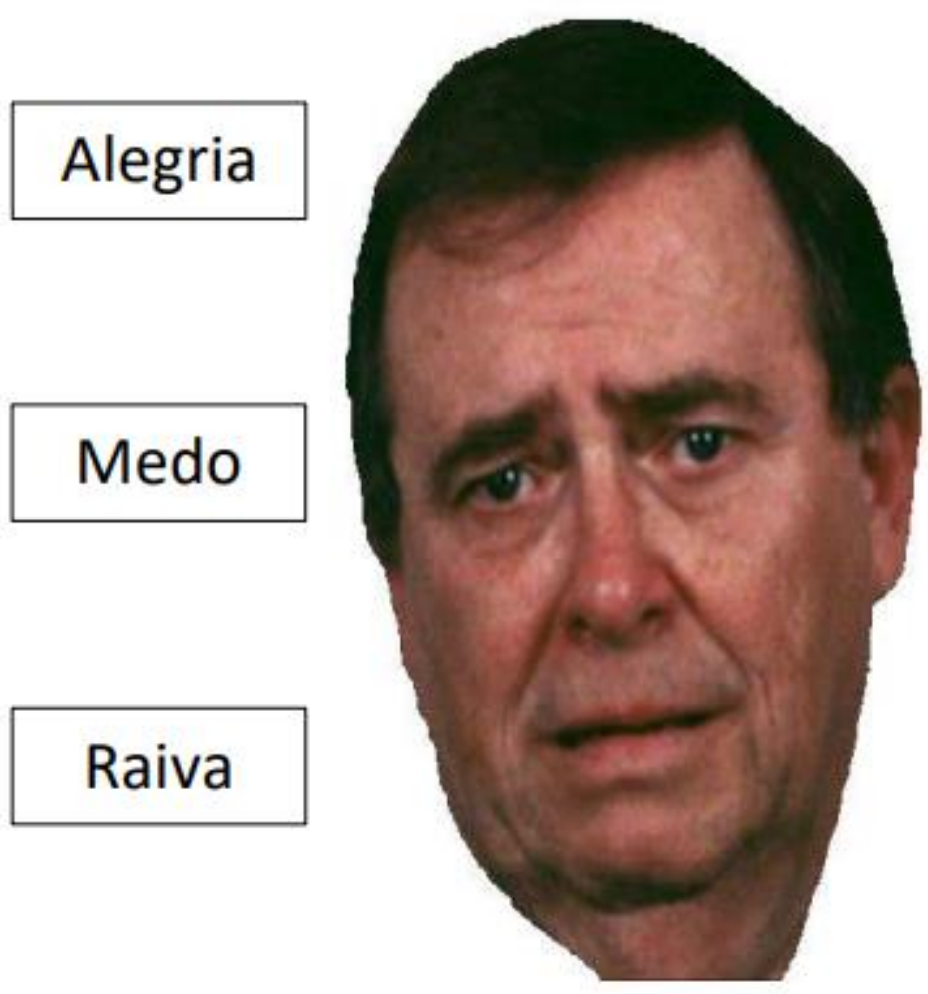

Tristeza

Neutro

Nojo 
Qual a emoção dessa face?

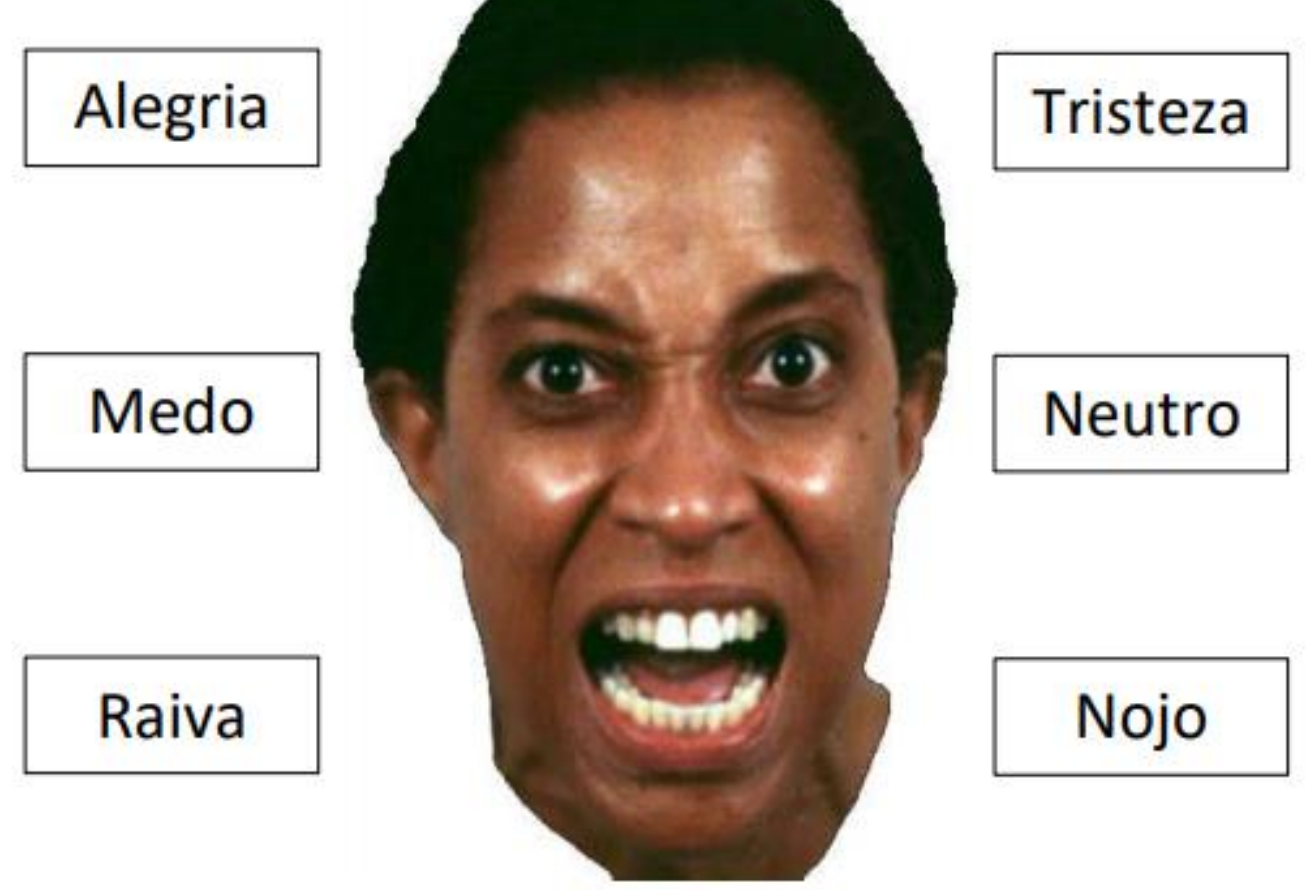


Qual a emoção dessa face?
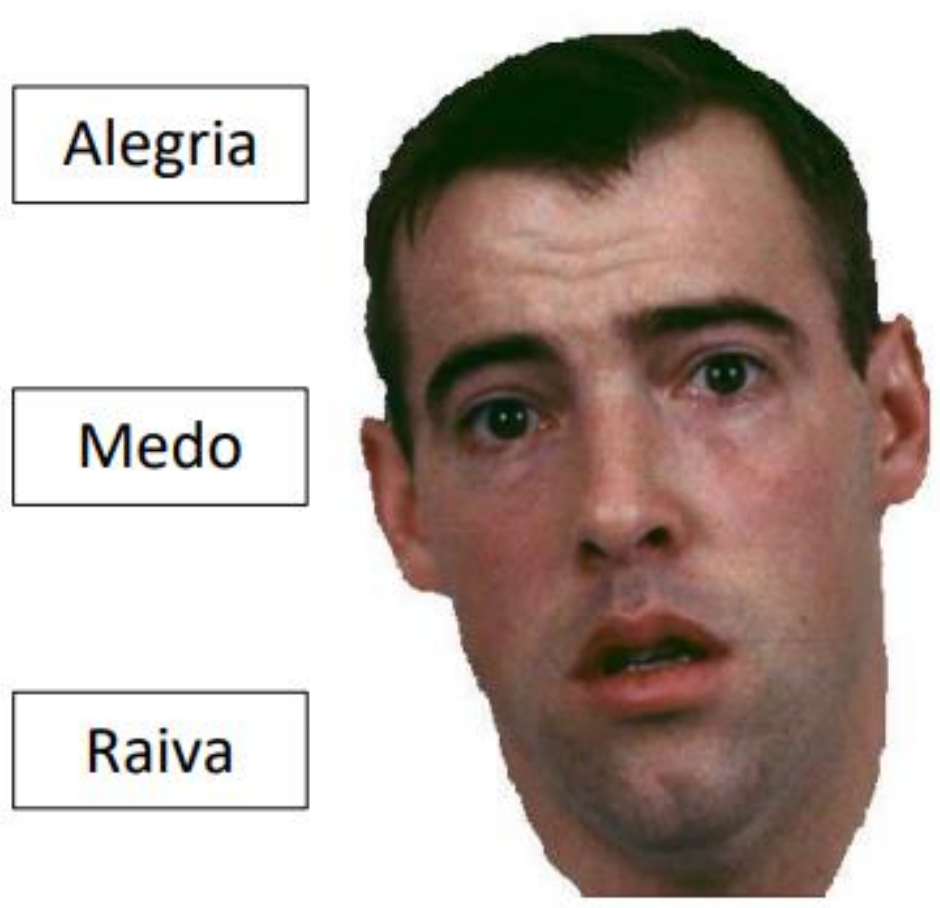

\section{Tristeza}

Neutro

Nojo 
Qual a emoção dessa face?

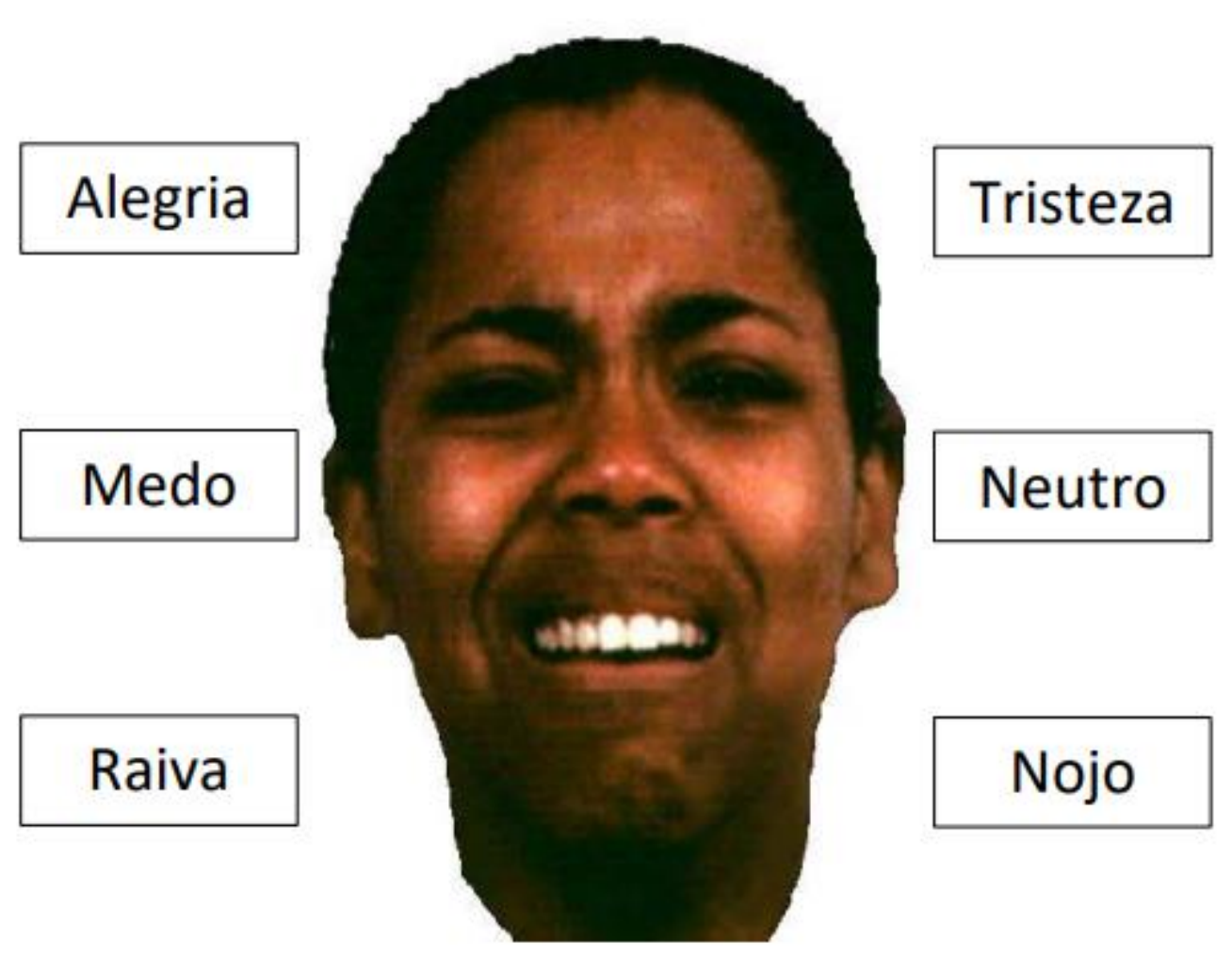


Qual a emoção dessa face?

Alegria

Medo

Raiva
Tristeza

Neutro

Nojo 